\title{
Cobalamin deficiency, hyperhomocysteinemia, and dementia
}

This article was published in the following Dove Press journal:

Neuropsychiatric Disease and Treatment

23 April 2010

Number of times this article has been viewed

\author{
Steven F Werder ${ }^{1,2}$ \\ 'Kansas University School of \\ Medicine - Wichita, Wichita, KS, \\ USA; ${ }^{2}$ Community Health Center \\ of Southeast Kansas, Pittsburg, KS, \\ USA
}

Correspondence: Steven FWerder

Community Health Center of Southeast Kansas, 30 I I N. Michigan Avenue,

Pittsburg, KS 66762, USA

Tel +l 6202322500

Fax +I 6202322532

Email drwerder@chcsek.org
Introduction: Although consensus guidelines recommend checking serum B12 in patients with dementia, clinicians are often faced with various questions: (1) Which patients should be tested? (2) What test should be ordered? (3) How are inferences made from such testing? (4) In addition to serum B12, should other tests be ordered? (5) Is B12 deficiency compatible with dementia of the Alzheimer's type? (6) What is to be expected from treatment? (7) How is B12 deficiency treated? Methods: On January 31st, 2009, a Medline search was performed revealing 1,627 citations related to cobalamin deficiency, hyperhomocysteinemia, and dementia. After limiting the search terms, all abstracts and/or articles and other references were categorized into six major groups (general, biochemistry, manifestations, associations and risks, evaluation, and treatment) and then reviewed in answering the above questions.

Results: The six major groups above are described in detail. Seventy-five key studies, series, and clinical trials were identified. Evidence-based suggestions for patient management were developed.

Discussion: Evidence is convincing that hyperhomocysteinemia, with or without hypovitaminosis B12, is a risk factor for dementia. In the absence of hyperhomocysteinemia, evidence is less convincing that hypovitaminosis B12 is a risk factor for dementia. B12 deficiency manifestations are variable and include abnormal psychiatric, neurological, gastrointestinal, and hematological findings. Radiological images of individuals with hyperhomocysteinemia frequently demonstrate leukoaraiosis. Assessing serum B12 and treatment of B12 deficiency is crucial for those cases in which pernicious anemia is suspected and may be useful for mild cognitive impairment and mild to moderate dementia. The serum B12 level is the standard initial test: 200 picograms per milliliter or less is low, and 201 to 350 picograms per milliliter is borderline low. Other tests may be indicated, including plasma homocysteine, serum methylmalonic acid, antiparietal cell and anti-intrinsic factor antibodies, and serum gastrin level. In B12 deficiency dementia with versus without pernicious anemia, there appear to be different manifestations, need for further workup, and responses to treatment. Dementia of the Alzheimer's type is a compatible diagnosis when B12 deficiency is found, unless it is caused by pernicious anemia. Patients with pernicious anemia generally respond favorably to supplemental B12 treatment, especially if pernicious anemia is diagnosed early in the course of the disease. Some patients without pernicious anemia, but with B12 deficiency and either mild cognitive impairment or mild to moderate dementia, might show some degree of cognitive improvement with supplemental B12 treatment. Evidence that supplemental B12 treatment is beneficial for patients without pernicious anemia, but with B12 deficiency and moderately-severe to severe dementia is scarce. Oral cyanocobalamin is generally favored over intramuscular cyanocobalamin.

Keywords: Alzheimer, dementia, cognitive impairment, cognitive dysfunction, cobalamin, cyanocobalamin, B12, homocysteine, hyperhomocysteinemia, homocystinuria 


\section{Introduction}

The notion of vitamin B12 deficiency (ie, B12 hypovitaminosis), its psychiatric and neurological manifestations, and its treatment is an age-old issue that has generated much controversy over many years. Although consensus guidelines ${ }^{1-4}$ recommend checking serum B12 levels in patients with dementia, clinicians are often faced with questions regarding how to interpret and what to do with the results. ${ }^{5}$ In order to help in clarifying these uncertainties, six questions were posed and then answered: 1) In which patients should vitamin B12 be routinely assessed? 2) What test or tests should be ordered, and how are inferences made from such testing? 3) Does the finding of low serum B12 or elevated homocysteine (Hcy) require evaluation for other medical conditions? 4) When vitamin B12 deficiency is found in dementia, is dementia of the Alzheimer's type (DAT) a compatible diagnosis? 5) Based on the benefit-torisk ratio in treatment of dementia, if vitamin B12 deficiency is determined, should supplemental B12 be initiated? 6) How is vitamin B12 deficiency treated?

By assimilating data from in vitro, in vivo animal, and in vivo human studies and epidemiological studies, this article clarifies these and other issues regarding hypovitaminosis B12, hyperhomocysteinemia (HHcy), and dementia.

\section{Methods/results}

The study design is a qualitative and quantitative review of the literature. The problem discussed is that in clinicians' geriatric practices, patients with dementia and low vitamin $\mathrm{B} 12$ were not showing significant improvement with supplemental B12 therapy. Our hypothesis is that patients with dementia and low vitamin B12 improve with supplemental B12 therapy. The null hypothesis is that patients with dementia and low vitamin B12 do not improve with supplemental B12 therapy.

On January 31st, 2009 a Medline search was performed using the search terms: (Alzheimer OR Alzheimer's OR dementia OR cognitive impairment OR cognitive dysfunction) AND (cobalamin OR cyanocobalamin OR B12 OR B-12 OR B 12 OR homocysteine OR hyperhomocysteinemia OR homocystinuria), which revealed 1,627 citations. "Title/Abstract" field limits decreased the search to 1,095 citations, which included 230 review articles. Using a Boolean operation, the review articles were removed, reducing the search to 865 citations. Subsequently, the search was limited to only citations with abstracts, so as to exclude publications such as 'Letters to the Editor' and case reports, which revealed 824 citations. Furthermore, in order to not miss any positive findings of individual case reports or case series, on September 6th, 2009 another Medline search was performed using the search terms: pernicious anemia AND dementia AND (case report OR case series) revealing 20 citations. Of the 844 articles, all abstracts were reviewed and, when useful, relevant articles were obtained and reviewed. Bibliographies from relevant articles were reviewed and, when applicable, review articles, 'Letters to the Editor,' and case reports were included in the overall review. Data from (1) other Medline searches, (2) Internet searches, (3) basic and clinical science textbooks, and (4) personal communications were added for clarification of technical issues. All abstracts, articles, and other references were categorized, allowing duplications, into six major categories: (1) general information, (2) biochemical evidence suggesting that hypovitaminosis B12 or HHcy are causal factors in dementia, (3) clinical and radiological manifestations, (4) associations between hypovitaminosis B12 or HHcy and cognitive impairment, (5) evaluation, and (6) treatment. Endnote version X.0.2 (Thomson Reuters, Philadelphia, PA) was used to maintain the reference library, which contained 839 citations. Evidencedbased medicine was used to develop suggestions for vitamin B12 workup and treatment in patients with suspected mild cognitive impairment (MCI) or dementia.

There are 511 articles and other references relevant to the six questions posed in the introduction and the six major categories listed above. Question 5 in the Introduction considers treatment benefits and risks. In terms of treatment benefits, the study objective was to determine whether or not vitamin B12 is beneficial for B12-deficient dementia. Letting the null hypothesis be, "Patients with dementia and low vitamin B12 do not improve with supplemental B12 therapy," not rejecting the null hypothesis when it is not true would be a type 2 error (false negative). In order to avoid a type 2 error, thus concluding B12 treatment is not beneficial, when in truth it is beneficial, all published studies and reports contained in Medline (Box 1), including case series, in which supplemental B12 was an exposure and cognitive change was an outcome are included in the discussion and tables $(\mathrm{N}=38)$, regardless of the quality of the study or number of subjects. Also included are all published cohort and longitudinal studies in Medline, where exposure pertains to metabolic or serum B12 deficiency and outcomes pertain to change in cognitive function or development or prevention of dementia $(\mathrm{N}=37)$. Also included are the majority of the retrospective and cross-sectional studies in Medline that examine similar outcomes and exposures. Articles pertaining to genetics, biochemistry, pathophysiology, clinical manifestations, and radiological manifestations illuminating our understanding on relationships between HHcy with and without cobalamin 
Box I Studies and reports in which supplemental BI2 is an exposure and cognitive change is an outcome

\begin{tabular}{lll}
\hline Abyad, 2002 & Fox, I975 & McMahon, 2006 \\
Aisen, 2008 & Healton, 199I & Nilsson, 200I \\
Bolaman, 2003 & Hvas 2004 & Osimani, 2005 \\
Bryan, 2002 & Ikeda, 1992 & Remington, 2009 \\
Carmel, 1995 & Kalita, 2008 & Seal, 2002 \\
Clarke, 2003 & Kwok, 1998 & Stott, 2005 \\
Crystal, 1994 & Kwok, 2008 & Sun, 2007 \\
Cunha, 1990 & La Rue, 1997 & Teunisse, 1996 \\
Cunha, 1995 & Lehmann, 2003 & van Asselt, 200I \\
Eastley, 2000 & Levine 2006 & van Dyck, 2008 \\
El Otmani, 2008 & Lin, 2008 & van Uffelen, 2008 \\
Eussen, 2006 & Lindenbaum, 1988 & Wolters, 2005 \\
Fourniere, 1997 & Martin, 1992 & \\
\hline
\end{tabular}

deficiency and dementia are included in the review, as are articles relevant to evaluation, prognosis, and treatment.

\section{Discussion}

\section{General information}

Vitamin B12 is composed of a central cobalt atom, attached to a dimethylbenzimidazole group, four nitrogen atoms, each pertaining to four pyrrole rings, and an $\mathrm{R}$ group $(-\mathrm{CN},-\mathrm{OH}$, $-\mathrm{CH}_{3}$, or adenosyl group), denoting the specific type of cobalamin. ${ }^{6-8}$ The definition of vitamin B12 deficiency is a quantitative lack of vitamin B12 in the diet, body fluids, or cells or a qualitative lack of intracellular B12 utilization.

B12 deficiency occurs in roughly $10 \%$ of general ${ }^{9-23}$ and $17 \%$ of demented ${ }^{10,24-26}$ elderly populations. B12 deficiency in demented individuals ranges from one ${ }^{10,27,28}$ to five $\mathrm{e}^{25,29}$ times that of controls. Serum B12 levels and cerebral spinal fluid (CSF) folate levels decrease with advancing age, ${ }^{9-12,30-34}$ whereas serum folate levels may either increase or decrease with age. ${ }^{32} \mathrm{Hcy}$ is a nonessential thiol amino acid. ${ }^{35,36} \mathrm{HHcy}$ is defined as an abnormally high level of total Hcy in the plasma. HHcy occurs in $6 \%$ to $81 \%$ of individuals, depending on the population studied. ${ }^{37-44}$ Causes of HHcy and B12 deficiency are listed in Table 1..$^{7,18,19,39,45-62}$ Further details regarding differential diagnoses are available on the Internet. ${ }^{62}$

\section{Biochemical evidence suggesting that hypovitaminosis $\mathrm{BI} 2$ or hyperhomocysteinemia are causal factors in dementia}

The means by which HHcy is involved in dementia may possibly be explained by aging and reduced vitamin B12
Table I Causes of hyperhomocysteinemia and BI2 deficiency

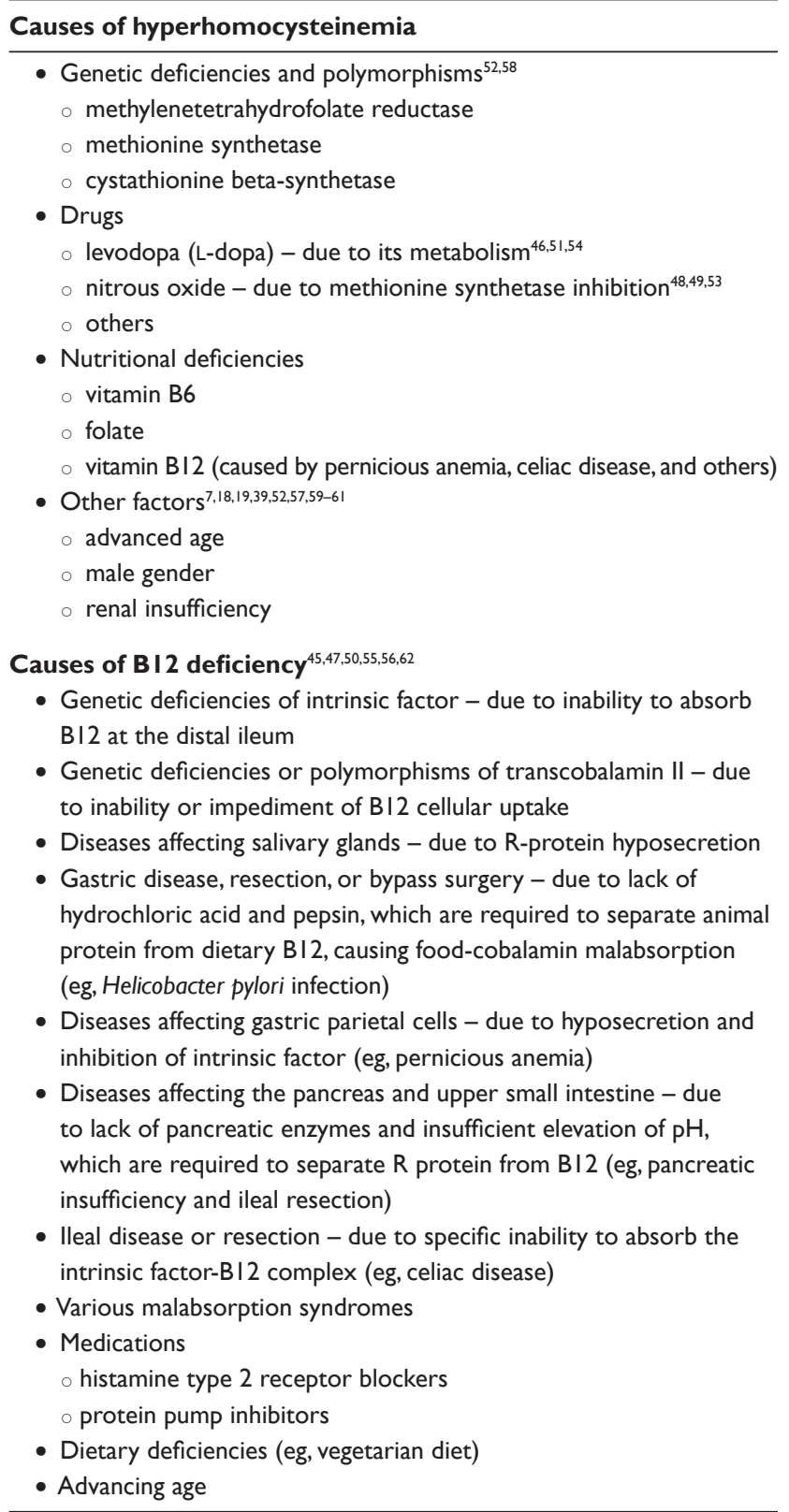

or folate supply versus demand ratio, ${ }^{63,64}$ with functional, structural, genetic, and nutritional determinants. Possible functional determinants include Hcy agonism of N-methylD-aspartic acid (NMDA) receptors, which causes excessive intracellular calcium influx and neuronal death ${ }^{65,66}$ and HHcy creating a state of hypomethylation in the pathogenesis of Alzheimer's disease (AD), ${ }^{21,58,67}$ causing deoxyribonucleic acid (DNA) damage and apoptosis. ${ }^{68-71}$ HHcy inhibits adult mammal hippocampal neurogenesis. ${ }^{72}$ Hcy may compete with gamma-amino butyric acid (GABA) at the GABA receptor and may affect its inhibitory function. ${ }^{73,74}$ 
Potential structural determinants include HHcy causing blood-brain barrier (BBB) dysfunction ${ }^{75-78}$ and endothelial cell toxicity, ${ }^{47,64}$ whereby Hcy changes endothelial cell surface properties from anticoagulant to procoagulant. ${ }^{47,52,73,79}$ Genetic determinants include various polymorphisms and homozygous monogenic deficiencies, involving methylenetetrahydrofolate reductase (MTHFR), transcobalamin (TC) II, methionine synthetase (MS), and cystathione beta-synthetase (CBS). These may contribute to hypovitaminosis B12, HHcy, and dementia. ${ }^{7,47,52,64,73,80-82}$ Meta-analyses $^{83-89}$ of the MTHFR polymorphism show that those with $677 \mathrm{TT}$ alleles compared to $677 \mathrm{CC}$ alleles have elevated Hcy and increased risk for myocardial infarction (MI), transient ischemic attack, and stroke. Hyperhomocysteinemic individuals with certain butyrylcholinesterase-K (BuChE-K) alleles cognitively decline more rapidly than those with wild-type BuChE alleles. ${ }^{90}$ Nutritional determinants include decreased vitamin B12 ingestion ${ }^{9,45,47}$ and food-cobalamin malabsorption. ${ }^{9,15,19,45,49,91-93}$

In vitro, in vivo animal, and in vivo human studies suggest AD pathophysiology conceivably involves a hypomethylation state, ${ }^{67,94-97}$ reactive oxygen species (ROS) generation, ${ }^{27,98-101}$ immune activation, ${ }^{102-110}$ and anomalous protein development. ${ }^{111}$ Abnormal Hcy metabolism is involved in each of these four processes. Hcy is metabolized by the methionine cycle and transsulfuration pathway (Figure 1), ${ }^{112}$ where it has one of three possible fates: methylation to methionine (Met), transsulfuration to cystathionine, or adenosylation to S-adenosylhomocysteine (SAH). ${ }^{113,114}$ With normal Hcy levels, the first two reactions are maintained, the first occurring in the brain and body and the second predominately occurring in the body, promoting homeostatic methylation reactions and maintaining healthy cells. With Hcy elevation the third reaction ensues, promoting a hypomethylation state leading to disease. ${ }^{115}$

On the one hand, without oxidative chemical reactions, as the basis for cellular respiration, we would not have life, at least as we know it. On the other hand, without these reactions, we would not have ROS. ${ }^{116}$ There are thousands of publications related to ROS and aging, the greatest known risk factor for sporadic $\mathrm{AD} .{ }^{114,116,117}$ Oxidative metabolism generates a very small fraction of ROS, ${ }^{117}$ which can be beneficial or detrimental to the central nervous system. Oxidative stress occurs when ROS generation exceeds ROS defense, ${ }^{118}$ leading to potential molecular and cellular damage. ${ }^{117}$ Aberrant mitochondrial enzymes may facilitate this process, thereby contributing to the pathophysiology of AD. ${ }^{116}$
Hcy is rapidly auto-oxidized to homocysteine thiolactone, homocystine, and mixed disulfides, ${ }^{7,119}$ producing ROS, ${ }^{18,21,47,52,68,120}$ including singlet oxygen, superoxide anions, hydroxyl radicals, and hydrogen peroxide. ${ }^{21,42,52,68,117,118}$ Hcy elevation is associated with microglia activation and proliferation ${ }^{71}$ and immune activation and deposition, ${ }^{108}$ which is associated with choroid plexus dysfunction, ${ }^{121-123}$ possibly impeding vitamin $\mathrm{B} 12^{123-125}$ and folate ${ }^{122,125}$ influx to, and amyloid beta $(A \beta)$ peptide ${ }^{123,126,127}$ clearance from, brain tissue in AD. In certain systems, Hcy elevation leads to amyloid precursor $^{128}$ and tau ${ }^{128-132}$ protein hyperphosphorylation, and Hcy oxidation produces products that crosslink with $\mathrm{A} \beta$ and tau proteins, causing their precipitation. ${ }^{119,128,133} \mathrm{Hcy}$ elevation is associated with increased $A \beta$ peptide, in both brain $^{134}$ and plasma. ${ }^{51,135,136}$

A deleterious cycle may occur between ROS generation and immune activation, where the former may cause the latter $^{137-139}$ and vice versa. ${ }^{63,64,140-144}$

Hcy may promote a means for such a cycle, ${ }^{64,106,120}$ because ROS generation is associated with Hcy elevation, ${ }^{120,142,145-147}$ which is associated with immune activation, ${ }^{64,71,79,148-150}$ and immune activation is associated with Hcy elevation, ${ }^{64,142,151,152}$ which is associated with ROS generation (Figure 2). ${ }^{47,64,71,153-155}$ Additional evidence verifies ROS, ${ }^{145,151,156}$ hypomethylation, ${ }^{21,58,67,94,95,128,136,157}$ immunological components, ${ }^{64,79,106,109,110,142}$ and $A \beta$ and tau proteins ${ }^{58,65,66,120,136,158}$ interact with one another, producing a neurodegeneration cascade in AD. ROS generation precedes both $\mathrm{A} \beta$ peptide deposition ${ }^{159-162}$ and tau-associated neurodegeneration. ${ }^{163}$ ROS generation deregulates tau protein phosphorylation, ${ }^{164,165}$ and is associated with decreased S-adenosylmethionine (SAM), ${ }^{120}$ increased SAH, a decreased SAM/SAH ratio, ${ }^{115}$ and hyperconsumption and depletion of antioxidants ${ }^{98,151,156}$ and tetrahydrofolate (THF). ${ }^{64,120,151,156,166}$

With absolutely or relatively low folate or vitamin B12, MS-mediated Hcy clearance is impeded, ${ }^{52,120}$ resulting in a hypomethylation state. Also, Hcy elevation may lead to hyperconsumption and depletion of vitamin B12 in various cases of $\mathrm{AD}$ and vascular dementia $(\mathrm{VaD}) .{ }^{146} \mathrm{Hcy}$ potentiates $\mathrm{A} \beta$ peptide-induced ROS generation and apoptosis. ${ }^{69,154,155,167}$ $A \beta$ and tau proteins are concentrated sources for further ROS generation, Hcy elevation, and immune activation, thereby perpetuating the deleterious cycle. ${ }^{120,143,168-170}$ Also, in vivo human studies show that free cobalt is elevated in individuals with AD compared to controls. ${ }^{8}$ In vitro studies show free cobalt generates oxidative stress, as measured by reduced 


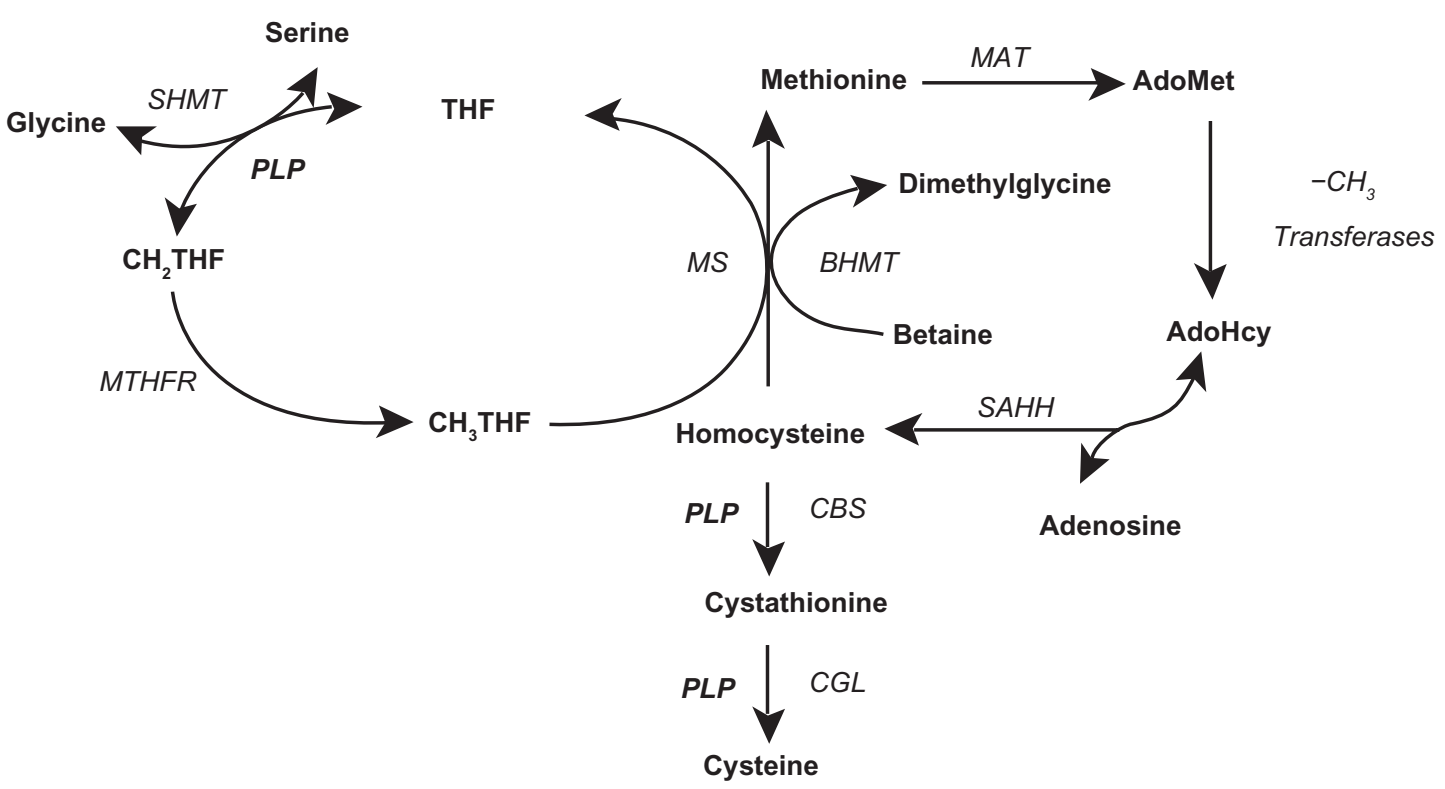

Figure I Folate cycle, methionine cycle, and transsulfuration pathway. Copyright @ 2005 . Adapted with permission from Davis SR, Quinlivan EP, Shelnutt KP, et al. Homocysteine synthesis is elevated but total remethylation is unchanged by the methylenetetrahydrofolate reductase $677 \mathrm{C}->\mathrm{T}$ polymorphism and by dietary folate restriction in young women. J Nutr. 2005; 135(5):1045-1050.

Notes: This schematic is of the folate cycle (left), methionine cycle (right), and transsulfuration pathway (bottom), with homocysteine being the common substance to all three. Folic acid (synthetic) is converted by DHFR to dihydrofolic acid (dietary), which is converted by DHFR to THF, which enters the folate cycle:THF $\rightarrow \mathrm{N}^{5}$, $\mathrm{N}^{10}$-methylene THF $\rightarrow$ $\mathrm{N}^{5}$-methyl THF $\rightarrow$ THF. In this last step, vitamin BI2 is required as a cofactor for MS. With low or absent vitamin $\mathrm{BI}$, this last step is hindered leading to the methylfolate trap with elevated $\mathrm{CH}_{3}$-THF. Homocysteine metabolism: homocysteine is produced in the methionine cycle by the deadenosylation/hydration of AdoHcy, and is either remethylated to methionine, by the methionine cycle or catabolized to cysteine, by the transsulfuration pathway. Note the AdoHcy deadenosylation/hydration to Hcy is a reversible reaction favoring homocysteine adenosylation/hydration to AdoHcy. Methyl groups produced by AdoMet demethylation to AdoHcy are used for nucleic acid, protein, lipid, and neurotransmitter biosynthesis. Cysteine is a nonessential amino acid used in the biosynthesis of proteins, glutathione, coenzyme A, taurine, and inorganic sulfur. Glutathione is an antioxidant that protects cells from ROS.

Abbreviations: AdoHcy, S-adenosylhomocysteine; AdoMet, S-adenosylmethionine; BHMT, betaine-homocysteine methyltransferase; CBS, cystathionine $\beta$-synthase; CGL, cystathionine gamma-lyase; $\mathrm{CH}_{2}$ THF, methylenetetrahydrofolate; $-\mathrm{CH}_{3}$, methyl group; $\mathrm{CH}_{3}$ THF methyl tetrahydrofolate; DHFR, dihydrofolate reductase; $\mathrm{MAT}$, methionine adenosyltransferases; MS, methionine synthase; MTHFR, methylenetetrahydrofolate reductase; PLP, pyridoxal phosphate (the active form of vitamin B6, pyridoxine); ROS, reactive oxygen species; SAHH, S-adenosylhomocysteine hydrolase; SHMT, serine hydroxymethyltransferase; THF, tetrahydrofolate.

glutathione, increases $A \beta$ peptide secretion, and produces neuroblastoma cytotoxicity. ${ }^{8,120}$

Within the central nervous system, a balance may occur between endogenous neurotoxic agents on one hand and endogenous neurotrophic agents on the other hand. ${ }^{171}$ Examples of potential neurotoxic agents include tumor necrosis factor-alpha (TNF- $\alpha$ ), nerve growth factor

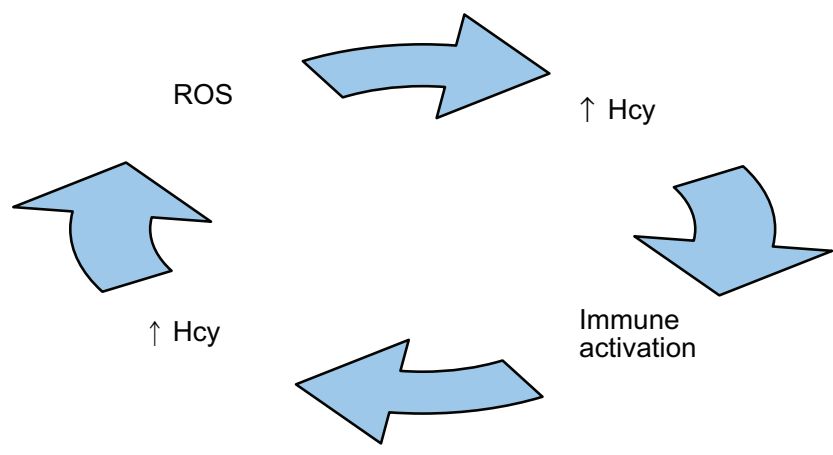

Figure 2 Illustration of a biologically plausible deleterious cycle of reactive oxygen species (ROS), homocysteine (Hcy), and immune activation that possibly may be involved in the pathogenesis of Alzheimer's disease.
(NGF), and the soluble CD40-soluble CD40 ligand dyad (sCD40-sCD40). Examples of potential neurotrophic agents include interleukin-6 (IL-6), epidermal growth factor (EGF), and transforming growth factor-beta1 (TGF- $\beta 1$ ). In animals, if the balance is tilted in favor of TNF- $\alpha$, NGF, and $\mathrm{SCD} 40-\mathrm{sCD} 40$ (eg, by the administration of exogenous TNF- $\alpha),{ }^{172}$ as opposed to IL- 6 , NGF, and TGF- $\beta 1$, then the morphological changes of subacute combined degeneration (SCD) are observed: white matter interstitial edema, intramyelinic edema, spongy vacuolation, and astrogliosis. ${ }^{172-175}$ Vitamin B12-depleted animals exhibit increased levels of TNF- $\alpha$, NGF, and sCD40-sCD40 ${ }^{172,176}$ and decreased levels of IL-6 and EGF, ${ }^{176}$ thereby tilting the balance and developing the myelopathic changes of SCD. Not only does treatment with vitamin B12 reduce or reverse these changes, ${ }^{172,175}$ but treatment with anti-TNF- $\alpha$ antibodies, IL-6, EGF, and TGF- $\beta 1$ does so as well. ${ }^{172,176}$ Interestingly, a similar observation has been observed in humans. Serum TNF- $\alpha$ is higher and serum EGF is lower in subjects with severe B12 deficiency compared to controls, where a 
direct correlation is found between plasma Hcy and serum TNF- $\alpha .{ }^{173}$ The association is translative into the CSF, where CSF B12 and EGF are lower and CSF Hcy and TNF- $\alpha$ are higher in subjects with SCD compared to non-B12 deficient controls. ${ }^{177}$ B12-repletion lowers serum TNF- $\alpha$ and raises serum EGF, thereby normalizing the imbalance, which occurs concomitantly with clinical and hematological disease remission. ${ }^{173}$ Hence, in addition to well-known enzymatic roles for vitamin B12, it is thought to also have nonenzymatic roles, where it is associated with downgrading synthesis and release of TNF- $\alpha$ and upgrading synthesis and release of EGF. ${ }^{173,177,178}$

\section{Clinical and radiological manifestations}

Clinical manifestations of low vitamin B12 include abnormal psychiatric, neurological, and gastrointestinal findings. Psychiatric manifestations consist of psychoses, including paranoia, delusions, and hallucinations, ${ }^{23,58,179-184}$ cognitive dysfunction, including memory impairment, delirium, and dementia, 7,21,23,49,58,93,180,181,185-188 and affective syndromes, including mania and depression, ${ }^{7,21,23,58,93,180,181,186,189-191}$ which also occurs with elevated Hcy ${ }^{192-194}$ and low SAM. ${ }^{67,192}$ Associations exist between HHcy and cognitive dysfunction in bipolar disorder ${ }^{195-197}$ and perhaps schizophrenia. ${ }^{198}$ Neurological manifestations include myelopathy and peripheral, autonomic, and optic neuropathies. ${ }^{199}$ Paresthesia is caused by a sensory lesion anywhere between the peripheral nerve and brain and is often the initial symptom. . $^{23,58,92,180,181,188}$ SCD refers to myelopathy affecting posterior and lateral columns, characterized by a pernicious sequence of vacuolar demyelination, axonal degeneration, and neuronal death. ${ }^{18,58,200-202}$ Posterior column myelopathy affects afferent pathways, causing the most common neurological signs: ataxia, diminished proprioception and vibratory senses, and presence of Romberg's sign. . $^{\text {, } 49,58,180,185,188,200,201,203}$ Lateral column myelopathy affects efferent pathways, causing the second most common neurological signs: extremity muscular weakness, spasticity, hyperactive reflexes, and Babinski's sign. ${ }^{18,49,58,180,181,200,201}$ Peripheral and autonomic neuropathies cause hypoactive reflexes, sensory loss, orthostatic hypotension, fecal and urinary incontinence, and impotence. ${ }^{18,23,49,58,92,180,181,185,188,200,203}$ Although optic neuropathy is uncommon, ${ }^{23,58,180,203}$ visual impairment may occasionally be the earliest or sole manifestation of the disease. ${ }^{203}$ Gastrointestinal manifestations include epithelial atrophy of the tongue, referred to as atrophic glossitis, which causes the tongue to be sore and beefy red, ${ }^{18,23}$ and epithelial atrophy of the stomach. ${ }^{15}$
Computerized axial tomographic (CAT) and magnetic resonance imaging (MRI) scans of nondemented elderly brains may show age-related cerebral atrophy and various grades of periventricular white matter disease consistent with chronic microvascular ischemia. ${ }^{204-208}$ Although linear and volume measurement methods, evaluating ventricle-to-brain ratios and medial temporal lobe atrophy, reveal significant differences in group means, between those with $\mathrm{AD}$ and controls, ${ }^{205,207,209-217}$ such strategies are not recommended for the purpose of diagnosing AD. ${ }^{3,218}$ Assuming normal distributions of both nondemented and demented groups, a certain degree of overlap may exist, ${ }^{205,207,216}$ unless specified by scan angle-adjusted temporal lobe neuroimaging. ${ }^{207,214}$ Even so, such imaging may not distinguish non-Alzheimer's dementia from controls. ${ }^{217}$ Although CAT scans of nondemented elderly commonly show age-related cerebral atrophy, those of demented elderly often show cerebral atrophy more than expected for age, ${ }^{210}$ and are read as variably judged atrophy and differently interpreted white matter changes. ${ }^{218,219}$ Whether or not such findings relate to dementia with low vitamin B12 and/or elevated Hcy is often unclear.

Accordingly, a literature review finds radiological manifestations of low vitamin B12 and/or elevated Hcy to include leukoaraiosis, brain atrophy, and silent brain infarcts. ${ }^{199,220-237}$ Leukoaraiosis is a radiological term that refers to brain white matter hypodensity on CAT scans or hyperintensity on $\mathrm{T}_{2}$-weighted magnetic resonance imaging (MRI). ${ }^{238}$ It is associated with aging, ${ }^{221,230,239-244}$ chronic microvascular hypoperfusion, ${ }^{245} \mathrm{BBB}$ dysfunction, ${ }^{246}$ hypertension, $221,230,240,241,242,244$ stroke, ${ }^{230,239,240-242,244,247}$ and death. ${ }^{239}$ Leukoaraiosis is described pathologically as periventricular leukoencephalopathy or subcortical arteriosclerotic encephalopathy; it occurs in brains of individuals with $\mathrm{AD}^{243}$ and dementia of the Binswanger type (DBT), ${ }^{248}$ which is a relatively rarer type of dementia and is associated with other findings. HHcy increases the risk for leukoaraiosis. ${ }^{220,221,223-226,228,230,232,236}$ Independently from plasma Hcy levels, one cross-sectional study ${ }^{249}$ found an inverse association between the concentration of normal range serum B12 levels and the degree of leukoaraiosis; nonetheless, in the absence of HHcy, two studies $^{227,231}$ found low serum B12 does not increase the risk for leukoaraiosis. Parenthetically, one prospective study 250 found an inverse association between serum folate levels and the degree of leukoaraiosis. Although leukoaraiosis is more prevalent in demented than nondemented individuals ${ }^{225,247}$ and it increases the risk for developing dementia, ${ }^{247,248,251}$ results are mixed in terms of whether or not the link between HHcy and cognitive dysfunction is specifically mediated by 
leukoaraiosis. ${ }^{228,232,240,243,252-255}$ In both cross-sectional and prospective evaluations, hypovitaminosis B12 and HHcy are associated with brain atrophy. ${ }^{199,222,229,232,234,237}$ HHcy is associated with silent brain infarcts. ${ }^{232}$

VaD, ${ }^{61} \mathrm{DBT},{ }^{256}$ and $\mathrm{AD},{ }^{61,222,243,257-259}$ represent various spectra of vascular pathology. To illustrate, cerebral amyloid angiopathy occurs in many cases of $\mathrm{DBT}^{248}$ and in most cases of $\mathrm{AD},{ }^{46,260,261}$ where increased vessel atrophy, ${ }^{262}$ decreased microvascular density, ${ }^{262}$ reduced temporal lobe blood flow, ${ }^{263,264}$ and spontaneous cerebral emboli ${ }^{265,266}$ are other significant findings. Hcy permeates through the $\mathrm{BBB},{ }^{267,268}$ causing $\mathrm{BBB}$ dysfunction, ${ }^{74,76-78}$ which is observed in $\mathrm{AD},{ }^{247,269} \mathrm{DBT},{ }^{220,223,256,270}$ and $\mathrm{VaD},{ }^{75}$ allowing easy influx for a wide variety of proteins to cerebral interstitial fluid ${ }^{271,272}$ and vice versa. ${ }^{273}$ With BBB dysfunction, brain parenchyma likely becomes less protected from toxic effects of systemic HHcy, ${ }^{229}$ which increases risk for acute macrovascular disease, or strokes, ${ }^{7,21,70,84,85,87,151,223,274-279}$ causing loss of volume, and chronic microvascular disease, or ischemia, ${ }^{135,220,280}$ causing loss of cortical-to-subcortical connections, ${ }^{248}$ occasionally with findings as those in DBT. 220,223,281,282

\section{Associations between hypovitaminosis $\mathrm{BI} 2$ or HHcy and cognitive impairment}

HHcy, with hypovitaminosis B12, are common findings in the evaluation of $\mathrm{MCI},{ }^{59,283-288} \mathrm{AD},{ }^{43,60,61,82,111,222,276,284,289-291}$ $\mathrm{VaD},{ }^{43,61,145,276,284,292}$ and other dementia subtypes. ${ }^{90,282,293,294}$ This raises the question of whether or not these findings are the cause of, result of, or unrelated to the disease process. Although multiple retrospective and cross-sectional studies find associations between hypovitaminosis B12 and HHcy and cognitive impairment with or without dementia, 28,39,43,59-61,82,90,111,145,186,196,222,276,283-306 cohort studies are required to provide evidence that hypovitaminosis B12 or HHcy are risk factors for cognitive dysfunction. Eighteen ${ }^{106,136,252,258,301,307-320}$ of 22 cohort studies demonstrate HHcy either increases the risk for cognitive impairment or development of dementia. Depending upon whether plasma Hcy levels increase or decrease over time, the degree of change either increases the risk for developing dementia ${ }^{313}$ or decreases the risk for poorer memory performance, ${ }^{316}$ respectively. The greater the baseline plasma Hcy level, the faster the rate of cognitive decline. ${ }^{320}$ However, one study found that the elevated plasma Hcy risk for developing dementia diminished when controlling for low serum folic acid. ${ }^{301}$ Four $^{321-324}$ of 22 cohort studies conclude Hcy is not a factor in the development of MCI or dementia, although outcome assessment may have been a methodological weakness in one of these. ${ }^{324}$ One cohort study ${ }^{325}$ concludes HHcy is a consequence of the development of cognitive impairment. Most, ${ }^{222,276,316,326-328}$ but not all, ${ }^{329}$ studies find HHcy is associated with intensity, rather than duration, of illness in AD. Thus, evidence that HHcy increases the risk for cognitive impairment and dementia usually is consistent and reproducible, ${ }^{233}$ with HHcy predictably increasing the risk that subjects with MCI will progress to dementia. ${ }^{233}$ With respect to the involvement of low vitamin B12, seven cohort studies $^{308,312,313,330-333}$ show low vitamin B12 either increases the risk for cognitive impairment or development of dementia, while eight ${ }^{13,325,334-339}$ show no increased risk. Paradoxical findings in these studies include modest increases in serum B12 levels over time may increase the risk for dementia ${ }^{313}$ and individuals with normal serum B12 levels having a higher incidence of AD compared to those with low serum B12 levels. ${ }^{13}$ Thus, evidence that low vitamin B12 increases the risk for cognitive impairment or dementia is inconclusive. Then again, the increased risk may occur in the opposite direction. $\mathrm{AD}$ may increase the risk for B12 deficiency. ${ }^{340}$

\section{Evaluation}

In which patients should vitamin BI2

be routinely assessed?

Guidelines for the workup of dementia are listed in Figure 3.,341 Although practices may range from checking serum B12 in all elderly to only particular patients with dementia, an evidence-based approach warrants checking serum B12 in all patients with MCI and mild to moderate dementia of two years or less duration. It is especially useful to assess serum B12 levels in all patients with MCI, because many will ultimately advance to dementia, where there may be a window of opportunity when vitamin B12 treatment of B12 deficiency-related cognitive dysfunction is potentially beneficial. Additionally, serum B12 should be checked in all patients with (1) history of gastric bypass surgery, partial or total gastrectomy, terminal ileum disease or resection, or pancreatic insufficiency, ${ }^{14,20,33,200}$ (2) chronic use of levodopa, histamine type-2 $(\mathrm{H} 2)$ receptor blockers, or protein pump inhibitors (PPIs), ${ }^{22,33,51,54,342-345}$ or (3) findings suggestive of (a) behavioral and psychological symptoms of dementia (BPSD), (b) SCD, including paresthesias, ataxia, or loss of position or vibratory senses, or (c) pernicious anemia (PA), including low hemoglobin ( $\mathrm{Hgb})$, elevated mean corpuscular volume (MCV), or corpuscular changes on peripheral smear. ${ }^{62}$ If such findings are absent, and patients have moderately severe to severe dementia of longer than two years duration, then universal recommendations ${ }^{1-4}$ of 
Guidelines for the workup of dementia, adapted from the American Academy of Neurology Guidelines on Dementia, 2004.

(1) The DSM-IIIR definition of dementia is reliable, and its use is appropriate.

(2) The DSM-IV or the NINCDS-ADRDA diagnostic criteria for DAT and CJD have sufficient reliability and validity, and their use is appropriate.

(3) VaD, DLB, and FTD should be excluded, but the current diagnostic criteria for those diseases have imperfect reliability and validity.

(4) Screening for depression is indicated.

(5) Structural neuroimaging, with either a noncontrast CAT scan or MRI scan of the brain, in the initial evaluation of patients with dementia, is appropriate in order to detect lesions that may result in cognitive impairment.

(6) Evidence supports the following tests in the routine evaluation of the demented patient:

(a) Complete blood count

(b) Liver panel (or liver function test)

(c) Renal panel (or serum electrolytes, glucose, blood urea nitrogen, and creatinine)

(d) Serum B12 Level

(e) Thyroid-stimulating hormone (or thyroid function test)

(f) Urinalysis

(7) Evidence indicates the following tests should not be included in the routine evaluation of the demented patient:

(a) Screening for syphilis (unless patient has risk factors such as living in a highincidence region or engaging in behaviors at high risk for syphilis)

(b) Linear or volumetric MRI or CAT measurement strategies

(c) SPECT

(d) Genetic testing for DLB or CJD

(e) APOE genotyping for AD

(f) EEG

(g) Lumbar puncture (unless presence of metastatic cancer, suspicion of CNS infection, reactive serum syphilis serology, hydrocephalus, age under 55 , rapidly progressive or unusual dementia, immunosuppression, or suspicion of CNS vasculitis)

(8) At this time, there is not enough evidence to support or refute the use of the following tests:
(a) PET
(b) Genetic markers for AD not listed above
(c) CSF or other biomarkers for AD
(d) Tau mutations in patients with FTD
(e) AD gene mutations in patients with FTD

Figure 3 Guidelines for the workup of dementia.

Note: Excellent guidelines for the diagnosis of dementia also are available at http://www.cmaj.ca/cgi/content/full// $78 / 7 / 825$.

Abbreviations: AD, Alzheimer's disease; APOE, apolipoprotein E; CAT, computerized axial tomography; CJD, Creutzfeldt-Jakob Disease; CNS, central nervous system; DAT, Dementia of the Alzheimer Type; DLB, Dementia with Lewy Bodies; DSM-IIIR, Diagnostic and Statistical Manual of Mental Disorders-III-Revised; DSM-IV, Diagnostic and Statistical Manual of Mental Disorders-IV; EEG, electroencephalogram; FTD, frontotemporal dementia; MRI, magnetic resonance imaging; NINCDS-ADRDA, National Institute of Neurologic, Communicative Disorders and Stroke-Alzheimer's Disease and Related Disorders Association; PET, positron emission tomography; SPECT, single photon emission computerized tomography; $\mathrm{VaD}$, vascular dementia. 
assessing for and, when found, treating B12 deficiency may not be supported by reliable evidence. ${ }^{13,16,24,26,92,187,326,346-364}$ H2 receptor blockers and PPIs impair cobalamin absorption; ${ }^{18,22,33,365,366}$ their use is associated with supplemental B12 initiation. ${ }^{367}$ Individuals who have had gastric surgery have a high prevalence of B12 deficiency, ${ }^{20}$ and those who have had gastrectomies, who are B12-deficient, have a high prevalence of cognitive dysfunction and electroencephalographic (EEG) abnormalities. ${ }^{332}$ Therefore, patients prescribed $\mathrm{H} 2$ receptor blockers or PPIs, and those who have had gastrectomies or gastric bypass surgery, require monitoring for hypovitaminosis B12.368

\section{What test or tests should be ordered,} and how are inferences made from such testing?

Common tests include the deoxyuridine suppression test (dUST), serum B12, serum TC II, plasma Hcy, serum or urinary methylmalonic acid (MMA), and the post-methionine load test. For convenience, conversion of vitamin B12 units (nanograms per liter to picograms per milliliter $(\mathrm{pg} / \mathrm{mL}$ ) and $\mathrm{pg} / \mathrm{mL}$ to picomoles per liter) are available at http://www.cdc. gov/ncbddd/b12/index.html.

The dUST is probably the most sensitive and specific test for assessing functional folate or B12 deficiency. ${ }^{92,369}$ Although the test is not fully understood and probably more complex than a simple explanation, ${ }^{369}$ if incubated bone marrow cells or peripheral blood lymphocytes have sufficient folate and cobalamin, nonradioactive deoxyuridine is believed to suppress the thymidylate synthetase conversion of radioactive thymidine into thymidylate, which is a normal response, but if cells have insufficient folate or cobalamin, nonradioactive deoxyuridine does not suppress the thymidylate synthetase conversion of radioactive thymidine into thymidylate, which is an abnormal response.

The most common test is the serum B12 level, ${ }^{15}$ but often it is difficult to determine which serum B12 levels represent deficiency states and which do not. When using a specific serum B12 cutoff point, for example $200 \mathrm{pg} / \mathrm{mL}$ or less, ${ }^{22,181,200,368}$ in determining which individuals do and do not have B12 deficiency, problems encountered include false positives and false negatives. ${ }^{7,15,19,30,33,57,188,370-376}$ One of the reasons for this is because most serum B12 assays measure total B12, including free B12 and that bound to B12 binding proteins: TC I, also called haptocorrin, TC II, simply referred to as transcobalamin, and TC III, which is

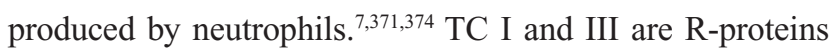
( $\mathrm{R}$ for rapid movement on electrophoresis).,23,200,377 TC I is a storage protein and does not participate in cellular uptake. ${ }^{200,377}$
TC II participates in all cellular uptake. ${ }^{7,58,200,371,372,377}$ TC III participates in hepatocyte uptake only. ${ }^{200} \mathrm{TC}$ I and II comprise about $80 \%$ and $20 \%$ of total B12, respectively. Falsely low serum B12 occurs in congenital TC I deficiency, where TC I is low or absent, but TC II, intracellular B12, and hematopoiesis are normal. ${ }^{7,56,200,377}$ Other causes of falsely low serum B12 include folate deficiency, multiple myeloma, oral contraceptive use, and pregnancy., ${ }^{7,56}$ The mechanism by which low serum folate causes falsely low serum B12 is poorly understood. ${ }^{7,368}$ Alternatively, low serum cobalamin causes methyltetrahydrofolate (CH3-THF) trapping, elevating serum CH3-THF, which causes falsely high serum folic acid (Figure 1). ${ }^{58,200,372,378}$ Falsely normal serum B12 occurs in congenital TC II deficiency, where TC I is normal, but TC II is low or absent, and intracellular B12 is insufficient, causing severe megaloblastic, macrocytic anemia. ${ }^{7,56,200,377,379}$ Other causes of falsely normal serum B12 include liver disease, myeloproliferative disorders, and intestinal bacterial overgrowth., ${ }^{7,56}$ Since serum TC II levels decrease with advancing age, a given serum B12 level in an elder may represent a deficiency, compared with the same level in a younger adult. ${ }^{30,380}$ Directly measuring serum TC II may be helpful in these cases and others. ${ }^{17,38,308,335,351,372,374,380-383}$

Studies show $10 \%{ }^{56,203}$ to $50 \%{ }^{19,368}$ of truly vitamin B12 deficient individuals have serum B12 between 200 and 350 pg/ $\mathrm{mL}$, presenting clinicians with a diagnostic challenge. Based upon known biochemistry, specific tests can be ordered to help with this challenge. Cytoplasmic methylcobalamin is needed for MS-catalyzed Hcy methylation to Met, and mitochondrial adenosylcobalamin is needed for L-methylmalonyl-CoA mutase-catalyzed L-methylmalonyl-CoA conversion to succinyl-CoA. ${ }^{7,18,19,20,52,57,58,203}$ With low cellular B12, these reactions are impeded, elevating Hcy in the former and L-methylmalonyl-CoA, D-methylmalonyl-CoA, and MMA in the latter. ${ }^{18,20,285}$ Thus, HHcy and hypermethylmalonic acidemia (HMMA) are surrogate markers for low vitamin B12 cellular levels (ie, metabolic B12 deficiency). 7,11,15,19-22,30,33,44, 59,60,188,203,285,294,351,353,368,370,372,373,376,380,384,385 HHcy occurs with deficiency of pyridoxine, folate, or vitamin B12; 19,306,355,370,386 usually, only deficiency of vitamin B12 causes HMMA. ${ }^{19,20,370}$ Hcy may be the more sensitive and MMA the more specific surrogate marker. ${ }^{17,20,38,40,151,156,285,387-389}$ Either surrogate marker is more sensitive than serum B12 in evaluating PA, ${ }^{7,19,373,390}$ and many individuals with HHcy have normal serum folate and B12 levels. ${ }^{38,39,42}$ When used alone, B12, ${ }^{371,375}$ TC II, ${ }^{371} \mathrm{Hcy}^{38}$ or $\mathrm{MMA}^{389}$ may be insufficient as screening tests, but in combination, normal plasma Hcy and serum MMA rule out B12 deficiency in virtually all 
cases. ${ }^{19,390}$ Although the post-methionine load test is twice as sensitive as basal Hcy in detecting HHcy in individuals with $\mathrm{AD},{ }^{391}$ it is not recommended as an initial test. ${ }^{17}$

Most laboratory assays measure total Hcy, including reduced and oxidized forms: Hcy representing the former and homocystine and mixed disulfides (protein-bound Hcy and cysteine-Hcy) the latter. ${ }^{52}$ Although the upper reference limit for plasma Hcy varies according to different conditions, ${ }^{17,33}$ plasma Hcy greater than $14 \mu \mathrm{mol} / \mathrm{L}$ in patients with vitamin B12 levels between 201 and 350 pg/mL suggests cellular B12 deficiency. 23,41,200,222,252,258,357,387,392 Serum B12 greater than $350 \mathrm{pg} / \mathrm{mL}$ rules out B12 deficiency in almost all individuals. ${ }^{56,200,340}$ Since tissues store vitamin B12 for up to five years ${ }^{18,368,393}$ and plasma Hcy increases only minimally after protein-rich meals, ${ }^{17}$ serum B12 and plasma Hcy may be obtained fasting or nonfasting. Immediate centrifugation, or keeping samples refrigerated or ice cooled until centrifugation, prevents spuriously elevated Hcy results. ${ }^{17,394,395}$ Suspected B12 deficiency can be confirmed when individuals having characteristic findings, including anemia, macrocytosis, corpuscular changes on peripheral smear, or signs and symptoms of SCD or peripheral neuropathy, improve with vitamin B12 treatment or when elevated Hcy or MMA are lowered with vitamin B12 treatment. 19,20,92,135,188,347,362,370,392,396,397 Although not intended to replace clinical judgment, suggestions for vitamin B12 workup and treatment in patients with suspected MCI or dementia are presented (Figure 4).

\section{Does the finding of low serum BI2 or elevated Hcy require evaluation for other medical conditions?}

Some authors recommend establishing the etiology of B12 deficiency as part of the diagnostic approach. ${ }^{5}$ It is beyond the scope of this paper to cover all diagnostic considerations in Table 1, but levodopa treatment, folate deficiency, and PA are noteworthy.

In Parkinson's disease (PD) it is the treatment rather than the disease that causes HHcy. ${ }^{37,54,294}$ In such cases, HHcy may ${ }^{293,294}$ or may not ${ }^{398}$ be associated with cognitive impairment. Recall from Figure 1, Met is converted to SAM, which is converted to SAH, which is converted to Hcy. SAM demethylation to SAH serves as a methyl group donor for the biosynthesis of nucleic acids, proteins, phospholipids, and catecholamines and the metabolism of drugs and toxins. Catechol-O-methyl transferase (COMT) catalyzes levodopa methylation to 3-O-methyldopa. ${ }^{344}$ Increased methyl group demand, required for the methylation of levodopa to 3-O-methyldopa, favors the conversion of Met to SAM, demethylation to SAH, conversion to Hcy, and development of HHcy. ${ }^{51,54,342,344}$ In a cross-sectional study, ${ }^{342}$ individuals on levodopa alone, compared to those on combined levodopa and COMT inhibitor therapy, had higher plasma Hcy levels. However, only one ${ }^{344}$ of three ${ }^{54,343,344}$ prospective studies showed addition of a COMT inhibitor to those on levodopa prevents dopamine-associated plasma Hcy elevation or serum B12 reduction.

Since the relationship between folate and vitamin B12 is biochemically and, in deficiency states, pathologically united, ${ }^{285}$ there are caveats to keep in mind when working up and treating folate and B12 deficiencies. When folate and B12 deficiencies occur together, monotherapy with either folate or vitamin B12 can worsen the manifestations of the other vitamin deficiency. ${ }^{7,23,180,285,303,355,371,399,400}$ Thus, it is beneficial to assess serum levels of both vitamins and treat whichever deficiency occurs. Although PA and SCD share the common etiology, type A (autoimmune) chronic atrophic gastritis, with vitamin B12 malabsorption, they have distinct pathophysiologies. ${ }^{18,201}$ In the methionine cycle, folate- and vitamin B12-dependent MS catalyzes Hcy methylation to Met, as CH3-THF, serving as the methyl group donor, is demethylated to THF. $47,52,58,151,200$ Impairment of this reaction causes defective DNA synthesis, leading to megaloblastic, macrocytic anemia (ie, PA). ${ }^{21,58}$ Supplemental folic acid can override the impairment, restoring DNA synthesis and normalizing erythropoiesis. ${ }^{58,401}$ Furthermore, in the methionine cycle, Met is adenosylated to SAM, which is demethylated to $\mathrm{SAH}$, which is deadenosylated to Hcy. ${ }^{58}$ Impairment of SAM demethylation to SAH impedes methylation reactions, leading to vacuolar demyelination, axonal degeneration, and neuronal death (ie, SCD). ${ }^{21,58}$ Supplemental folic acid cannot override the methylation impairment, resulting in progressive neuropathology and neuronal death. ${ }^{58}$ Treating a combined folate and B12 deficiency with folic acid alone may correct hematological abnormalities, but not neurological abnormalities, and can aggressively worsen B12-deficient neurological

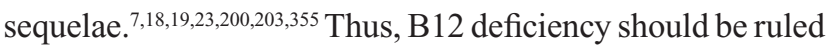
out before correcting folate deficiency.

When folate and vitamin B12 are in balance, increased serum folate levels are associated with decreased plasma Hcy and serum MMA levels, but when vitamin B12 is underrepresented, increased serum folate levels are associated with increased plasma Hcy and serum MMA levels. ${ }^{285}$ Also, higher folate states require relatively higher vitamin B12 levels than normal folate states to protect against metabolic B12 deficiency. ${ }^{285}$ Therefore, the borderline (201-350 pg/mL) serum B12 range may be higher in the presence of high folate states. 
Suggestions for vitamin B12 workup and treatment in patients with suspected neuropathology

A. Check serum B12 level when patients have any of the following:

(1) Neurological symptoms suggesting subacute combined degeneration of the cord or autonomic, optic, or peripheral neuropathy

(2) Abnormal signs including red, beefy tongue, paresthesias, ataxia, or loss of position or vibratory senses

(3) Mild cognitive impairment or dementia of mild to moderate intensity or two years or less duration

(4) History of abnormal laboratory results including low Hgb, high MCV, or peripheral smear showing corpuscular changes (eg, macrocytes and hypersegmented neutrophils)

(5) Malnutrition

B. If serum B12 level has not been assesses in the past, it is useful to check a serum B12 level when patients have any of the following.

(1) Behavioral and psychological symptoms of dementia

(2) History of gastric bypass surgery, stomach resection, terminal ileum disease or resection, or pancreatic insufficiency

(3) Long-term treatment with levodopa, histamine type 2 receptor blocker, or protein pump inhibitor

(4) Findings of leukoaraiosis on brain imaging studies

C. If $A$ (1) or $A(2)$ are applicable and recent $C B C$ is not available, check $C B C$. If $A$ (1) or A (2) are applicable and $C B C$ reveals low $\mathrm{Hgb}$ or high $\mathrm{MCV}$, these findings suggest PA may be present.

D. If serum B12 level is level is $\leq 200 \mathrm{pg} / \mathrm{mL}$, check antiparietal cell and anti-intrinsic factor antibodies. If both are negative, then there is low likelihood that the patient has PA. If both are positive, then there is high likelihood that the patient has PA.

E. If serum B12 level is level is $\leq 200 \mathrm{pg} / \mathrm{mL}$ and antiparietal cell and anti-intrinsic factor antibodies are incongruent (ie, one is positive, but the other is negative), check the serum gastrin level. If elevated, then there is high likelihood that the patient has PA.

F. If serum B12 level is 201 to $350 \mathrm{pg} / \mathrm{mL}$, then check plasma Hcy.

(1) If plasma Hcy $\leq 14 \mu$ moles/L, there is low likelihood for metabolic B12 deficiency.

(2) If plasma Hcy $>14 \mu$ moles/L, there is high likelihood for metabolic B12 deficiency.

G. Initiate vitamin B12 treatment in those cases where serum B12 levels are $200 \mathrm{pg} / \mathrm{mL}$ or less and those where serum B12 levels are $201-350 \mathrm{pg} / \mathrm{mL}$ with plasma Hcy greater than $14 \mu \mathrm{mol} / \mathrm{L}$.

$\mathrm{H}$. If anemia is severe, consider a dosage regimen similar to that made by American Regent, a manufacturer for Cobalamin Injection: $100 \mu \mathrm{g}$ daily for one week, then every other day for two weeks, then every third day for three weeks, then monthly thereafter, by IM or deep SC injection.* One may consider changing from parenteral to oral therapy (as in paragraph I below) after hematological abnormalities return to normal, rather than monthly vitamin B12 injections. If vitamin B12 deficiency is due to PA, supplemental B12 therapy is continued for life.

I. If anemia is less severe or absent, other preferred dosage regimens, including cyanocobalamin $1,000 \mu \mathrm{g}$ PO daily, are more preferable and potentially more effective. Other common practices include cyanocobalamin $1,000 \mu \mathrm{g} I \mathrm{M}$ daily for one week, then weekly for one month, then monthly thereafter.

J. Since folate and B12 deficiencies often occur concomitantly, checking serum folate levels also may be useful whenever B12 deficiency is suspected.

Figure 4 Suggestions for vitamin BI2 workup and treatment in patients with suspected neuropathology.

Notes: *Studies have reliably shown that PO cyanocobalamin therapy is another option.

Abbreviations: $\mu \mathrm{mol} / \mathrm{L}$, micromoles per liter; $\mathrm{CBC}$, complete blood count; Hcy, homocysteine; Hgb, hemoglobin; IM, intramuscular; MCV, mean corpuscular volume; $\mathrm{PA}$, pernicious anemia; $\mathrm{Pg} / \mathrm{mL}$, picograms per milliliter; $\mathrm{PO}$, oral; $\mathrm{SC}$, subcutaneous.

In what was described as the most severe neuropathic epidemic of modern times, ${ }^{402}$ between 1991 and 1993 more than 50,000 Cubans developed peripheral neuropathy, associated with reduced nutrient intake of group B vitamins, ${ }^{403-409}$ in the setting of strict embargos and economic deterioration. $404,405,407,408$ Although widespread distribution of group B vitamins ${ }^{404,406,407,409}$ and government-mandated folic acid fortification ${ }^{404,410}$ curbed the epidemic, ${ }^{404,406}$ some speculate that endemic subclinical 
group B vitamin deficiencies, coupled with Helicobacter pylori (H. pylori) infections, are responsible for the higher prevalence of dementia in Cuba compared with other Caribbean countries. ${ }^{404}$ Before and after the Cuban epidemic, in 1976 and 1995, researchers ${ }^{411,412}$ discovered that folate deficiency and relatively high, compared with relatively low, Hcy levels in pregnant women are associated with neural tube defects (NTDs) in infants born to such women, findings that have since been replicated. ${ }^{7,18,52,355,393,413,414}$ Since supplemental folic acid during pregnancy decreases the risk for such abnormalities, ${ }^{415-420}$ in 1998 the United States Food and Drug Administration (FDA) and Health Canada required wheat and other grain products to be fortified with folic acid..$^{35,58,421-423}$ To date, more than 50 countries have mandated folic acid fortification. ${ }^{410,420}$ It is largely accepted that high-dose folic acid may mask B12 deficiency. It is less clear whether or not low dose folic acid masks B12 deficiency. ${ }^{285,401}$ Although the United States FDA requires $140 \mu \mathrm{g}$ of folic acid per $100 \mathrm{~g}$ of grain or flour, ${ }^{424,425}$ an amount chosen because it was considered high enough to prevent NTDs, but low enough to not mask B12 deficiency, some have advocated increasing this amount. ${ }^{426}$ Due to insufficient sensitivity, neither $\mathrm{Hgb}$ nor MCV are useful in ruling out B12-deficient dementia or SCD. $7,13,33,58,124,289,300,371,373,377,385,427$ Although the complete blood count (CBC) is part of routine diagnostic testing for dementia, ${ }^{368}$ additional vigilance is needed, ${ }^{20,58,381,428}$ especially in the era of folic acid fortification. In B12 deficiency, supplemental folic acid may protect against anemia, but not neurodegeneration; ${ }^{19,52,371}$ thus, the $\mathrm{CBC}$ alone may become even less sensitive in evaluating B12-deficient psychiatric and neurological abnormalities.

Further evaluation to rule out type A chronic atrophic gastritis, or PA, ${ }^{181,429}$ might be warranted because of increased risk for gastric cancer, where radiographic or endoscopic screening is useful, especially in cases of MCI and early dementia. ${ }^{15,18,33,200,201}$ Thus, it is useful to obtain additional testing when B12-deficient dementia occurs with anemia, macrocytosis, corpuscular changes on peripheral smear, or signs and symptoms of SCD or peripheral neuropathy. ${ }^{7}$ When B12-deficient dementia occurs in the absence of such findings, the decision to rule out type A chronic atrophic gastritis may be made on a case by case basis.

Although PA, or type A chronic atrophic gastritis, ${ }^{181,429}$ is often cited as the most common cause of low serum B12, 7,18,19,33, $49,56,58,180,201,390$ emerging evidence suggests dissociation between

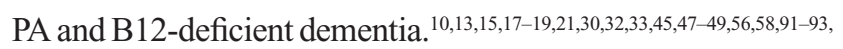
146,180,190,200,201,203,290,350,368,371,373,376,393,427-434 Thus, B12-deficient dementia may be subdivided into B12-deficient dementia with PA and B12-deficient dementia without PA. Studies support the postulate that these two disease states are different. ${ }^{10,13-15 \text {, }}$ 17,19,21,25,30,32,33,45,47-49,58,91-93,146,190,201,203,289,290,350,368,427,429,431-435 They appear to have different etiologies, pathophysiological findings, prevalences, and responses to treatment.

B12-deficient dementia with PA and B12-deficient dementia without PA have separate etiologies, whereby the former is caused by type A chronic atrophic gastritis ${ }^{181,429}$ and the latter is generally caused by type B (nonautoimmune) chronic atrophic gastritis, age-associated decrease in hydrochloric acid production, or decreased vitamin B12 ingestion. ${ }^{9} 10,14,17,21,22,30,45,47,49,58,91,92,203,368$ Type B chronic atrophic gastritis and age-associated decrease in hydrochloric acid production cause food-cobalamin malabsorption. ${ }^{30}$ Less established causes of relative B12 deficiency include impairment of vitamin B12 transfer, from capillaries to $\mathrm{CSF}^{436}$ and from CSF to neurons, ${ }^{382}$ and vitamin B12 hyperconsumption, ${ }^{54,63,340,342}$ inactivation, ${ }^{146}$ or destruction. ${ }^{290}$ Type A chronic atrophic gastritis is due to antiparietal cell and anti-intrinsic factor antibodies, ${ }^{15,33,58,181,201,203,429}$ which occur in $90 \%$ and $55 \%$ of cases, respectively, ${ }^{7,203}$ causing parietal cell insufficiency and intrinsic factor dysfunction, sparing the antrum. ${ }^{33,58,201}$ Type B chronic atrophic gastritis is usually caused by $H$. pylori infection, involving the antrum. ${ }^{15,58,201,203}$ This is especially worth mentioning, because gastritis involving both body and antrum ${ }^{437}$ and H. pylori infection, confirmed by serological, ${ }^{437-439}$ histological, ${ }^{437,438,440}$ and rapid urease ${ }^{438}$ tests, is significantly more prevalent in individuals with $\mathrm{MCI}^{437}$ and $\mathrm{AD}^{438-440}$ compared to controls. In those with MCI, there is a correlation between serum antiH. pylori immunoglobulin $\mathrm{G}$ concentration and degree of cognitive impairment, ${ }^{437}$ which may be mediated by elevated Hcy levels. ${ }^{437}$ One study ${ }^{438}$ showed H. pylori eradication improved both cognitive and functional measures in patients with AD. Since gastrin is secreted by antral G-cells, serum gastrin is elevated with type $\mathrm{A},{ }^{378}$ but low with type $\mathrm{B},{ }^{21}$ chronic atrophic gastritis.

B12-deficient dementia with and without PA have separate pathophysiological findings, where myeloneuropathy is characteristic and macrocytosis or anemia are present in the former, ${ }^{181,190,429}$ but myeloneuropathy may be rare ${ }^{19}$ and macrocytosis and anemia are often absent ${ }^{13,19,25,30,92,146,289,290,350,427,431-433}$ in the latter. Neuropathy associated with PA classically involves disease progression, beginning in the cervicothoracic region of the spine, ${ }^{202,441}$ with upper extremity findings classically occurring before lower extremity findings, followed by peripheral nerve involvement, and lastly, if at all, brain involvement. ${ }^{23,200,203}$ Dementia is believed to be a late and rare finding of neuropathy associated with PA. ${ }^{19,25,48,203,290}$ 
Alternatively, dementia with B12 deficiency often occurs independently from PA. $13,25,146,290,427,432,433$

B12-deficient dementia without PA is relatively common, ${ }^{25,146,290,427,432,433}$ but B12-deficient dementia with PA is considered rare, ${ }^{14,19,25,30,32,48,93,203,290,427,432}$ where it causes only a small fraction of B12 deficiency in demented individuals. ${ }^{14,25,30,32,93,290,427,432}$ PA incidence peaks late in midlife, ${ }^{181,429}$ while dementia incidence increases with age. ${ }^{233}$ Both chronic atrophic gastritis type $\mathrm{A}$ and $\mathrm{B}$ are characterized by low pepsinogen I/pepsinogen II ratios and achlorhydria; ; $;^{75,21,22,33,378}$ however, low pepsinogen I/pepsinogen II ratios occur in roughly $30 \%$ of elderly populations $\mathrm{s}^{378}$ and PA occurs in only about $2 \%,{ }^{23,428}$ suggesting the majority of cases with low ratios are caused by factors other than PA.

Meta-analyses or systematic reviews confirm that HHcy is a risk factor for $\mathrm{AD},{ }^{11,233}$ but they also confirm that vitamin $\mathrm{B} 12$ treatment of B12-deficient dementia is ineffective for improving cognitive function. ${ }^{16,348,355}$ Thus, B12-deficient dementia without PA and B12-deficient dementia with PA have distinct responses to supplemental B12 treatment, where it appears that moderately severe to severe dementia does not improve in the former, ${ }^{13,15,16,24,26,33,92,187,326,349,350,355,356,358,359,362}$ but may improve in the latter. ${ }^{185,190,199,429,434,435}$ The apparent dissociation of hematological findings and neurocognitive impairment provides additional support to the postulate that B12-deficient dementia with or without PA represent two separate disease states. Progressive neurocognitive decline often occurs in the presence of normal $\mathrm{Hgb}$ and $\mathrm{MCV}$, where one or both values are normal in many individuals with B12-deficient dementia $^{13,33,124,188,200,433}$ or neurological abnormalities. ${ }^{18,20,124,180,188,373}$ When anemia is absent, Hgb is indirectly proportional to cognitive function, ${ }^{18,19,200}$ and when present, it is an inconsistent risk factor for cognitive dysfunction. ${ }^{92,430}$ Neurological impairment occurring concomitantly with anemia is more likely to improve with supplemental B12 therapy in those cases where the anemia is more severe and less likely to improve where the anemia is less severe. ${ }^{180,393}$ With supplemental B12 therapy, increased reticulocytosis occurs within one week, ${ }^{376,393}$ but neurological improvement may require six months or longer. ${ }^{180,393}$ Vitamin B12 supplementation reverses hematological abnormalities in almost all patients, ${ }^{15,33,185,362}$ may improve neurological abnormalities in roughly one-half, ${ }^{15,33,185}$ and arrests or reverses dementia in only very few. ${ }^{13,15,16,24,26,33,92,187,326,347,349,350,355,361,362}$

In B12 deficiency dementia with versus without PA, there appear to be different manifestations, need for further workup, and responses to treatment. Therefore, when findings include low serum B12 or elevated Hcy, it is useful to rule out PA. In the workup for type A chronic atrophic gastritis, assessment of antiparietal cell and anti-intrinsic factor antibodies is an initial option. ${ }^{32,181,368,429}$ Since the former are sensitive, occurring in up to $10 \%$ of elderly populations, ${ }^{56}$ and the latter are specific, the absence of antiparietal cell antibodies suggests low likelihood, ${ }^{7}$ while the presence of anti-intrinsic factor antibodies suggests high likelihood, ${ }^{7}$ for type A chronic atrophic gastritis. If antiparietal cell antibodies are present and anti-intrinsic factor antibodies are absent, assessment of serum gastrin levels is a further option. ${ }^{7,33}$ Type A and B chronic atrophic gastritis also can be distinguished by endoscopy with mucosal surface biopsy. ${ }^{7111,429}$ Although Schilling's test has been largely supplanted by the aforementioned tests, ${ }^{203,368}$ it may be useful if such tests are unremarkable or equivocal. ${ }^{434}$ However, decreased vitamin B12 ingestion ${ }^{9,47}$ and food-cobalamin malabsorption ${ }^{9,45,49}$ are common causes of low serum B12 in elderly populations, and Schilling's test is most often negative (ie, step one results are normal) in these conditions. .5,33,93,203 $^{25}$

\section{When vitamin BI2 deficiency is found in dementia, is dementia of the Alzheimer's type a compatible diagnosis?}

$\mathrm{AD}$ is diagnosed by tissue pathology. According to the Diagnostic and Statistical Manual of Mental Disorders, Fourth Edition, Text Revision (DSM-IV-TR), DAT is essentially a diagnosis of exclusion, after other causes of dementia, including B12 deficiency, have been ruled out, thus dichotomizing dementia due to B12 deficiency and DAT. Although two studies ${ }^{359,442}$ support this dichotomy, most studies ${ }^{13,26,82,222,333,336,382}$ suggest DAT occurs with or without B12 deficiency. When MCI and various subtypes of dementia are compared with one another, similar concentrations of serum B12 and Hcy are observed. ${ }^{276,284,443}$ When B12-deficient dementia is compared to other subtypes of dementia, similar rates of decline are observed across almost all measured outcomes. ${ }^{33,350,444}$ Nonetheless, there is likely a DAT subgroup, having low serum B12 $2^{427,445}$ and perhaps elevated platelet monoamine oxidase (MAO) activity. ${ }^{29}$ Since B12 deficiency dementia with PA may arrest or reverse with treatment ${ }^{190,429,434}$ and B12 deficiency dementia without PA is usually progressively neurodegenerative despite treatment, the presence of PA would suggest dementia due to B12 deficiency, while its absence would suggest DAT. ${ }^{446}$

\section{Treatment}

Based on the benefit-to-risk ratio in treatment of dementia, if vitamin $\mathrm{B} I 2$ deficiency is determined, should supplemental $\mathrm{B} / 2$ be initiated?

Vitamin B12 treatment is considered one of the safest medical treatments available. ${ }^{47}$ Although severe adverse events are 
very rare, those reported include anaphylactic shock and death with administration of parenteral vitamin B12, hypokalemia with sudden death in conditions of severe anemia, and severe and sudden optic atrophy in those with Leber's hereditary optic neuropathy. ${ }^{448}$ Other adverse events include polycythemia, thrombosis, pruritus, rash, skin eruptions ${ }^{449}$ congestive heart failure, diarrhea, edema, and swelling. One randomized controlled trial $(\mathrm{RCT})^{347}$ found a greater prevalence of depression in the treatment group, who received high-dose pyridoxine, folate, and vitamin B12, than in the placebo group.

Although no overdosage has been reported, in treating hypovitaminosis B12 with supplemental B12, there is a fine line between help and harm. The serum cobalamin-plasma Hcy concentration-response curve appears curvilinear. ${ }^{17}$ As serum cobalamin increases from the lowest detectable level to $950 \mathrm{pg} / \mathrm{mL}$, plasma Hcy decreases, but as serum cobalamin further increases from $950 \mathrm{pg} / \mathrm{mL}$ to $1,350 \mathrm{pg} / \mathrm{mL}$, plasma Hcy begins to rise. One cohort study, ${ }^{386}$ found a dose-dependent association between increasing serum B12 levels and incidence of coronary artery disease (CAD) and mortality, where each $100 \mathrm{pg} / \mathrm{mL}$ increase in serum cobalamin was associated with a $10 \%$ increased incidence for such events. One RCT ${ }^{450}$ found that low-dose pyridoxine, folic acid, and vitamin B12 treatment decreased the risk for stroke, CAD events, and death, while moderately high dose pyridoxine, folic acid, and vitamin B12 treatment did not. Although the earliest two ${ }^{451,452}$ of eight other RCTs showed combined pyridoxine, folic acid, and vitamin B12 treatment decreased morbidity in individuals with or at risk for CAD, the later $\operatorname{six}^{453-458}$ failed to validate these findings, and four ${ }^{454,456-458}$ of the six showed treatment potentially increased the risk for harm. One of these RCTs ${ }^{455}$ was prematurely terminated due to potential risk for harm demonstrated by group B vitamin treatment. ${ }^{454}$ Therefore, some authors ${ }^{386,454}$ suggest supplemental B12 should not be administered unless B12 deficiency is present, and when present, only enough supplemental B12 should be administered to correct the deficiency. Parenthetically, meta-analyses of folic acid treatment, aimed at lowering HHcy, show mixed results in terms of whether or not treatment decreases the risk for stroke. ${ }^{459,460}$ Since most prospective studies show supplemental B12 does not improve cognitive function or prevent dementia in cognitively intact individuals, ${ }^{306,354,360}$ including those with hypovitaminosis $\mathrm{B} 12^{351,353}$ or HHcy, ${ }^{357}$ it is not recommended ${ }^{401}$ for these purposes.

HHcy increases the risks for birth defects, cognitive dysfunction, dementia, cerebrovascular disease, stroke, CAD, MI, peripheral vascular disease, venous thrombosis, osteoporosis, hip fractures, and death. ${ }^{21,39,279,386,461-468}$ Benefits of treating B12 deficiency include lowering Hcy levels, ${ }^{19,21,47,135,198,326,347,351,357,360-362,397,469}$ lowering $A \beta$ peptide levels, ${ }^{470}$ decreasing tau hyperphosphorylation, ${ }^{132}$ antiinflammation, ${ }^{471}$ neuroprotection, ${ }^{471}$ reduction of MAO activity, ${ }^{29}$ and causing the BBB to be less leaky. ${ }^{469}$

It may not be feasible to perform a meta-analysis on studies that have ascertained whether or not vitamin B12 treatment is associated with improved cognitive function or prevention of dementia due to the heterogeneity of these studies (Table 2). Published studies include multiple designs (eg, case-control, other retrospective studies, RCTs, and other prospective studies), subjects (eg, those who are healthy, ill, communitydwelling, residents of tertiary care facilities, with and without cognitive dysfunction, and with and without vitamin B12 deficiency), interventions, including vitamin B12 alone or in combination with other drugs or dietary supplements, type of vitamin B12 administered, and route of administration.

Traditional recommendations of assessing for and, when found, treating B12-deficient dementia are supported by casecontrol studies, ${ }^{350,359}$ retrospective series, ${ }^{49,180,188,435,472}$ and case reports, ${ }^{190,429,434}$ where B12 deficiency was specifically caused by PA. Evidence supporting these recommendations appears to diminish with many RCTs, ${ }^{16,185,198,298,306,326,347,348,351-353,355,35}$ 7,360,361,364,473,474 clinical trials (CTs), ${ }^{13,24,185,187,199,346,356,362,397,469}$ and other prospective studies ${ }^{26,92,349,358,475}$ (Tables $3 \mathrm{a}$ and b). Twelve ${ }^{16,306,326,347,351-353,355,357,360,361,364}$ of 16 RCTs found supplemental B12 therapy was of no benefit for improving cognitive function. Four ${ }^{185,198,473,474}$ of 16 RCTs found supplemental B12 therapy was beneficial for improving cognitive function; however, subjects in these studies included nondemented, healthy adult women, ${ }^{473}$ individuals with schizophrenia and HHcy, ${ }^{198}$ and individuals with dementia, irrespective of serum B12 levels, treated with multiple vitamins and other dietary supplements. ${ }^{474}$ The design of one of these studies $^{185}$ did not include a separate control group. In all other RCTs of individuals with hypovitaminosis B12, 16,351,353,355 HHcy, ${ }^{357}$ HMMA, ${ }^{352}$ dementia, ${ }^{16,326,347,355,361}$ or at risk for dementia, ${ }^{326,348,352,360,364}$ vitamin B12 treatment group results were no better than placebo group results. Nonetheless, the results from the RCTs may not generalize to all patients. Five of these $\mathrm{s}^{306,351,353,357,360}$ did not examine subjects with MCI or dementia, three ${ }^{16,326,355}$ may have included subjects in various dementia stages, and six appear to have enrolled subjects, with either normal $1^{347,361}$ or irrespective $e^{306,326,360,364}$ of baseline folate and vitamin B12 statuses.

Although few included control groups, ${ }^{198,199,473,474}$ CTs and other prospective studies with positive 
Table 2 Examples of multiple binary variables in studies examining efficacy of B 12 treatment on cognition

\begin{tabular}{|c|c|c|c|c|c|}
\hline No & Time course & Type of study & $\begin{array}{l}\text { Absence/presence of } \\
\text { cognitive dysfunction }\end{array}$ & B I 2 status* & Study results; author, year \\
\hline I & $\begin{array}{l}\text { Retrospective } \\
\text { and cross-sectional }\end{array}$ & Not case control & Absent & Unknown & Positive; La Rue, I 997 \\
\hline 2 & & Not case control & Absent & Low & Positive; Healton, I99I' \\
\hline 3 & & Not case control & Present & Low & $\begin{array}{l}\text { Positive; Lindenbaum, } 1988 \\
\text { El Otmani, 2008² Fox, } 1975^{3} \\
\text { Healton, }\left.199\right|^{\prime}\end{array}$ \\
\hline 4 & & Case control & Absent & Normal & Negative; Lin, $2008^{4}$ \\
\hline 5 & & Case control & Present & Low & Negative; Eastley, $2000^{5}$ \\
\hline 6 & & Case control & Present & Low & $\begin{array}{l}\text { Positive; Eastley, } 2000^{5} \\
\text { Osimani, } 2005^{6}\end{array}$ \\
\hline 7 & & Not randomized controlled trial & Absent & Low & Positive; van Asselt, 200I \\
\hline 8 & Prospective & Not randomized controlled trial & Present & Unknown & Positive; Ikeda, $1992^{7}$ \\
\hline 9 & & Not randomized controlled trial & Present & Normal & Positive; Lehmann, $2003^{8}$ \\
\hline 10 & & Not randomized controlled trial & Present & Low & $\begin{array}{l}\text { Negative; Carmel, } 1995 \\
\text { Crystal, } 1994^{9} \text { Cunha, } 1990^{10} \\
\text { Kwok, 2008" Teunisse, } 1996^{12} \\
\text { van Dyck, 2008'3 }\end{array}$ \\
\hline 11 & & Not randomized controlled trial & Present & Low & $\begin{array}{l}\text { Positive; Abyad, } 2002^{14} \text { Cunha, } \\
1995^{15} \text { Kalita, } 2008 \text { Kwok, } \\
2008^{11} \text { Martin, } 1992^{16} \text { Nilsson, } \\
2001^{17}\end{array}$ \\
\hline 12 & & Randomized controlled trial & Absent & Unknown & $\begin{array}{l}\text { Negative; Stott, } 2005^{18} \\
\text { Wolters, } 2005\end{array}$ \\
\hline 13 & & Randomized controlled trial & Absent & Unknown & Positive; Bryan, 2002 \\
\hline 14 & & Randomized controlled trial & Absent & Normal & Positive; Levine, $2006^{19}$ \\
\hline 15 & & Randomized controlled trial & Absent & Low & $\begin{array}{l}\text { Negative; Eussen, } 2006 \text { Kwok, } \\
\text { I } 998 \text { McMahon, } 2006\end{array}$ \\
\hline 16 & & Randomized controlled trial & Present & Unknown & Negative; van Uffelen, 2008 \\
\hline 17 & & Randomized controlled trial & Present & Unknown & Positive; Remington, $2009^{20}$ \\
\hline 18 & & Randomized controlled trial & Present & Normal & $\begin{array}{l}\text { Negative;Aisen, } 2008 \text { Clarke, } \\
2003^{21} \text { Sun, } 2007\end{array}$ \\
\hline 19 & & Randomized controlled trial & Present & Low & $\begin{array}{l}\text { Negative; Clarke, } 2003^{21} \\
\text { Fourniere, } 1997 \text { Hvas, } 2004 \\
\text { Seal, } 2002\end{array}$ \\
\hline 20 & & Randomized controlled trial & Present & Low & Positive; Bolaman, $2003^{22}$ \\
\hline
\end{tabular}

Notes: I, Subjects had nervous system involvement; $2, N=1 ; 3, N=1 ; 4$, sample consisted of asymptomatic nursing home males; 5 , results were negative for subjects with dementia, and positive for those with mild cognitive impairment; 6 , baseline neuropsychiatric tests determined those who did not improve from those who improved; 7 , BI 2 status was not a major factor mentioned in the methods or results sections, treatment consisted of intravenous mecobalamin; 8 , subjects had normal vitamin BI2, hyperhomocysteinemia, and mild cognitive impairment at baseline, and there were no subjects who progressed to dementia; $9, \mathrm{~N}=3 ; 10, \mathrm{~N}=13 ; \mathrm{I}$, delirium improved, but dementia did not improve; $12, N=26 ; 13, N=28 ; 14$, shorter duration of cognitive dysfunction was associated with greater response to BI2 treatment; 15 , outcome was obtained in $19 / 46$ patients, $16 / 19$ worsened, and $3 / 16$ improved with BI 2 therapy, those who improved had mild dementia of less than two years duration; 16 , individuals who were symptomatic less than 12 months improved with BI2 therapy; 17, those with mild-moderate dementia and those with hyperhomocysteinemia improved with supplemental BI2 therapy; 18 , subjects were elders with ischemic vascular disease; 19, subjects had schizophrenia; 20, the dietary supplement also contained $\mathrm{N}$-acetylcysteine, $\mathrm{S}$-adenosylmethionine, and multiple other ingredients; 2 I, the sample presumably included those with normal and low serum BI2; 22, all subjects had pernicious anemia, oral was compared with intramuscular cyanocobalamin. *Binary variables include BI 2 status: known versus unknown, and known-normal versus known-low.

results $^{24,185,187,198,199,346,356,358,397,469,473-475}$ show cognitive improvement may be associated with five factors: Hcy state, ${ }^{37,57,200,358,397}$ disease duration, ${ }^{18,24,30,180,346,356}$ disease intensity, $24,180,350,358,359$ and treatment type, ${ }^{474,475}$ as shown in Table $4 .{ }^{17,24,37,58,146,180,290,}$ 306,346,350,351,353,356-359,361,473-495 The fifth factor, and perhaps the most striking, is whether or not the B12 deficiency-associated cognitive dysfunction is due to PA. If so, then these individuals may respond remarkably well to supplemental B12 treatment, regardless of the severity of the dementia. ${ }^{185,190,429,434}$ Parenthetically, all RCTs show supplemental folic acid is no better than 


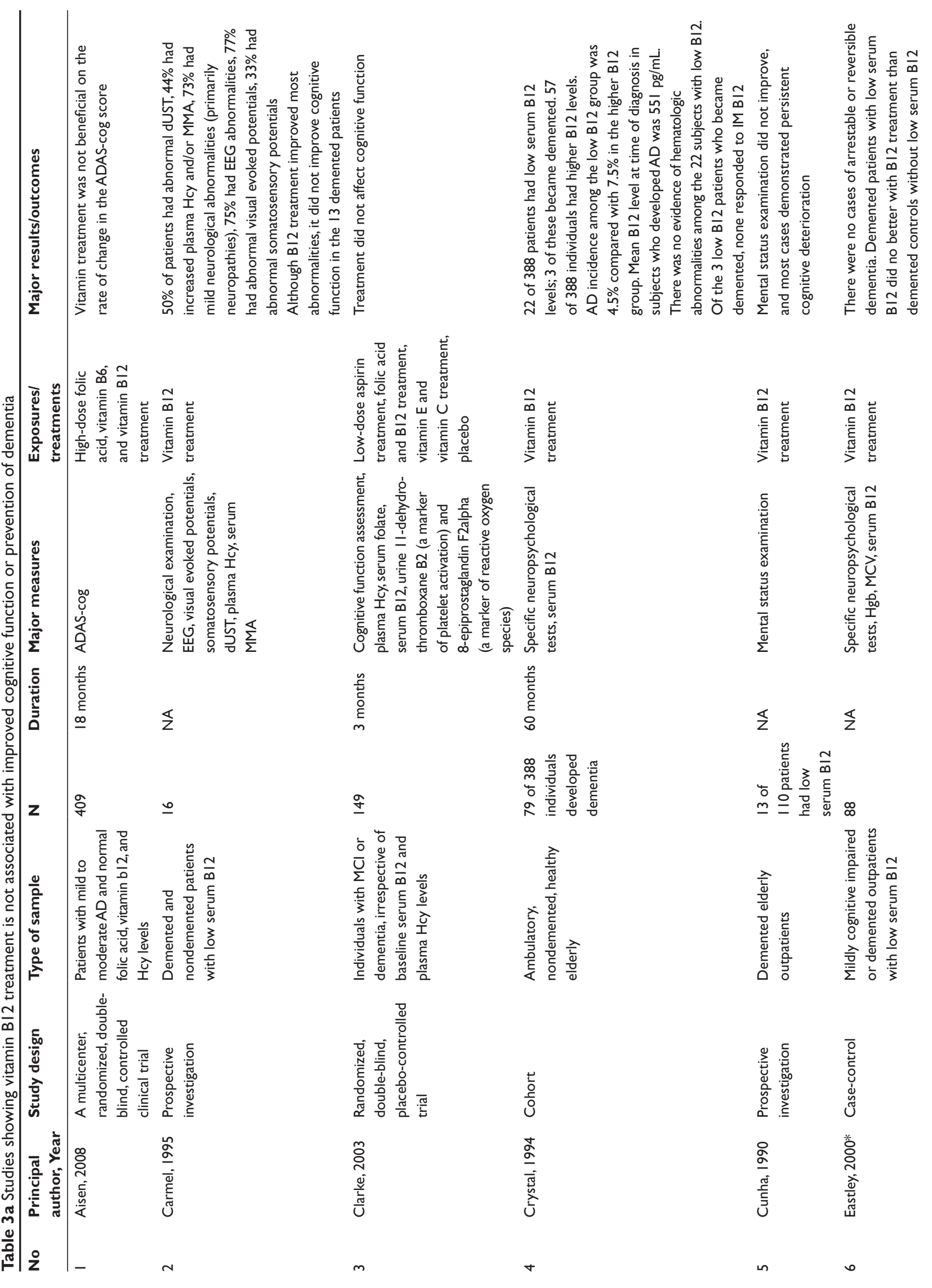



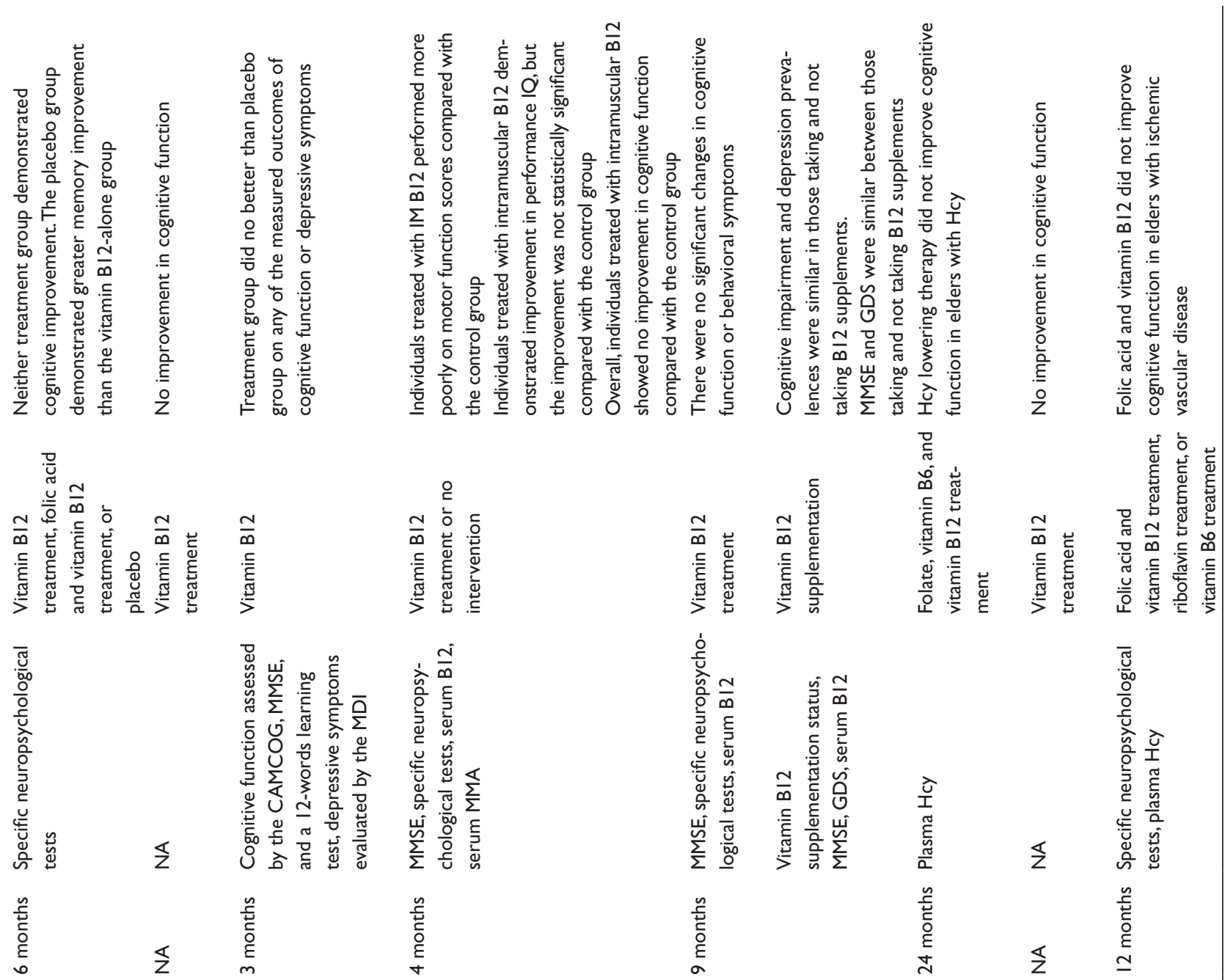

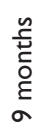
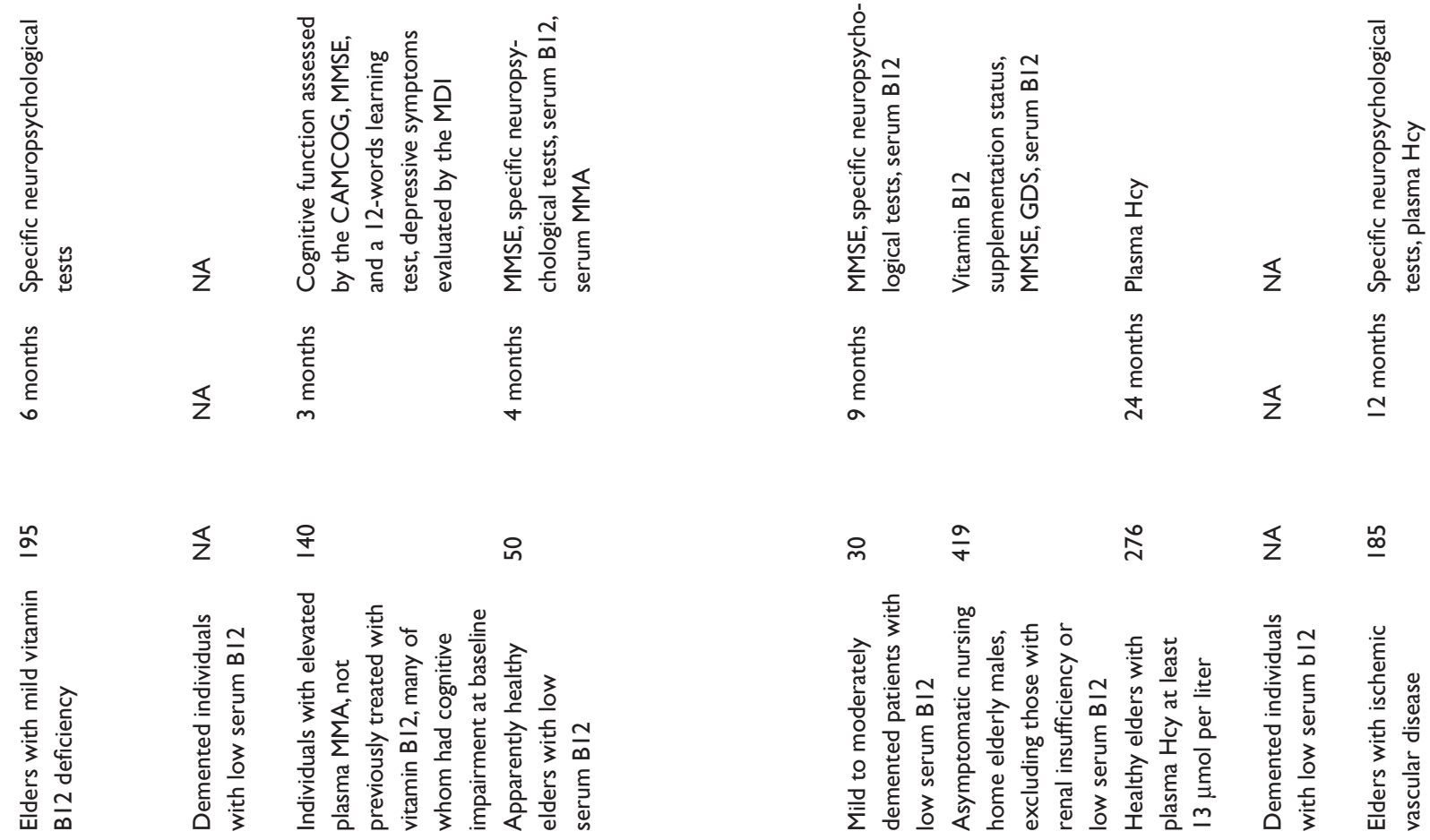

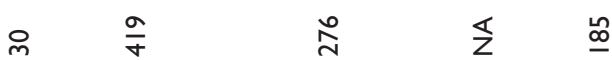
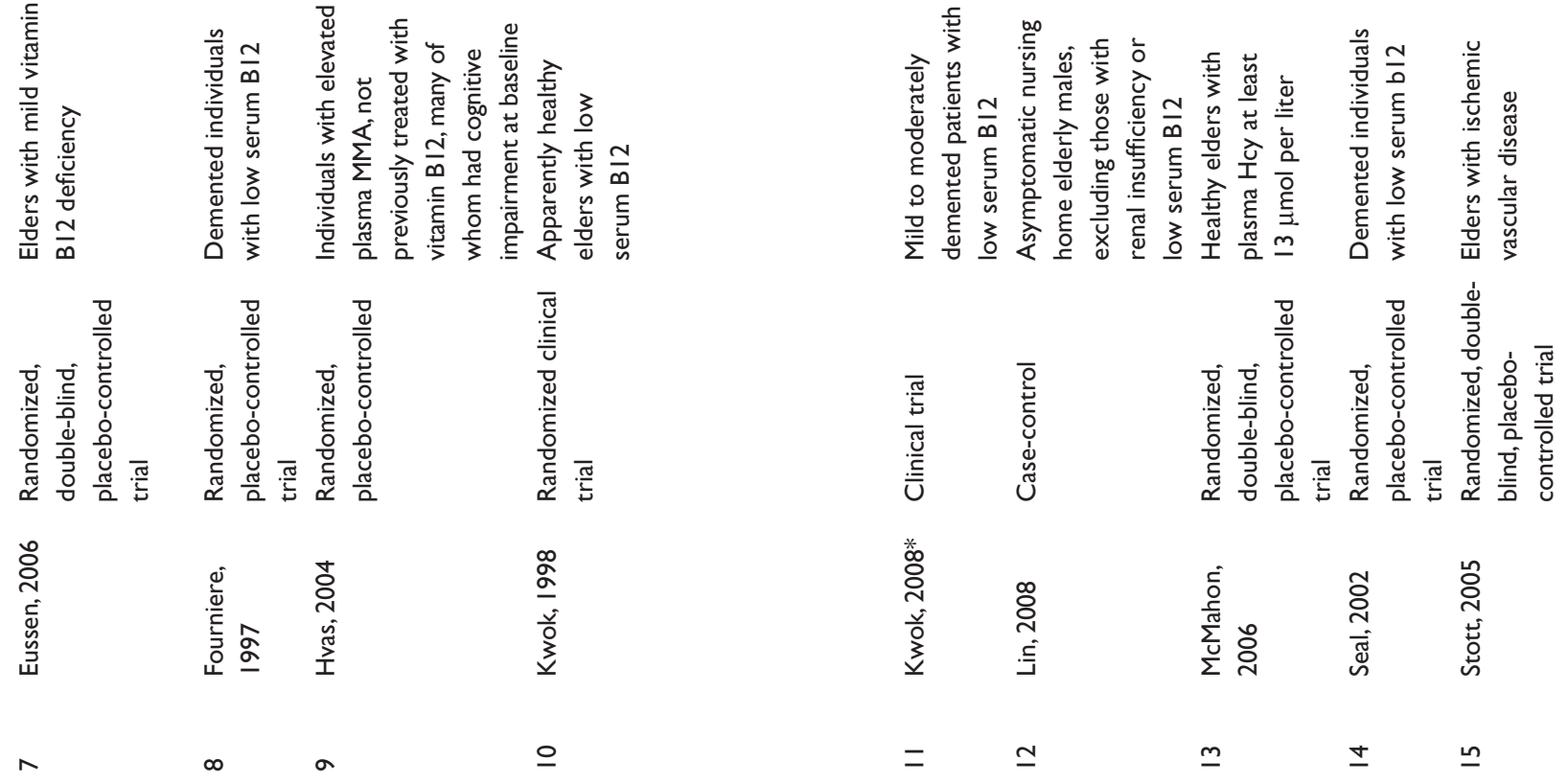

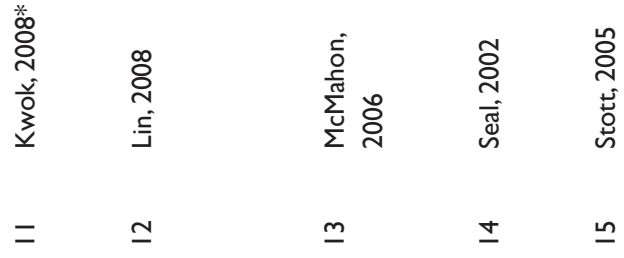




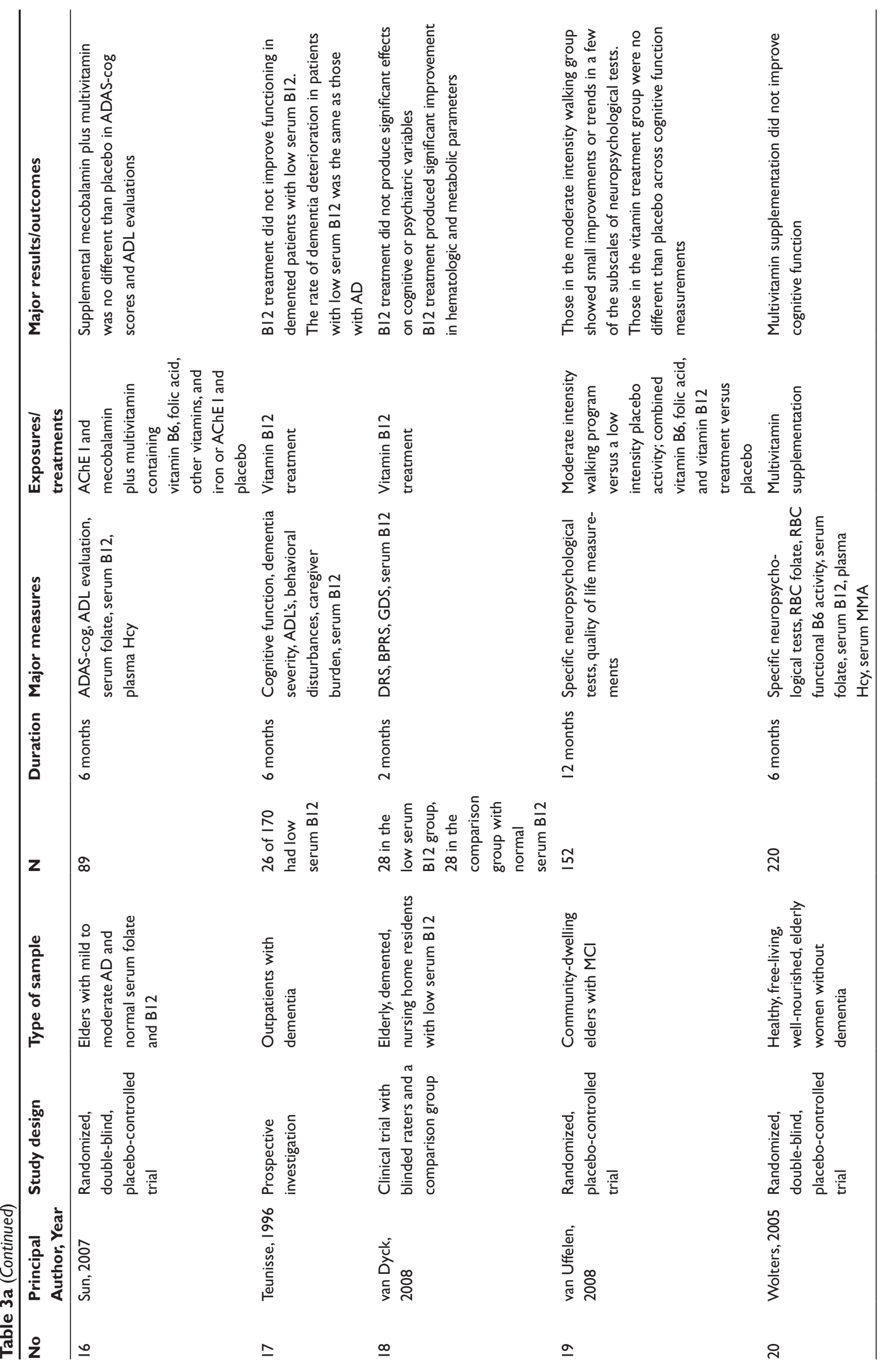




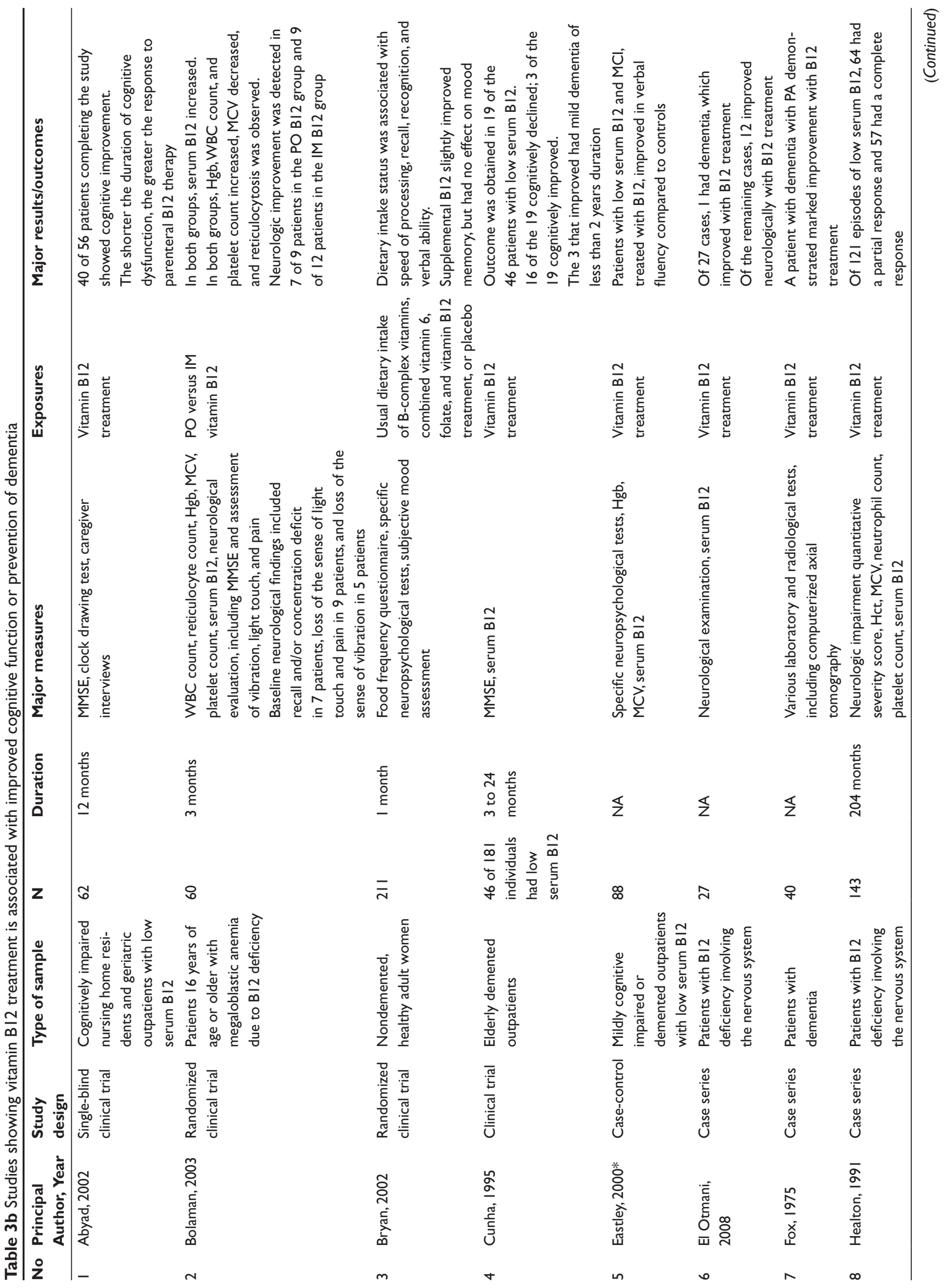




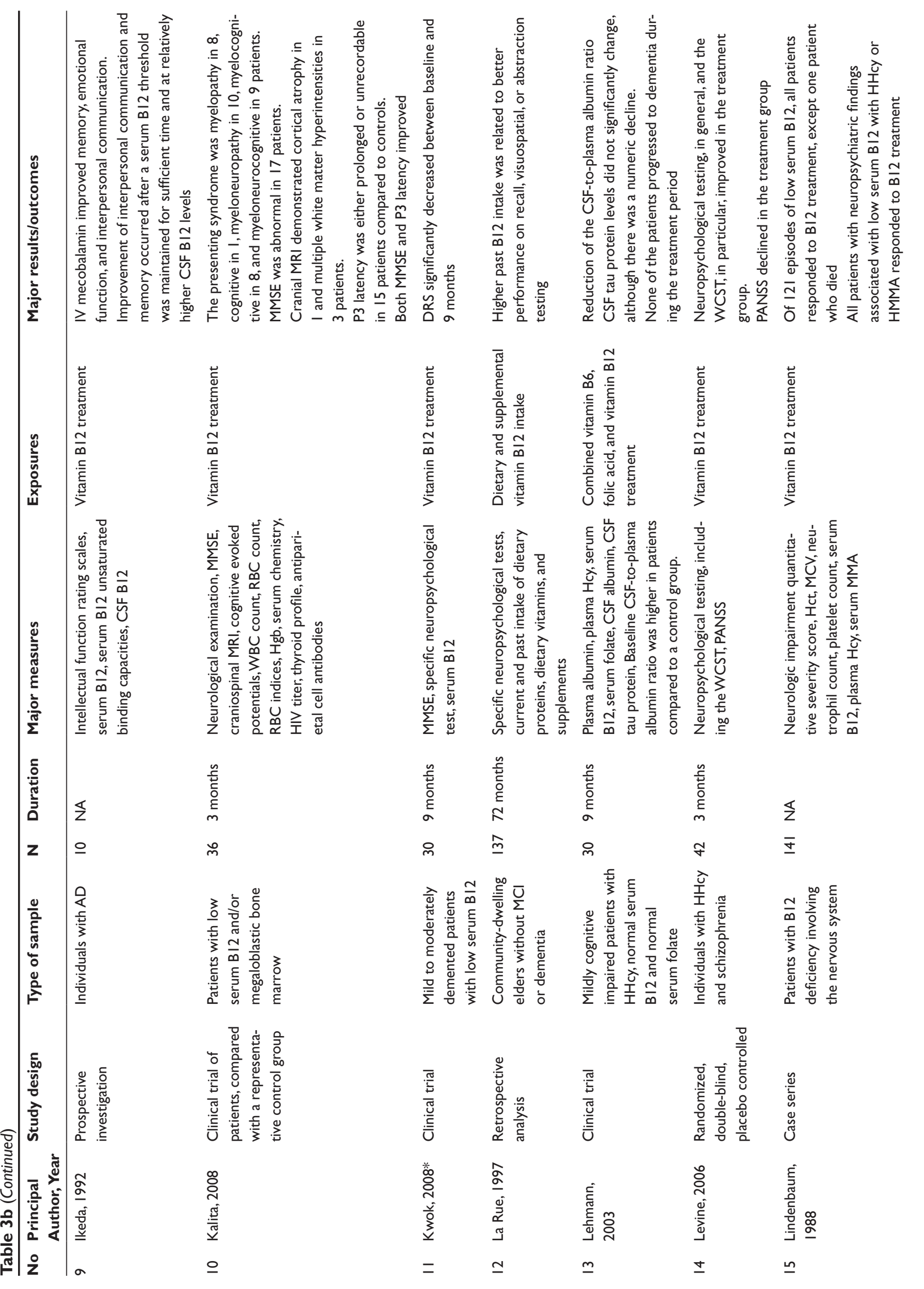




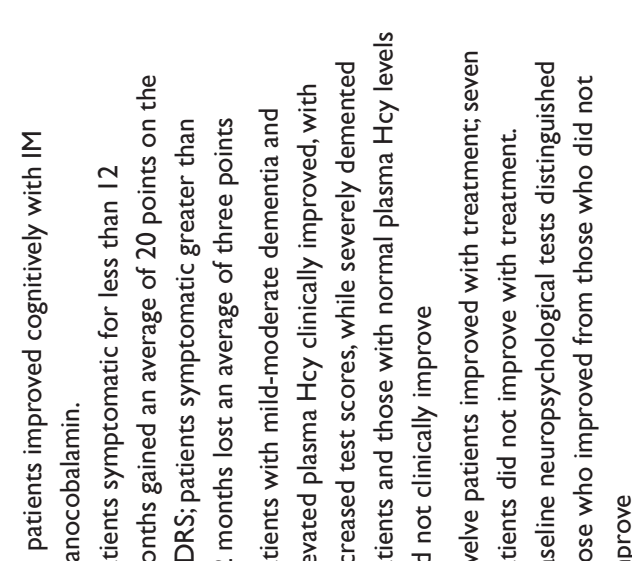

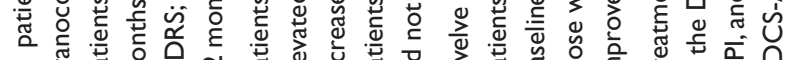

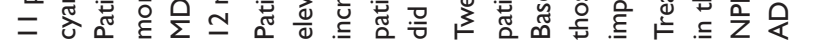

苞

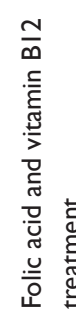
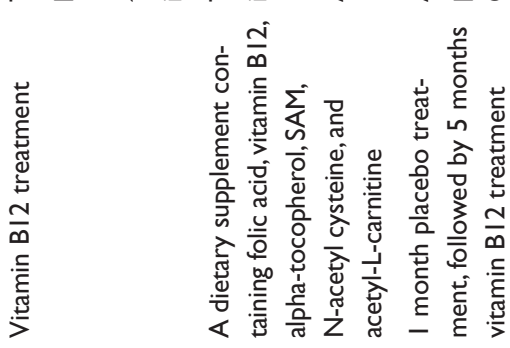

芒

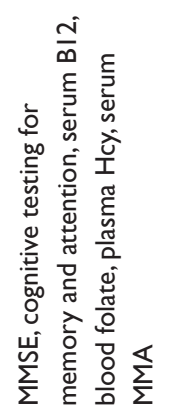

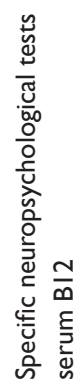

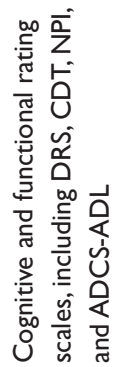

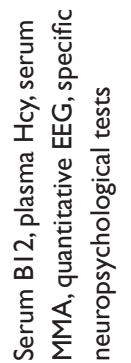

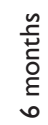

$\underline{\infty}$

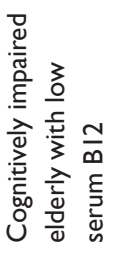

$\frac{\sqrt{4}}{\frac{\pi}{3}}$

ส

立

$\underline{0}$

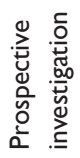

m
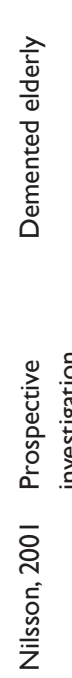

$\simeq$

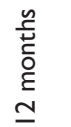

$\stackrel{n}{+}$
$\stackrel{0}{0}$
$\stackrel{1}{\simeq}$

$\underline{a}$

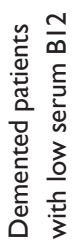

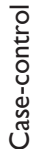

菅

竎

$\underline{\infty}$

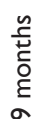

$\simeq$

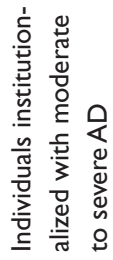

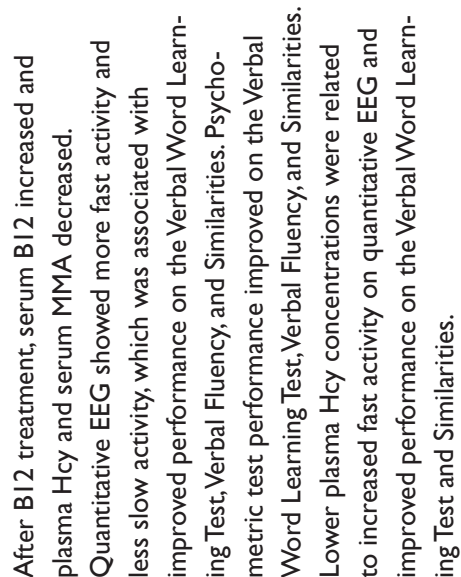

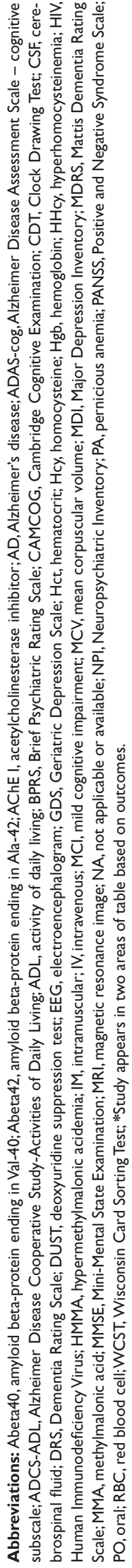


placebo at improving cognitive function in individuals with dementia. ${ }^{348,355,361,496}$

BPSD include symptoms and signs of disturbed behavior, mood, psychomotor activity, and thought content (eg, delusions and hallucinations) in patients with dementia. Exogenous SAM improves depression in patients with $\mathrm{PD}^{481}$ and other conditions. ${ }^{494,495}$ In individuals with $\mathrm{AD}$, those with HHcy have increased EEG slow wave activity (ie, increased theta and delta waves) compared to those without HHcy. ${ }^{184,257}$ In nondemented individuals, lowering plasma Hcy levels with vitamin B12 treatment reverses such EEG findings. ${ }^{184,397}$ Accordingly, prospective studies of individuals with B12-deficient dementia show patients with delirium ${ }^{187}$ or psychoses ${ }^{359}$ improve with vitamin B12 supplementation. In demented individuals, prospective studies show vitamin B12 supplementation enhances vigilance when combined with bright light therapy, ${ }^{497}$ improves mood disturbances, ${ }^{475}$ but may worsen motor performance. ${ }^{353}$ Although not a consistent finding, ${ }^{187,362}$ supplemental B12 in B12-deficient dementia may be beneficial for some patients with BPSD. ${ }^{359,475}$ Independent from serum folic acid and B12 levels, an association was found between HHcy and schizophrenia; ${ }^{498}$ in spite of the HHcy association being independent from group B vitamins in that study, another study ${ }^{198}$ showed combined pyridoxine, folic acid and vitamin B12 treatment in individuals with HHcy and schizophrenia improved positive symptoms, negative symptoms, and cognitive function. Depression, mania, psychoses, and delirium associated with PA or hypovitaminosis B12 may improve with supplemental B12 treatment. ${ }^{181-184,190,191}$

Considering the potential risks for adverse events, added cost, and added administration, and the potential benefit for arresting or reversing dementia, if B12 deficiency is determined, it should be treated. Vitamin B12 treatment should be initiated in those cases where serum B12 levels are $200 \mathrm{pg} / \mathrm{mL}$ or less and those where serum B12 levels are $201-350 \mathrm{pg} / \mathrm{mL}$ with plasma Hcy greater than $14 \mu \mathrm{mol} / \mathrm{L} \cdot{ }^{320}$ Duration of therapy is based on etiology and other factors, with an optimum serum B12 not being more than $950 \mathrm{pg} / \mathrm{mL}$. In cases of PA, treatment is continued for life. In cases of dietary deficiency, low vitamin B12 in dementia normalizes with dietary correction. ${ }^{14}$ Possible explanations on why dementia does not reverse or arrest with supplemental B12 include treatment being an ineffective form, ${ }^{146,290}$ initiation outside of a time course window, ${ }^{30,346,356}$ or dementia not solely being caused by PA or low serum B12. ${ }^{13,26,82,222,333,336,359,442}$

\section{How is vitamin $B 12$ deficiency treated?}

Since bacteria produce natural forms of vitamin B12, which humans ingest by consuming animal products, ${ }^{19,58,201}$ strict vegetarians may require oral (PO) vitamin B12 supplementation. ${ }^{58}$ The recommended daily allowance (RDA) is $2.4 \mu \mathrm{g}$ daily. ${ }^{499}$ Supplemental forms of vitamin B12 include cyanocobalamin, used in the United States, hydroxocobalamin, used in Europe, and mecobalamin, used in Asia. ${ }^{7,361,475}$ Mecobalamin is a synthetic form of methylcobalamin, which is the type of cobalamin utilized intracellularly. Although it may be advantageous in cognitive improvement or protection, ${ }^{475}$ it has not been compared with cyanocobalamin or hydroxocobalamin in clinical trials, and it may not be readily available in many western countries. Routes for cyanocobalamin administration include PO, sublingual (SL), intranasal (IN), intramuscular (IM), and subcutaneous (SC). Although the intravenous (IV) route has been used in patients with renal failure, ${ }^{500,501}$ this route is not recommended for general use. ${ }^{448}$ Compared to PO cyanocobalamin, IM and IV cyanocobalamin potentially pose greater risks for anaphylaxis. Up to $98 \%$ of an IM dose is lost in the urine, and even more is lost with an IV dose. ${ }^{387,448}$ Alternatively, $1 \%$ of PO cyanocobalamin is absorbed, throughout the gastrointestinal tract, by passive diffusion, independent of intrinsic factor. ${ }^{18,52,201,368,387}$ Thus, $10 \mu \mathrm{g}$ will be absorbed from a $1,000 \mu \mathrm{g}$ dose, well above the RDA; $;^{18,201,502}$ this effect is seen even in those with PA, prior gastrectomies, or diseases of the terminal ileum. ${ }^{52,368,387,503}$ Most physicians favor IM over PO routes, ${ }^{20,23,31,203,504}$ while most patients favor PO over IM routes. ${ }^{503,505}$ Patient preference is supported by a $\mathrm{CT}^{91}$ and $\mathrm{RCTs}^{31,34,185,392}$ showing PO cyanocobalamin provides equal, if not greater, serum B12 therapeutic levels. Since PO cyanocobalamin is as effective as IM cyanocobalamin in treating B12 deficiency, and its complications, it may be the preferred route of administration, unless there is concern regarding PO cyanocobalamin adherence, such as dysphagia. ${ }^{19,200,376,505}$ Variance exists in recommendations for dose and administration frequency: common practices include cyanocobalamin $1,000 \mu \mathrm{g}$ PO daily $203,503,505$ or cyanocobalamin $1,000 \mu \mathrm{g}$ IM daily for one week, then weekly for one month, then monthly thereafter. ${ }^{23,185,200,203,346,356,387,393}$ Alternative regimens are recommended for those with manifestations of severe PA. ${ }^{448}$

\section{Conclusions}

Although this paper represents a synopsis of our current understanding between HHcy and hypovitaminosis B12 and $\mathrm{MCI}$ or dementia, some investigations and reviews reveal 
Table 4 Factors associated with cognitive improvement in BI2 supplementation of BI2-deficient dementia

\section{Etiology}

- Treatment of $\mathrm{B} / 2$ deficiency caused by pernicious anemia generally is associated with cognitive improvement.

- Treatment of BI2 deficiency caused by etiologies other than pernicious anemia generally is not associated with cognitive improvement.

\section{Homocysteine state}

- Presence of hyperhomocysteinemia at treatment onset is associated with improvement, whereas absence is not. ${ }^{37,358}$

\section{Disease duration}

- Duration of disease two years or less is associated with improvement, whereas duration of disease more than two years is not. $24,180,346,356$

\section{Disease intensity}

- Mild cognitive impairment and mild to moderate dementia are associated with improvement, whereas moderately severe to severe dementia is not. . $^{24,180,350,358,359}$

- Four ${ }^{306,351,353,357}$ of five ${ }^{30,351,353,357,473}$ prospective studies, in individuals without cognitive dysfunction, showed supplemental BI2 does not improve cognitive function, including in those with hypovitaminosis $\mathrm{B} 12^{351,353}$ and hyperhomocysteinemia..$^{357}$

\section{Treatment type}

- Compounds

- Glutathionylcobalamin

- used by neurons under oxidative stress conditions ${ }^{146}$

- not commercially available ${ }^{146,290}$

- Cyanocobalamin

- not used by neurons under oxidative stress conditions s $^{14,290}$

- commercially available

- Hydroxocobalamin

- not used by neurons under oxidative stress conditions ${ }^{146,290}$

- commercially available

- Mecobalamin

- not used by neurons under oxidative stress conditions ${ }^{146,290}$

- commercially available

\section{- Routes of administration}

- Cyanocobalamin

- can be administered orally, sublingually, intranasally, intramuscularly, subcutaneously, or intravenously

- The intravenous route is not advised unless the patient is in renal failure, since more than $98 \%$ of an intravenous dose may be lost in the urine.

- Methylcobalamin

- Oral doses

- do not increase serum or cerebral spinal fluid BI2 levels ${ }^{490}$

- do not improve cognitive function or activities of daily living in patients with Alzheimer's disease ${ }^{361}$

- Intramuscular or intravenous doses are required

- Intravenous doses have been shown to improve cognition, communication, emotions, and memory in patients with Alzheimer's disease. ${ }^{475}$

\section{- Whether or not methyl donors or antioxidants are administered}

- $\mathrm{N}$-acetylcysteine, a cell-permeate glutathione precursor, ${ }^{483}$ when combined with $\mathrm{BI}$ 2, improves cognition in patients with $\mathrm{HHcy}$. ${ }^{474,488}$

- S-adenosylmethionine may be a useful adjunct for treatment of depression, ${ }^{47-479,485,487}$ associated with Parkinson's disease, ${ }^{481}$ human immunodeficiency virus infection, ${ }^{494}$ and fibromyalgia. ${ }^{495}$

- Betaine lowers systemic Hcy ${ }^{476,482,49,492}$ and may delay illness progression in Alzheimer's disease. ${ }^{486}$

- Homocysteine methylation to methionine occurs by one of two means

- methionine synthetase converting methyltetrahydrofolate to tetrahydrofolate, with methyltetrahydrofolate as the methyl group donor - occurs in all cells

o betaine homocysteine methyltransferase converting betaine to dimethylglycine, with betaine as the methyl group donor $17,58,484$ - confined to the liver and kidneys ${ }^{480,489,493}$ This may not matter in the treatment of dementia, as a leaky blood brain barrier may allow influx of systemic homocysteine. 
contrary results or recommendations. . $7,41,62,188,340,398,401,506-508$ Possible errors from this review and its conclusions are that Medline was the primary database, searches may not have captured all relevant studies and case reports, and it is presumed that there are unpublished vitamin B12 treatment responses. In order to attempt to minimize erroneous conclusions, results were crosschecked with Internet searches and basic and clinical science textbooks, other Medline searches were performed using various search terms, and communication took place with experts who care for demented patients. Owing to the latter, it is crucial that PA be ruled out in all demented patients. Also, the trials that have been reported to date may have been of insufficient size or duration to determine a beneficial effect. ${ }^{233}$

Biological data support the notion that ROS generation may lead to elevated Hcy, but this may be, at least in part, an adaptive mechanism to generate cysteine, which is used in the biosynthesis of glutathione, ${ }^{120,509}$ an antioxidant that protects cells from oxidative stress. Biochemical and epidemiological evidence is convincing that HHcy, with or without hypovitaminosis B12, is a risk factor for dementia. Evidence is less convincing that hypovitaminosis B12 is a risk factor for dementia in the absence of HHcy. B12 deficiency manifestations are variable and include abnormal psychiatric, neurological, gastrointestinal, and hematological findings. Radiological images of nondemented and demented individuals with HHcy frequently demonstrate leukoaraiosis, potentially related to $\mathrm{BBB}$ dysfunction. Thus, the finding of leukoaraiosis on CAT or MRI scan is an indication for checking plasma Hcy and serum B12 levels.

Although historically neuropathy related to PA was described according to a classical disease progression, patient samples now show that symptoms and signs secondary to the neuropathy can be variable. ${ }^{180,188}$ Nonetheless, dementia secondary to PA, occurring separately from other manifestations of SCD or peripheral neuropathy, and in the absence of macrocystosis and anemia, may still be considered sufficiently rare to be the basis of case reports. ${ }^{190,199,434}$

On the one hand, literature suggests assessing serum B12 and treatment of B12 deficiency is useful early in the course of cognitive dysfunction, for instance, $\mathrm{MCI}^{199,350,469}$ and mild to moderate dementia of less than two years duration. ${ }^{24,180,346,356,358,359}$ If low serum B12 is determined, it may be worthwhile to check for antiparietal cell and anti-intrinsic factor antibodies and obtain testing for H. pylori, for management and prognostic purposes. On the other hand, literature suggests assessing serum B12 and treatment of B12 deficiency may not be useful late in the course of cognitive dysfunction, for instance, moderately severe to severe dementia, if symptoms and signs of SCD and peripheral neuropathy, hematological manifestations of PA, and other factors listed on Figure 4 are absent. However, if one has not inquired about neurological symptoms, examined the mouth and tongue, performed a neurological examination, and obtained a $\mathrm{CBC}$ on a moderately-severe to severely demented patient, then it could be a 'medical-legal pitfall' not to check the serum B12 level. ${ }^{62}$ The suggestions for vitamin B12 workup and treatment in patients with suspected MCI or dementia are evidence-based. However, since the rate of dementia progression is poorly measured and variable and there are no specific criteria for vitamin B12 testing, the suggestions are not intended to replace care based upon clinical decisions. The serum B12 level remains the standard initial test. ${ }^{181}$ DAT is a compatible diagnosis when B12 deficiency is found, unless it is caused by PA. Cyanocobalamin PO is favorable over IM, in terms of both therapeutic efficacy and patient preference, unless there is concern regarding PO adherence.

Since the original observations by Biermer in 1872, to the more recent epidemic neuropathy in Cuba, it is evident that adequate folate and vitamin B12 function is required for physical and mental health. Issues surrounding folate, vitamin B12, Hcy, and MMA as they relate to health, especially microvascular disease and cognitive dysfunction, are high interest among researchers and clinicians. Puzzling questions remain. Since B12 deficiency can lead to depression, mania, and psychoses, should clinicians routinely check serum B12 levels in patients with such findings? Among those individuals who are B12 deficient, what are the prevalences of antiparietal, anti-intrinsic factor, and anti-H. pylori antibodies? Is HHcy a risk factor for other types of dementia, such as DBT, dementia due to PD, or dementia with Lewy bodies? ${ }^{193,510,511}$ Since HHcy has been prospectively shown to be an 'independent' risk factor for dementia, then why are Hcy-lowering therapies ineffective, or at best modestly effective, at preventing or treating dementia? Answers to questions such as these may one day unleash knowledge necessary for more effective treatment. The notions of age-related, and perhaps disease-related, degradation of the BBB and oxidative chemical reactions, generating ROS and elevating Hcy, coupled with immune activation, both without and within the brain, remain novel areas for further work. ${ }^{120}$

\section{Acknowledgments}

The author wishes to thank the reviewers of this manuscript, for their thoughtful work and kind suggestions, which were 
highly valuable in the final writing of this publication. The author reports no conflicts of interest in this work.

\section{References}

1. Arnold SE, Kumar A. Reversible dementias. Med Clin North Am. 1993;77(1):215-230.

2. Practice guideline for psychiatric evaluation of adults. American Psychiatric Association. Am J Psychiatry. 1995;152(11 Suppl):63-80.

3. Knopman DS, DeKosky ST, Cummings JL, et al. Practice parameter: diagnosis of dementia (an evidence-based review). Report of the Quality Standards Subcommittee of the American Academy of Neurology. Neurology. 2001;56(9):1143-1153.

4. Feldman HH, Jacova C, Robillard A, et al. Diagnosis and treatment of dementia: 2. Diagnosis. CMAJ. 2008;178(7):825-836.

5. Schneede J, Ueland PM. Novel and estabslished markers of cobalamin deficiency: complementary or exclusive diagnostic strategies. Semin Vasc Med. 2005;5(2):140-155.

6. Vanderjagt DJ, McCarthy DM. Pernicious Anemia. In: Glew RH, Ninomiya Y, editors. Clinical Studies in Medical Biochemistry. 2nd Ed. New York, NY: Oxford University Press; 2006. p. 122-133.

7. Klee GG. Cobalamin and folate evaluation: measurement of methylmalonic acid and homocysteine vs vitamin $\mathrm{B}(12)$ and folate. Clin Chem. 2000;46(8 Pt 2):1277-1283.

8. Olivieri G, Hess C, Savaskan E, et al. Melatonin protects SHSY5Y neuroblastoma cells from cobalt-induced oxidative stress, neurotoxicity and increased beta-amyloid secretion. J Pineal Res. 2001;31(4) 320-325.

9. Allen LH. How common is vitamin B-12 deficiency? Am J Clin Nutr. 2009;89(2):693S-696S.

10. Basun H, Fratiglioni L, Winblad B. Cobalamin levels are not reduced in Alzheimer's disease: results from a population-based study. J Am Geriatr Soc. 1994;42(2):132-136.

11. Clarke R, Refsum H, Birks J, et al. Screening for vitamin B-12 and folate deficiency in older persons. Am J Clin Nutr. 2003;77(5):1241-1247.

12. Clarke R, Grimley Evans J, Schneede J, et al. Vitamin B12 and folate deficiency in later life. Age Ageing. 2004;33(1):34- 41.

13. Crystal HA, Ortof E, Frishman WH, Gruber A, Hershman D, Aronson M. Serum vitamin B12 levels and incidence of dementia in a healthy elderly population: a report from the Bronx Longitudinal Aging Study. $J \mathrm{Am}$ Geriatr Soc. 1994;42(9):933-936.

14. Elsborg L, Hansen T, Rafaelsen OJ. Vitamin B12 concentrations in psychiatric patients. Acta Psychiatr Scand. 1979;59(2):145-152.

15. Lechner K, Fodinger M, Grisold W, Puspok A, Sillaber C. Vitamin B12 deficiency. New data on an old theme. Wien Klin Wochenschr. 2005;117(17):579-591.

16. Malouf R, Areosa Sastre A. Vitamin B12 for cognition. Cochrane Database Syst Rev. 2003(3):CD004326.

17. Refsum H, Smith AD, Ueland PM, et al. Facts and recommendations about total homocysteine determinations: an expert opinion. Clin Chem. 2004;50(1):3-32.

18. Singh NN, Thomas FP, Diamond AL, Diamond R. Vitamin B-12 associated neurological diseases. 2006. Available from: http://emedicine. medscape.com/article/1152670-overview. Accessed on Nov 3, 2009.

19. Stabler SP, Lindenbaum J, Allen RH. Vitamin B-12 deficiency in the elderly: current dilemmas. Am J Clin Nutr. 1997;66(4):741-749.

20. Sumner AE, Chin MM, Abrahm JL, et al. Elevated methylmalonic acid and total homocysteine levels show high prevalence of vitamin B12 deficiency after gastric surgery. Ann Intern Med. 1996;124(5): 469-476.

21. Wolters M, Strohle A, Hahn A. Age-associated changes in the metabolism of vitamin $\mathrm{B}(12)$ and folic acid: prevalence, aetiopathogenesis and pathophysiological consequences. Z Gerontol Geriatr. 2004;37(2): 109-135.

22. Wolters M, Strohle A, Hahn A. Cobalamin: a critical vitamin in the elderly. Prev Med. 2004;39(6):1256-1266.
23. Worrall B, Rowland L. Nutritional disorders: Malnutrition, malabsorption, and B12 and other vitamin deficiencies. In: Rowland L, editor. Merritt's Neurology. 11th ed. Philadelphia, PA: Lippincott Williams \& Wilkins; 2005. p. 1091-1098.

24. Cunha UG, Rocha FL, Peixoto JM, Motta MF, Barbosa MT. Vitamin B12 deficiency and dementia. Int Psychogeriatr. 1995;7(1):85-88.

25. Karnaze DS, Carmel R. Low serum cobalamin levels in primary degenerative dementia. Do some patients harbor atypical cobalamin deficiency states? Arch Intern Med. 1987;147(3):429-431.

26. Teunisse S, Bollen AE, van Gool WA, Walstra GJ. Dementia and subnormal levels of vitamin B12: effects of replacement therapy on dementia. J Neurol. 1996;243(7):522-529.

27. Greilberger J, Koidl C, Greilberger M, et al. Malondialdehyde, carbonyl proteins and albumin-disulphide as useful oxidative markers in mild cognitive impairment and Alzheimer's disease. Free Radic Res. 2008;42(7):633-638.

28. Whyte EM, Mulsant BH, Butters MA, et al. Cognitive and behavioral correlates of low vitamin B12 levels in elderly patients with progressive dementia. Am J Geriatr Psychiatry. 2002;10(3):321-327.

29. Regland B, Gottfries CG, Oreland L. Vitamin B12-induced reduction of platelet monoamine oxidase activity in patients with dementia and pernicious anaemia. Eur Arch Psychiatry Clin Neurosci. 1991;240(4-5):288-291.

30. Bopp-Kistler I, Ruegger-Frey B, Grob D, Six P. Vitamin B12 deficiency in geriatrics. Schweiz Rundsch Med Prax. 1999;88(45): 1867-1875.

31. Butler CC, Vidal-Alaball J, Cannings-John R, et al. Oral vitamin B12 versus intramuscular vitamin B12 for vitamin B12 deficiency: a systematic review of randomized controlled trials. Fam Pract. 2006;23(3):279-285.

32. Nagga K, Rajani R, Mardh E, Borch K, Mardh S, Marcusson J. Cobalamin, folate, methylmalonic acid, homocysteine, and gastritis markers in dementia. Dement Geriatr Cogn Disord. 2003;16(4):269-275.

33. Nilsson-Ehle H. Age-related changes in cobalamin (vitamin B12) handling. Implications for therapy. Drugs Aging. 1998;12(4):277-292.

34. Vidal-Alaball J, Butler CC, Cannings-John R, et al. Oral vitamin B12 versus intramuscular vitamin B12 for vitamin B12 deficiency. Cochrane Database Syst Rev. 2005(3):CD004655.

35. Diaz-Arrastia R. Homocysteine and neurologic disease. Arch Neurol. 2000;57(10):1422-1427.

36. Brosnan JT, Brosnan ME. The sulfur-containing amino acids: an overview. J Nutr. 2006;136(6 Suppl):1636S-1640S.

37. Barone P, Burn DJ, van Laar T, Hsu C, Poewe W, Lane RM. Rivastigmine versus placebo in hyperhomocysteinemic Parkinson's disease dementia patients. Mov Disord. 2008;23(11):1532-1540.

38. Gonzalez-Gross M, Sola R, Albers U, et al. B-vitamins and homocysteine in Spanish institutionalized elderly. Int J Vitam Nutr Res. 2007;77(1):22-33.

39. Marengoni A, Cossi S, De Martinis M, Calabrese PA, Orini S, Grassi V. Homocysteine and disability in hospitalized geriatric patients. Metabolism. 2004;53(8):1016-1020.

40. Nilsson K, Gustafson L, Hultberg B. The plasma homocysteine concentration is better than that of serum methylmalonic acid as a marker for sociopsychological performance in a psychogeriatric population. Clin Chem. 2000;46(5):691-696.

41. Ravaglia G, Forti P, Maioli F, et al. Blood homocysteine and vitamin $\mathrm{B}$ levels are not associated with cognitive skills in healthy normally ageing subjects. J Nutr Health Aging. 2000;4(4):218-222.

42. Welch GN, Loscalzo J. Homocysteine and atherothrombosis. $N$ Engl J Med. 1998;338(15):1042-1050.

43. Briani C, Cagnin A, Gallo L, et al. Anti-heparan sulphate antibodies and homocysteine in dementia: markers of vascular pathology? J Neurol Sci. 2005;229-230:215-218.

44. Nilsson K, Gustafson L, Hultberg B. Plasma homocysteine is a sensitive marker for tissue deficiency of both cobalamines and folates in a psychogeriatric population. Dement Geriatr Cogn Disord. 1999; 10(6):476-482. 
45. Andres E, Loukili NH, Noel E, et al. Vitamin B12 (cobalamin) deficiency in elderly patients. CMAJ. 2004;171(3):251-259.

46. Bergeron C, Ranalli PJ, Miceli PN. Amyloid angiopathy in Alzheimer's disease. Can J Neurol Sci. 1987;14(4):564-569.

47. Cook S, Hess OM. Homocysteine and B vitamins. Handb Exp Pharmacol. 2005(170):325-338.

48. El Otmani H, El Moutawakil B, Moutaouakil F, Gam I, Rafai MA, Slassi I. Postoperative dementia: toxicity of nitrous oxide. Encephale. 2007;33(1):95-97.

49. El Otmani H, Moutaouakil F, Midafi N, et al. Cobalamin deficiency: Neurological aspects in 27 cases. Rev Neurol (Paris). 2009;165(3): 263-267.

50. Hadithi M, Mulder CJ, Stam F, et al. Effect of B vitamin supplementation on plasma homocysteine levels in celiac disease. World J Gastroenterol. 2009;15(8):955-960.

51. Irizarry MC, Gurol ME, Raju S, et al. Association of homocysteine with plasma amyloid beta protein in aging and neurodegenerative disease. Neurology. 2005;65(9):1402-1408.

52. Jacobsen DW, Gatautis VJ, Green R, et al. Rapid HPLC determination of total homocysteine and other thiols in serum and plasma: sex differences and correlation with cobalamin and folate concentrations in healthy subjects. Clin Chem. 1994;40(6):873-881.

53. Myles PS, Chan MT, Leslie K, Peyton P, Paech M, Forbes A. Effect of nitrous oxide on plasma homocysteine and folate in patients undergoing major surgery. Br J Anaesth. 2008;100(6):780-786.

54. O'Suilleabhain PE, Bottiglieri T, Dewey RB, Jr., Sharma S, DiazArrastia R. Modest increase in plasma homocysteine follows levodopa initiation in Parkinson's disease. Mov Disord. 2004;19(12):1403-1408.

55. Saibeni S, Lecchi A, Meucci G, et al. Prevalence of hyperhomocysteinemia in adult gluten-sensitive enteropathy at diagnosis: role of B12, folate, and genetics. Clin Gastroenterol Hepatol. 2005;3(6): 574-580.

56. Snow CF. Laboratory diagnosis of vitamin B12 and folate deficiency: a guide for the primary care physician. Arch Intern Med. 1999;159(12):1289-1298.

57. Stabler SP, Lindenbaum J, Allen RH. The use of homocysteine and other metabolites in the specific diagnosis of vitamin B-12 deficiency. J Nutr. 1996;126(4 Suppl):1266S-1272S.

58. Weir DG, Scott JM. Brain function in the elderly: role of vitamin B12 and folate. Br Med Bull. 1999;55(3):669-682.

59. Koike T, Kuzuya M, Kanda S, et al. Raised homocysteine and low folate and vitamin B-12 concentrations predict cognitive decline in communitydwelling older Japanese adults. Clin Nutr. 2008;27(6):865-871.

60. Li L, Cao D, Desmond R, et al. Cognitive performance and plasma levels of homocysteine, vitamin B12, folate and lipids in patients with Alzheimer disease. Dement Geriatr Cogn Disord. 2008;26(4): 384-390.

61. Nilsson K, Gustafson L, Hultberg B. Plasma homocysteine levels and different forms of vascular disease in patients with dementia and other psychogeriatric diseases. Dement Geriatr Cogn Disord. 2009;27(1): 88-95.

62. Conrad ME. Pernicious anemia. Available from: http://emedicine. medscape.com/article/204930-overview. Accessed September 5, 2009.

63. Schroecksnadel K, Frick B, Winkler C, Leblhuber F, Wirleitner B, Fuchs D. Hyperhomocysteinemia and immune activation. Clin Chem Lab Med. 2003;41(11):1438-1443.

64. Schroecksnadel K, Frick B, Wirleitner B, Winkler C, Schennach H, Fuchs D. Moderate hyperhomocysteinemia and immune activation. Curr Pharm Biotechnol. 2004;5(1):107-118.

65. Lehmann J, Tsai C, Wood PL. Homocysteic acid as a putative excitatory amino acid neurotransmitter: I. Postsynaptic characteristics at $\mathrm{N}$-methyl-D-aspartate-type receptors on striatal cholinergic interneurons. J Neurochem. 1988;51(6):1765-1770.

66. Lipton SA, Kim WK, Choi YB, et al. Neurotoxicity associated with dual actions of homocysteine at the N-methyl-D-aspartate receptor. Proc Natl Acad Sci U S A. 1997;94(11):5923-5928.
67. Bottiglieri T, Godfrey P, Flynn T, Carney MW, Toone BK, Reynolds EH. Cerebrospinal fluid S-adenosylmethionine in depression and dementia: effects of treatment with parenteral and oral S-adenosylmethionine. J Neurol Neurosurg Psychiatry. 1990;53(12):1096-1098.

68. Huang RF, Huang SM, Lin BS, Wei JS, Liu TZ. Homocysteine thiolactone induces apoptotic DNA damage mediated by increased intracellular hydrogen peroxide and caspase 3 activation in HL-60 cells. Life Sci. 2001;68(25):2799-2811.

69. Kim HJ, Cho HK, Kwon YH. Synergistic induction of ER stress by homocysteine and beta-amyloid in SH-SY5Y cells. J Nutr Biochem. 2008;19(11):754-761.

70. Kruman II, Culmsee C, Chan SL, et al. Homocysteine elicits a DNA damage response in neurons that promotes apoptosis and hypersensitivity to excitotoxicity. J Neurosci. 2000;20(18):6920-6926.

71. Zou CG, Zhao YS, Gao SY, et al. Homocysteine promotes proliferation and activation of microglia. Neurobiol Aging. 2009 Jan 6 [Epub ahead of print].

72. Rabaneda LG, Carrasco M, Lopez-Toledano MA, et al. Homocysteine inhibits proliferation of neuronal precursors in the mouse adult brain by impairing the basic fibroblast growth factor signaling cascade and reducing extracellular regulated kinase 1/2-dependent cyclin E expression. FASEB J. 2008;22(11):3823-3835.

73. Kumar M, Tyagi N, Moshal KS, et al. Homocysteine decreases blood flow to the brain due to vascular resistance in carotid artery. Neurochem Int. 2008;53(6-8):214-219.

74. Kumar M, Tyagi N, Moshal KS, et al. GABAA receptor agonist mitigates homocysteine-induced cerebrovascular remodeling in knockout mice. Brain Res. 2008;1221:147-153.

75. Herrmann W, Obeid R. Biomarkers of folate and vitamin B(12) status in cerebrospinal fluid. Clin Chem Lab Med. 2007;45(12):1614-1620.

76. Kamath AF, Chauhan AK, Kisucka J, et al. Elevated levels of homocysteine compromise blood-brain barrier integrity in mice. Blood. 2006;107(2):591-593.

77. Lominadze D, Roberts AM, Tyagi N, Moshal KS, Tyagi SC. Homocysteine causes cerebrovascular leakage in mice. Am J Physiol Heart Circ Physiol. 2006;290(3):H1206-H1213.

78. Tyagi SC, Lominadze D, Roberts AM. Homocysteine in microvascular endothelial cell barrier permeability. Cell Biochem Biophys. 2005;43(1):37-44.

79. Poddar R, Sivasubramanian N, DiBello PM, Robinson K, Jacobsen DW. Homocysteine induces expression and secretion of monocyte chemoattractant protein-1 and interleukin-8 in human aortic endothelial cells: implications for vascular disease. Circulation. 2001;103(22): 2717-2723.

80. Bi XH, Zhao HL, Zhang ZX, Zhang JW. Association of RFC1 A80G and MTHFR C677T polymorphisms with Alzheimer's disease. Neurobiol Aging. 2009;30(10):1601-1607.

81. Deshmukh A, Rodrigue KM, Kennedy KM, Land S, Jacobs BS, Raz N. Synergistic effects of the MTHFR C677T polymorphism and hypertension on spatial navigation. Biol Psychol. 2008;80(2):240-245.

82. Kim JM, Stewart R, Kim SW, et al. Methylenetetrahydrofolate reductase gene and risk of Alzheimer's disease in Koreans. Int $J$ Geriatr Psychiatry. 2008;23(5):454-459.

83. Weih M, Junge-Hulsing J, Mehraein S, Ziemer S, Einhaupl KM. Hereditary thrombophilia with ischemiC stroke and sinus thrombosis. Diagnosis, therapy and meta-analysis. Nervenarzt. 2000;71(12): 936-945.

84. Kelly PJ, Rosand J, Kistler JP, et al. Homocysteine, MTHFR 677C--> T polymorphism, and risk of ischemic stroke: results of a meta-analysis. Neurology. 2002;59(4):529-536.

85. Clarke R, Lewington S, Landray M. Homocysteine, renal function, and risk of cardiovascular disease. Kidney Int Suppl. 2003(84): S131-S133.

86. Kim RJ, Becker RC. Association between factor V Leiden, prothrombin G20210A, and methylenetetrahydrofolate reductase C677T mutations and events of the arterial circulatory system: a meta-analysis of published studies. Am Heart J. 2003;146(6):948-957. 
87. Casas JP, Bautista LE, Smeeth L, Sharma P, Hingorani AD. Homocysteine and stroke: evidence on a causal link from mendelian randomisation. Lancet. 2005;365(9455):224-232.

88. Haywood S, Liesner R, Pindora S, Ganesan V. Thrombophilia and first arterial ischaemic stroke: a systematic review. Arch Dis Child. 2005;90(4):402-405.

89. Cronin S, Furie KL, Kelly PJ. Dose-related association of MTHFR $677 \mathrm{~T}$ allele with risk of ischemic stroke: evidence from a cumulative meta-analysis. Stroke. 2005;36(7):1581-1587.

90. Lane R, He Y, Morris C, Leverenz JB, Emre M, Ballard C. BuChE-K and APOE epsilon4 allele frequencies in Lewy body dementias, and influence of genotype and hyperhomocysteinemia on cognitive decline. Mov Disord. 2009;24(3):392-400.

91. Andres E, Kaltenbach G, Noblet-Dick M, et al. Hematological response to short-term oral cyanocobalamin therapy for the treatment of cobalamin deficiencies in elderly patients. $J$ Nutr Health Aging. 2006;10(1):3-6.

92. Carmel R, Gott PS, Waters CH, et al. The frequently low cobalamin levels in dementia usually signify treatable metabolic, neurologic and electrophysiologic abnormalities. Eur J Haematol. 1995;54(4):245-253.

93. Karnaze DS, Carmel R. Neurologic and evoked potential abnormalities in subtle cobalamin deficiency states, including deficiency without anemia and with normal absorption of free cobalamin. Arch Neurol. 1990;47(9):1008-1012.

94. Fuso A, Cavallaro RA, Zampelli A, et al. gamma-Secretase is differentially modulated by alterations of homocysteine cycle in neuroblastoma and glioblastoma cells. J Alzheimers Dis. 2007;11(3):275-290.

95. Fuso A, Nicolia V, Cavallaro RA, et al. B-vitamin deprivation induces hyperhomocysteinemia and brain S-adenosylhomocysteine, depletes brain S-adenosylmethionine, and enhances PS1 and BACE expression and amyloid-beta deposition in mice. Mol Cell Neurosci. 2008;37(4):731-746.

96. Herrmann W. Significance of hyperhomocysteinemia. Clin Lab. 2006;52(7-8):367-374.

97. West RL, Lee JM, Maroun LE. Hypomethylation of the amyloid precursor protein gene in the brain of an Alzheimer's disease patient. J Mol Neurosci. 1995;6(2):141-146.

98. Foy CJ, Passmore AP, Vahidassr MD, Young IS, Lawson JT. Plasma chain-breaking antioxidants in Alzheimer's disease, vascular dementia and Parkinson's disease. QJM. 1999;92(1):39-45.

99. Harris ME, Hensley K, Butterfield DA, Leedle RA, Carney JM. Direct evidence of oxidative injury produced by the Alzheimer's beta-amyloid peptide (1-40) in cultured hippocampal neurons. Exp Neurol. 1995;131(2):193-202.

100. Nourhashemi F, Gillette-Guyonnet S, Andrieu S, et al. Alzheimer disease: protective factors. Am J Clin Nutr. 2000;71(2):643S-649S.

101. Pratico D, Clark CM, Liun F, Rokach J, Lee VY, Trojanowski JQ. Increase of brain oxidative stress in mild cognitive impairment: a possible predictor of Alzheimer disease. Arch Neurol. 2002;59(6):972-976.

102. Blasko I, Stampfer-Kountchev M, Robatscher P, Veerhuis R, Eikelenboom P, Grubeck-Loebenstein B. How chronic inflammation can affect the brain and support the development of Alzheimer's disease in old age: the role of microglia and astrocytes. Aging Cell. 2004;3(4):169-176.

103. Davis GK, Baboolal NS, Seales D, Ramchandani J, McKell S, McRae A. Potential biomarkers for dementia in Trinidad and Tobago. Neurosci Lett. 2007;424(1):27-30.

104. Mrak RE, Griffin WS. Potential inflammatory biomarkers in Alzheimer's disease. J Alzheimers Dis. 2005;8(4):369-375.

105. Streit WJ. Microglia and Alzheimer's disease pathogenesis. J Neurosci Res. 2004;77(1):1-8.

106. van den Kommer TN, Dik MG, Comijs HC, Jonker C, Deeg DJ. Homocysteine and inflammation: Predictors of cognitive decline in older persons? Neurobiol Aging. 2008 Nov 10. [Epub ahead of print].

107. Viel TA, Lima Caetano A, Nasello AG, et al. Increases of kinin B1 and B2 receptors binding sites after brain infusion of amyloid-beta 1-40 peptide in rats. Neurobiol Aging. 2008;29(12):1805-1814.
108. Frick B, Gruber B, Schroecksnadel K, Leblhuber F, Fuchs D. Homocysteine but not neopterin declines in demented patients on B vitamins. J Neural Transm. 2006;113(11):1815-1819.

109. Teunissen CE, Lutjohann D, von Bergmann K, et al. Combination of serum markers related to several mechanisms in Alzheimer's disease. Neurobiol Aging. 2003;24(7):893-902.

110. Teunissen CE, van Boxtel MP, Bosma H, et al. Serum markers in relation to cognitive functioning in an aging population: results of the Maastricht Aging Study (MAAS). Tijdschr Gerontol Geriatr. 2003;34(1):6-12.

111. Van Dam F, Van Gool WA. Hyperhomocysteinemia and Alzheimer's disease: A systematic review. Arch Gerontol Geriatr. 2009;48(3): 425-430.

112. Davis SR, Quinlivan EP, Shelnutt KP, et al. Homocysteine synthesis is elevated but total remethylation is unchanged by the methylenetetrahydrofolate reductase $677 \mathrm{C}-->\mathrm{T}$ polymorphism and by dietary folate restriction in young women. $J$ Nutr. 2005;135(5):1045-1050.

113. De La Haba G, Cantoni G. The enzymatic synthesis of S-adenosylL-homocysteine from adenosine and homocysteine. J Biol Chem. 1959;234(3):603-608.

114. Garcia A, Zanibbi K. Homocysteine and cognitive function in elderly people. CMAJ. 2004;171(8):897-904.

115. Tchantchou F, Graves M, Falcone D, Shea TB. S-adenosylmethionine mediates glutathione efficacy by increasing glutathione S-transferase activity: implications for S-adenosyl methionine as a neuroprotective dietary supplement. J Alzheimers Dis. 2008;14(3):323-328.

116. Gibson GE, Sheu KF, Blass JP. Abnormalities of mitochondrial enzymes in Alzheimer disease. J Neural Transm. 1998;105(8-9): $855-870$.

117. Markesbery WR. The role of oxidative stress in Alzheimer disease. Arch Neurol. 1999;56(12):1449-1452.

118. Turrens JF. Mitochondrial formation of reactive oxygen species. J Physiol. 2003;552(Pt 2):335-344.

119. Toohey JI. Mercaptopropionaldehyde from homocysteine: implications for Alzheimer's disease. J Alzheimers Dis. 2007;12(3):241-243.

120. McCaddon A, Hudson PR. Alzheimer's disease, oxidative stress and B-vitamin depletion. Future Neurology. 2007;2(5):537-547.

121. Serot JM, Bene MC, Faure GC. Comparative immunohistochemical characteristics of human choroid plexus in vascular and Alzheimer's dementia. Hum Pathol. 1994;25(11):1185-1190.

122. Serot JM, Christmann D, Dubost T, Bene MC, Faure GC. CSF-folate levels are decreased in late-onset AD patients. $J$ Neural Transm. 2001;108(1):93-99.

123. Serot JM, Bene MC, Faure GC. Choroid plexus, aging of the brain, and Alzheimer's disease. Front Biosci. 2003;8:s515-s521.

124. Nijst TQ, Wevers RA, Schoonderwaldt HC, Hommes OR, de Haan AF. Vitamin B12 and folate concentrations in serum and cerebrospinal fluid of neurological patients with special reference to multiple sclerosis and dementia. J Neurol Neurosurg Psychiatry. 1990;53(11):951-954.

125. Spector R, Cancilla P, Damasio A. Is idiopathic dementia a regional vitamin deficiency state? Med Hypotheses. 1979;5(7):763-767.

126. Crossgrove JS, Li GJ, Zheng W. The choroid plexus removes betaamyloid from brain cerebrospinal fluid. Exp Biol Med (Maywood). 2005;230(10):771-776.

127. Johanson CE, Duncan JA 3rd, Klinge PM, Brinker T, Stopa EG, Silverberg GD. Multiplicity of cerebrospinal fluid functions: new challenges in health and disease. Cerebrospinal Fluid Res. 2008; 5(1): 10 .

128. Sontag E, Nunbhakdi-Craig V, Sontag JM, et al. Protein phosphatase 2A methyltransferase links homocysteine metabolism with tau and amyloid precursor protein regulation. $J$ Neurosci. 2007;27(11): 2751-2759.

129. Chan AY, Alsaraby A, Shea TB. Folate deprivation increases tau phosphorylation by homocysteine-induced calcium influx and by inhibition of phosphatase activity: Alleviation by S-adenosyl methionine. Brain Res. 2008;1199:133-137.

130. Luo Y, Zhou X, Yang X, Wang J. Homocysteine induces tau hyperphosphorylation in rats. Neuroreport. 2007;18(18):2005-2008. 
131. Obeid R, Kasoha M, Knapp JP, et al. Folate and methylation status in relation to phosphorylated tau protein(181P) and beta-amyloid(1-42) in cerebrospinal fluid. Clin Chem. 2007;53(6):1129-1136.

132. Zhang CE, Tian Q, Wei W, et al. Homocysteine induces tau phosphorylation by inactivating protein phosphatase $2 \mathrm{~A}$ in rat hippocampus. Neurobiol Aging. 2008;29(11):1654-1665.

133. Agnati LF, Genedani S, Leo G, et al. Abeta peptides as one of the crucial volume transmission signals in the trophic units and their interactions with homocysteine. Physiological implications and relevance for Alzheimer's disease. J Neural Transm. 2007;114(1):21-31.

134. Pacheco-Quinto J, Rodriguez de Turco EB, DeRosa S, et al. Hyperhomocysteinemic Alzheimer's mouse model of amyloidosis shows increased brain amyloid beta peptide levels. Neurobiol Dis. 2006;22(3):651-656.

135. Viswanathan A, Raj S, Greenberg SM, et al. Plasma Abeta, homocysteine, and cognition: the Vitamin Intervention for Stroke Prevention (VISP) trial. Neurology. 2009;72(3):268-272.

136. Blasko I, Jellinger K, Kemmler G, et al. Conversion from cognitive health to mild cognitive impairment and Alzheimer's disease: prediction by plasma amyloid beta 42 , medial temporal lobe atrophy and homocysteine. Neurobiol Aging. 2008;29(1):1-11.

137. Kang J, Park EJ, Jou I, Kim JH, Joe EH. Reactive oxygen species mediate A beta(25-35)-induced activation of BV-2 microglia. Neuroreport. 2001;12(7):1449-1452.

138. Wang JY, Wen LL, Huang YN, Chen YT, Ku MC. Dual effects of antioxidants in neurodegeneration: direct neuroprotection against oxidative stress and indirect protection via suppression of glia-mediated inflammation. Curr Pharm Des. 2006;12(27):3521-3533.

139. Harman D. Alzheimer's disease: role of aging in pathogenesis. Ann N Y Acad Sci. 2002;959:384-395; discussion 463-385.

140. Hwang J, Zheng LT, Ock J, Lee MG, Suk K. Anti-inflammatory effects of m-chlorophenylpiperazine in brain glia cells. Int Immunopharmacol. 2008;8(12):1686-1694.

141. Liu B, Gao HM, Wang JY, Jeohn GH, Cooper CL, Hong JS. Role of nitric oxide in inflammation-mediated neurodegeneration. Ann NY Acad Sci. 2002;962:318-331.

142. Schroecksnadel K, Leblhuber F, Frick B, Wirleitner B, Fuchs D. Association of hyperhomocysteinemia in Alzheimer disease with elevated neopterin levels. Alzheimer Dis Assoc Disord. 2004;18(3):129-133.

143. Wilkinson BL, Landreth GE. The microglial NADPH oxidase complex as a source of oxidative stress in Alzheimer's disease. J Neuroinflammation. 2006;3:30.

144. Yamasaki R, Zhang J, Koshiishi I, et al. Involvement of lysosomal storage-induced p38 MAP kinase activation in the overproduction of nitric oxide by microglia in cathepsin D-deficient mice. Mol Cell Neurosci. 2007;35(4):573-584.

145. Koseoglu E, Karaman Y. Relations between homocysteine, folate and vitamin B12 in vascular dementia and in Alzheimer disease. Clin Biochem. 2007;40(12):859-863.

146. McCaddon A, Regland B, Hudson P, Davies G. Functional vitamin B(12) deficiency and Alzheimer disease. Neurology. 2002;58(9):1395-1399.

147. Shea TB. Effects of dietary supplementation with N-acetyl cysteine, acetyl-L-carnitine and S-adenosyl methionine on cognitive performance and aggression in normal mice and mice expressing human ApoE4. Neuromolecular Med. 2007;9(3):264-269.

148. Dawson H, Collins G, Pyle R, Deep-Dixit V, Taub DD. The immunoregulatory effects of homocysteine and its intermediates on T-lymphocyte function. Mech Ageing Dev. 2004;125(2):107-110.

149. Siow YL, Au-Yeung KK, Woo CW, O K. Homocysteine stimulates phosphorylation of NADPH oxidase p47phox and p67phox subunits in monocytes via protein kinase Cbeta activation. Biochem J. 2006;398(1):73-82.

150. Wang G, O K. Homocysteine stimulates the expression of monocyte chemoattractant protein-1 receptor (CCR2) in human monocytes: possible involvement of oxygen free radicals. Biochem J. 2001;357(Pt 1): 233-240.
151. Widner B, Enzinger C, Laich A, Wirleitner B, Fuchs D. Hyperhomocysteinemia, pteridines and oxidative stress. Curr Drug Metab. 2002;3(2):225-232.

152. Widner B, Leblhuber F, Frick B, Laich A, Artner-Dworzak E, Fuchs D. Moderate hyperhomocysteinaemia and immune activation in Parkinson's disease. J Neural Transm. 2002;109(12): 1445-1452.

153. Guidi I, Galimberti D, Lonati S, et al. Oxidative imbalance in patients with mild cognitive impairment and Alzheimer's disease. Neurobiol Aging. 2006;27(2):262-269.

154. Ho PI, Collins SC, Dhitavat S, et al. Homocysteine potentiates beta-amyloid neurotoxicity: role of oxidative stress. J Neurochem. 2001;78(2):249-253.

155. White AR, Huang X, Jobling MF, et al. Homocysteine potentiates copper- and amyloid beta peptide-mediated toxicity in primary neuronal cultures: possible risk factors in the Alzheimer's-type neurodegenerative pathways. $J$ Neurochem. 2001;76(5):1509-1520.

156. Fuchs D, Jaeger M, Widner B, Wirleitner B, Artner-Dworzak E, Leblhuber F. Is hyperhomocysteinemia due to the oxidative depletion of folate rather than to insufficient dietary intake? Clin Chem Lab Med. 2001;39(8):691-694.

157. Fuso A, Seminara L, Cavallaro RA, D’Anselmi F, Scarpa S. S-adenosylmethionine/homocysteine cycle alterations modify DNA methylation status with consequent deregulation of PS1 and BACE and beta-amyloid production. Mol Cell Neurosci. 2005;28(1): 195-204.

158. Jin Y, Brennan L. Effects of homocysteine on metabolic pathways in cultured astrocytes. Neurochem Int. 2008;52(8):1410-1415.

159. Perry G, Cash AD, Smith MA. Alzheimer Disease and Oxidative Stress. J Biomed Biotechnol. 2002;2(3):120-123.

160. Pratico D, Uryu K, Leight S, Trojanoswki JQ, Lee VM. Increased lipid peroxidation precedes amyloid plaque formation in an animal model of Alzheimer amyloidosis. J Neurosci. 2001;21(12):4183-4187.

161. Pratico D, Sung S. Lipid peroxidation and oxidative imbalance: early functional events in Alzheimer's disease. J Alzheimers Dis. 2004;6(2):171-175.

162. Swerdlow RH, Khan SM. A "mitochondrial cascade hypothesis" for sporadic Alzheimer's disease. Med Hypotheses. 2004; 63(1):8-20.

163. Dias-Santagata D, Fulga TA, Duttaroy A, Feany MB. Oxidative stress mediates tau-induced neurodegeneration in Drosophila. J Clin Invest. 2007;117(1):236-245.

164. Gamblin TC, King ME, Kuret J, Berry RW, Binder LI. Oxidative regulation of fatty acid-induced tau polymerization. Biochemistry. 2000;39(46):14203-14210.

165. Liu Q, Smith MA, Avila J, et al. Alzheimer-specific epitopes of tau represent lipid peroxidation-induced conformations. Free Radic Biol Med. 2005;38(6):746-754.

166. Percy M, Moalem S, Garcia A, et al. Involvement of ApoE E4 and H63D in sporadic Alzheimer's disease in a folate-supplemented Ontario population. J Alzheimers Dis. 2008;14(1):69-84.

167. Leo G, Genedani S, Filaferro M, et al. Hyper-homocysteinemia alters amyloid peptide-clusterin interactions and neuroglial network morphology and function in the caudate after intrastriatal injection of amyloid peptides. Curr Alzheimer Res. 2007;4(3): 305-313.

168. Akama KT, Albanese C, Pestell RG, Van Eldik LJ. Amyloid betapeptide stimulates nitric oxide production in astrocytes through an NFkappaB-dependent mechanism. Proc Natl Acad Sci U S A. 1998;95(10):5795-5800.

169. Butterfield DA, Lauderback CM. Lipid peroxidation and protein oxidation in Alzheimer's disease brain: potential causes and consequences involving amyloid beta-peptide-associated free radical oxidative stress. Free Radic Biol Med. 2002;32(11):1050-1060.

170. Cente M, Filipcik P, Pevalova M, Novak M. Expression of a truncated tau protein induces oxidative stress in a rodent model of tauopathy. Eur J Neurosci. 2006;24(4):1085-1090. 
171. Scalabrino G, Veber D, Mutti E. Experimental and clinical evidence of the role of cytokines and growth factors in the pathogenesis of acquired cobalamin-deficient leukoneuropathy. Brain Res Rev. 2008;59(1):42-54.

172. Buccellato FR, Miloso M, Braga M, et al. Myelinolytic lesions in spinal cord of cobalamin-deficient rats are TNF-alpha-mediated. FASEB J. 1999;13(2):297-304.

173. Peracchi M, Bamonti Catena F, Pomati M, De Franceschi M, Scalabrino G. Human cobalamin deficiency: alterations in serum tumour necrosis factor-alpha and epidermal growth factor. Eur $J$ Haematol. 2001;67(2):123-127.

174. Scalabrino G. Cobalamin (vitamin B(12)) in subacute combined degeneration and beyond: traditional interpretations and novel theories. Exp Neurol. 2005;192(2):463-479.

175. Scalabrino G, Veber D, Mutti E. New pathogenesis of the cobalamindeficient neuropathy. Med Secoli. 2007;19(1):9-18.

176. Scalabrino G. The multi-faceted basis of vitamin B12 (cobalamin) neurotrophism in adult central nervous system: Lessons learned from its deficiency. Prog Neurobiol. 2009;88(3):203-220.

177. Scalabrino G, Carpo M, Bamonti F, et al. High tumor necrosis factoralpha [corrected] levels in cerebrospinal fluid of cobalamin-deficient patients. Ann Neurol. 2004;56(6):886-890

178. Scalabrino G, Peracchi M. New insights into the pathophysiology of cobalamin deficiency. Trends Mol Med. 2006;12(6):247-254.

179. Dogan M, Ozdemir O, Sal EA, et al. Psychotic disorder and extrapyramidal symptoms associated with vitamin B12 and folate deficiency. J Trop Pediatr. 2009;55(3):205-207.

180. Healton EB, Savage DG, Brust JC, Garrett TJ, Lindenbaum J. Neurologic aspects of cobalamin deficiency. Medicine (Baltimore) 1991;70(4):229-245.

181. Durand C, Mary S, Brazo P, Dollfus S. Psychiatric manifestations of vitamin B12 deficiency: a case report. Encephale. 2003;29(6): $560-565$.

182. Ko SM, Liu TC. Psychiatric syndromes in pernicious anaemia - a case report. Singapore Med J. 1992;33(1):92-94.

183. Lassen E, Ewald H. Acute organic psychosis caused by thyrotoxicosis and vitamin B12 deficiency: case report. J Clin Psychiatry. 1985;46(3):106-107.

184. Evans DL, Edelsohn GA, Golden RN. Organic psychosis without anemia or spinal cord symptoms in patients with vitamin B12 deficiency. Am J Psychiatry. 1983;140(2):218-221.

185. Bolaman Z, Kadikoylu G, Yukselen V, Yavasoglu I, Barutca S, Senturk T. Oral versus intramuscular cobalamin treatment in megaloblastic anemia: a single-center, prospective, randomized, open-labe study. Clin Ther. 2003;25(12):3124-3134.

186. Cubero L, Mayor J, Almirall P, Valdes M. Memory disorders in the epidemic neuropathy. Rev Neurol. 1999;28(4):343-348.

187. Kwok T, Lee J, Lam L, Woo J. Vitamin B(12) supplementation did not improve cognition but reduced delirium in demented patients with vitamin B(12) deficiency. Arch Gerontol Geriatr. 2008;46(3):273-282.

188. Lindenbaum J, Healton EB, Savage DG, et al. Neuropsychiatric disorders caused by cobalamin deficiency in the absence of anemia or macrocytosis. N Engl J Med. 1988;318(26):1720-1728.

189. Heok KE, Ho R. The many faces of geriatric depression. Curr Opin Psychiatry. 2008;21(6):540-545.

190. Saracaceanu E, Tramoni AV, Henry JM. An association between subcortical dementia and pernicious anemia - a psychiatric mask. Compr Psychiatry. 1997;38(6):349-351.

191. Goggans FC. A case of mania secondary to vitamin B12 deficiency. Am J Psychiatry. 1984;141(2):300-301.

192. Bottiglieri T, Laundy M, Crellin R, Toone BK, Carney MW, Reynolds EH. Homocysteine, folate, methylation, and monoamine metabolism in depression. J Neurol Neurosurg Psychiatry. 2000;69(2): 228-232.

193. Meeks TW, Ropacki SA, Jeste DV. The neurobiology of neuropsychiatric syndromes in dementia. Curr Opin Psychiatry. 2006;19(6): 581-586.
194. Reif A, Pfuhlmann B, Lesch KP. Homocysteinemia as well as methylenetetrahydrofolate reductase polymorphism are associated with affective psychoses. Prog Neuropsychopharmacol Biol Psychiatry. 2005;29(7):1162-1168.

195. Dittmann S, Seemuller F, Schwarz MJ, et al. Association of cognitive deficits with elevated homocysteine levels in euthymic bipolar patients and its impact on psychosocial functioning: preliminary results. Bipolar Disord. 2007;9(1-2):63-70.

196. Dittmann S, Seemuller F, Grunze HC, et al. The impact of homocysteine levels on cognition in euthymic bipolar patients: A cross-sectional study. J Clin Psychiatry. 2008:e1-e8.

197. OsherY, Bersudsky Y, Silver H, Sela BA, Belmaker RH. Neuropsychological correlates of homocysteine levels in euthymic bipolar patients. $J$ Affect Disord. 2008;105(1-3):229-233.

198. Levine J, Stahl Z, Sela BA, et al. Homocysteine-reducing strategies improve symptoms in chronic schizophrenic patients with hyperhomocysteinemia. Biol Psychiatry. 2006;60(3):265-269.

199. Kalita J, Misra UK. Vitamin B12 deficiency neurological syndromes: correlation of clinical, MRI and cognitive evoked potential. J Neurol. 2008;255(3):353-359.

200. Goldman L AA, editor. Cecil Textbook of Medicine. 22nd ed. Philadelphia, PA: Saunders, Elsevier, Inc; 2004.

201. Toh BH, van Driel IR, Gleeson PA. Pernicious anemia. N Engl J Med. 1997;337(20):1441-1448.

202. Puntambekar P, Basha MM, Zak IT, Madhavan R. Rare sensory and autonomic disturbances associated with vitamin B12 deficiency. J Neurol Sci. 2009;287(1-2):285-287.

203. RopperA, Brown R. Diseases of the nervous system due to nutritional deficiency. In: Ropper A, Brown R, editors. Adams and Victor's Principles of Neurology. 8th ed. New York, NY: McGraw-Hill; 2005. p. 983-1003.

204. Huckman MS, Fox J, Topel J. The validity of criteria for the evaluation of cerebral atrophy by computed tomography. Radiology. 1975;116(1):85-92.

205. de Leon MJ, George AE, Reisberg B, et al. Alzheimer's disease: longitudinal CT studies of ventricular change. AJR Am J Roentgenol. 1989;152(6):1257-1262.

206. Takeda S, Matsuzawa T. Age-related brain atrophy: a study with computed tomography. J Gerontol. 1985;40(2):159-163.

207. LeMay M. Radiologic changes of the aging brain and skull. AJR Am J Roentgenol. 1984;143(2):383-389.

208. Ito M, Hatazawa J, Yamaura H, Matsuzawa T. Age-related brain atrophy and mental deterioration - a study with computed tomography. $\mathrm{Br} J$ Radiol. 1981;54(641):384-390.

209. Creasey H, Schwartz M, Frederickson H, Haxby JV, Rapoport SI. Quantitative computed tomography in dementia of the Alzheimer type. Neurology. 1986;36(12):1563-1568.

210. DeCarli C, Kaye JA, Horwitz B, Rapoport SI. Critical analysis of the use of computer-assisted transverse axial tomography to study human brain in aging and dementia of the Alzheimer type. Neurology. 1990;40(6):872-883.

211. DeCarli C, Murphy DG, McIntosh AR, Teichberg D, Schapiro MB, Horwitz B. Discriminant analysis of MRI measures as a method to determine the presence of dementia of the Alzheimer type. Psychiatry Res. 1995;57(2):119-130.

212. Frisoni GB, Beltramello A, Weiss C, Geroldi C, Bianchetti A, Trabucchi M. Linear measures of atrophy in mild Alzheimer disease. AJNR Am J Neuroradiol. 1996;17(5):913-923.

213. Horn R, Ostertun B, Fric M, Solymosi L, Steudel A, Moller HJ. Atrophy of hippocampus in patients with Alzheimer's disease and other diseases with memory impairment. Dementia. 1996;7(4):182-186.

214. Jobst KA, Smith AD, Szatmari M, et al. Detection in life of confirmed Alzheimer's disease using a simple measurement of medial temporal lobe atrophy by computed tomography. Lancet. 1992;340(8829):1179-1183.

215. Kawamura J, Meyer JS, Ichijo M, Kobari M, Terayama Y, Weathers S Correlations of leuko-araiosis with cerebral atrophy and perfusion in elderly normal subjects and demented patients. J Neurol Neurosurg Psychiatry. 1993;56(2):182-187. 
216. Luxenberg JS, Friedland RP, Rapoport SI. Quantitative X-ray computed tomography (CT) in dementia of the Alzheimer type (DAT). Can J Neurol Sci. 1986;13(4 Suppl):570-572.

217. Philpot M, Burns A. Jobst et al. Detection in life of confirmed Alzheimer's disease using a simple measurement of medial temporal lobe atrophy by computed tomography. $\mathrm{Br} J$ Psychiatry. 1993;163:809-812.

218. Whitehouse PJ. Clinical Practice Guidelines: Guidelines Abstracted from the American Academy of Neurology's Dementia Guidelines for Early Detection, Diagnosis, and Management of Dementia. The American Geriatrics Society. 2008. Available from: http://www. americangeriatrics.org/products/positionpapers/aan_dementia.shtml. Accessed on August 21, 2009.

219. Burns A, Jacoby R, Levy R. Computed tomography in Alzheimer's disease: a longitudinal study. Biol Psychiatry. 1991;29(4):383-390.

220. Bertsch T, Mielke O, Holy S, et al. Homocysteine in cerebrovascular disease: an independent risk factor for subcortical vascular encephalopathy. Clin Chem Lab Med. 2001;39(8):721-724.

221. Censori B, Partziguian T, Manara O, Poloni M. Plasma homocysteine and severe white matter disease. Neurol Sci. 2007;28(5):259-263.

222. Clarke R, Smith AD, Jobst KA, Refsum H, Sutton L, Ueland PM. Folate, vitamin B12, and serum total homocysteine levels in confirmed Alzheimer disease. Arch Neurol. 1998;55(11):1449-1455.

223. Evers S, Koch HG, Grotemeyer KH, Lange B, Deufel T, Ringelstein EB. Features, symptoms, and neurophysiological findings in stroke associated with hyperhomocysteinemia. Arch Neurol. 1997;54(10):1276-1282.

224. Hassan A, Hunt BJ, O'Sullivan M, et al. Homocysteine is a risk factor for cerebral small vessel disease, acting via endothelial dysfunction. Brain. 2004;127(Pt 1):212-219.

225. Hogervorst E, Ribeiro HM, Molyneux A, Budge M, Smith AD. Plasma homocysteine levels, cerebrovascular risk factors, and cerebral white matter changes (leukoaraiosis) in patients with Alzheimer disease. Arch Neurol. 2002;59(5):787-793.

226. Naka H, Nomura E, Takahashi T, et al. Plasma total homocysteine levels are associated with advanced leukoaraiosis but not with asymptomatic microbleeds on T2*-weighted MRI in patients with stroke. Eur $J$ Neurol. 2006;13(3):261-265.

227. Quadri P, Fragiacomo C, Pezzati R, et al. Homocysteine, folate, and vitamin B-12 in mild cognitive impairment, Alzheimer disease, and vascular dementia. Am J Clin Nutr. 2004;80(1):114-122.

228. Sachdev P, Parslow R, Salonikas C, et al. Homocysteine and the brain in midadult life: evidence for an increased risk of leukoaraiosis in men. Arch Neurol. 2004;61(9):1369-1376.

229. Sachdev PS. Homocysteine and brain atrophy. Prog Neuropsychopharmacol Biol Psychiatry. 2005;29(7):1152-1161.

230. Schwartz GL, Bailey KR, Mosley T, et al. Association of ambulatory blood pressure with ischemic brain injury. Hypertension. 2007;49(6):1228-1234.

231. Scott TM, Tucker KL, Bhadelia A, et al. Homocysteine and $\mathrm{B}$ vitamins relate to brain volume and white-matter changes in geriatric patients with psychiatric disorders. Am J Geriatr Psychiatry. 2004;12(6):631-638.

232. Seshadri S, Wolf PA, Beiser AS, et al. Association of plasma total homocysteine levels with subclinical brain injury: cerebral volumes, white matter hyperintensity, and silent brain infarcts at volumetric magnetic resonance imaging in the Framingham Offspring Study. Arch Neurol. 2008;65(5):642-649.

233. Smith AD. The worldwide challenge of the dementias: a role for B vitamins and homocysteine? Food Nutr Bull. 2008;29(2 Suppl): S143-S172.

234. Vogiatzoglou A, Refsum H, Johnston C, et al. Vitamin B12 status and rate of brain volume loss in community-dwelling elderly. Neurology. 2008;71(11):826-832.

235. Williams JH, Pereira EA, Budge MM, Bradley KM. Minimal hippocampal width relates to plasma homocysteine in community-dwelling older people. Age Ageing. 2002;31(6):440-444.
236. Wright CB, Paik MC, Brown TR, et al. Total homocysteine is associated with white matter hyperintensity volume: the Northern Manhattan Study. Stroke. 2005;36(6):1207-1211.

237. Yang LK, Wong KC, Wu MY, Liao SL, Kuo CS, Huang RF. Correlations between folate, B12, homocysteine levels, and radiological markers of neuropathology in elderly post-stroke patients. $\mathrm{J} \mathrm{Am} \mathrm{Coll}$ Nutr. 2007;26(3):272-278.

238. Jimenez I, Agulla J, Pouso M, et al. Cognitive impairment associated to leukoaraiosis: its pathophysiology, clinical manifestations and treatment. Rev Neurol. 2008;47(10):536-544.

239. Fu JH, Lu CZ, Hong Z, Dong Q, Luo Y, Wong KS. Extent of white matter lesions is related to acute subcortical infarcts and predicts further stroke risk in patients with first ever ischaemic stroke. $J$ Neurol Neurosurg Psychiatry. 2005;76(6):793-796.

240. Longstreth WT Jr, Manolio TA, Arnold A, et al. Clinical correlates of white matter findings on cranial magnetic resonance imaging of 3301 elderly people. The Cardiovascular Health Study. Stroke. 1996;27(8):1274-1282.

241. Streifler JY, Eliasziw M, Benavente OR, et al. Prognostic importance of leukoaraiosis in patients with symptomatic internal carotid artery stenosis. Stroke. 2002;33(6):1651-1655.

242. Streifler JY, Eliasziw M, Benavente OR, et al. Development and progression of leukoaraiosis in patients with brain ischemia and carotid artery disease. Stroke. 2003;34(8):1913-1916.

243. George AE, de Leon MJ, Gentes CI, et al. Leukoencephalopathy in normal and pathologic aging: 1 . CT of brain lucencies. AJNR Am J Neuroradiol. 1986;7(4):561-566.

244. Basile AM, Pantoni L, Pracucci G, et al. Age, hypertension, and lacunar stroke are the major determinants of the severity of age-related white matter changes. The LADIS (Leukoaraiosis and Disability in the Elderly) Study. Cerebrovasc Dis. 2006;21(5-6):315-322.

245. Bastos-Leite AJ, Kuijer JP, Rombouts SA, et al. Cerebral blood flow by using pulsed arterial spin-labeling in elderly subjects with white matter hyperintensities. AJNR Am J Neuroradiol. 2008;29(7):1296-1301.

246. Farrall AJ, Wardlaw JM. Blood-brain barrier: Ageing and microvascular disease - systematic review and meta-analysis. Neurobiol Aging. 2009;30(3):337-352.

247. Schwartz GL, Fornage M, Mosley T, Turner ST. Treatment of leukoaraiosis. Curr Treat Options Cardiovasc Med. 2005;7(3):173-177.

248. Roman GC. Senile dementia of the Binswanger type. A vascular form of dementia in the elderly. JAMA. 1987;258(13):1782-1788.

249. de Lau LM, Refsum H, Smith AD, Johnston C, Breteler MM. Plasma folate concentration and cognitive performance: Rotterdam Scan Study. Am J Clin Nutr. 2007;86(3):728-734.

250. de Lau LM, Smith AD, Refsum H, Johnston C, Breteler MM. Plasma vitamin B12 status and cerebral white-matter lesions. J Neurol Neurosurg Psychiatry. 2009;80(2):149-157.

251. Inzitari D, Simoni M, Pracucci G, et al. Risk of rapid global functional decline in elderly patients with severe cerebral age-related white matter changes: the LADIS study. Arch Intern Med. 2007;167(1):81-88.

252. Dufouil C, Alperovitch A, Ducros V, Tzourio C. Homocysteine, white matter hyperintensities, and cognition in healthy elderly people. Ann Neurol. 2003;53(2):214-221.

253. Polyak Z, Stern F, Berner YN, et al. Hyperhomocysteinemia and vitamin score: correlations with silent brain ischemic lesions and brain atrophy. Dement Geriatr Cogn Disord. 2003;16(1):39-45.

254. Stenset V, Hofoss D, Johnsen L, et al. White matter lesion severity is associated with reduced cognitive performances in patients with normal CSF Abeta42 levels. Acta Neurol Scand. 2008;118(6): 373-378.

255. Wong A, Mok V, Fan YH, Lam WW, Liang KS, Wong KS. Hyperhomocysteinemia is associated with volumetric white matter change in patients with small vessel disease. $J$ Neurol. 2006;253(4): 441-447.

256. Wallin A, Sjogren M. Cerebrospinal fluid cytoskeleton proteins in patients with subcortical white-matter dementia. Mech Ageing Dev. 2001;122(16):1937-1949. 
257. Babiloni C, Bosco P, Ghidoni R, et al. Homocysteine and electroencephalographic rhythms in Alzheimer disease: a multicentric study. Neuroscience. 2007;145(3):942-954.

258. Seshadri S, Beiser A, Selhub J, et al. Plasma homocysteine as a risk factor for dementia and Alzheimer's disease. $N$ Engl J Med. 2002;346(7):476-483.

259. Miller JW, Green R, Mungas DM, Reed BR, Jagust WJ. Homocysteine, vitamin B6, and vascular disease in AD patients. Neurology. 2002;58(10):1471-1475.

260. Ando S, Nakayama H. Cerebral amyloid angiopathy in Alzheimer's disease: with special reference to its incidence and distribution. No To Shinkei. 1984;36(11):1109-1116.

261. Coria F, Castano E, Prelli F, et al. Isolation and characterization of amyloid P component from Alzheimer's disease and other types of cerebral amyloidosis. Lab Invest. 1988;58(4):454-458.

262. Buee L, Hof PR, Bouras C, et al. Pathological alterations of the cerebral microvasculature in Alzheimer's disease and related dementing disorders. Acta Neuropathol (Berl). 1994;87(5):469-480.

263. Eberling JL, Jagust WJ, Reed BR, Baker MG. Reduced temporal lobe blood flow in Alzheimer's disease. Neurobiol Aging. 1992;13(4): 483-491.

264. Jobst KA, Smith AD, Barker CS, et al. Association of atrophy of the medial temporal lobe with reduced blood flow in the posterior parietotemporal cortex in patients with a clinical and pathological diagnosis of Alzheimer's disease. J Neurol Neurosurg Psychiatry. 1992;55(3):190-194.

265. Purandare N, Burns A, Daly KJ, et al. Cerebral emboli as a potential cause of Alzheimer's disease and vascular dementia: case-control study. BMJ. 2006;332(7550):1119-1124.

266. Purandare N, Voshaar RC, Morris J, et al. Asymptomatic spontaneous cerebral emboli predict cognitive and functional decline in dementia. Biol Psychiatry. 2007;62(4):339-344.

267. Agnati LF, Genedani S, Rasio G, et al. Studies on homocysteine plasma levels in Alzheimer's patients. Relevance for neurodegeneration. J Neural Transm. 2005;112(1):163-169.

268. Lee ES, Chen H, Soliman KF, Charlton CG. Effects of homocysteine on the dopaminergic system and behavior in rodents. Neurotoxicology 2005;26(3):361-371.

269. Choi BH, Kim RC, Vaughan PJ, et al. Decreases in protease nexins in Alzheimer's disease brain. Neurobiol Aging. 1995;16(4):557-562.

270. Hanyu H, Asano T, Tanaka Y, Iwamoto T, Takasaki M, Abe K. Increased blood-brain barrier permeability in white matter lesions of Binswanger's disease evaluated by contrast-enhanced MRI. Dement Geriatr Cogn Disord. 2002;14(1):1-6.

271. Arshavsky YI. Alzheimer's disease, brain immune privilege and memory: a hypothesis. J Neural Transm. 2006;113(11):1697-1707.

272. D'Andrea MR. Add Alzheimer's disease to the list of autoimmune diseases. Med Hypotheses. 2005;64(3):458-463.

273. Groppa SA, Chekhonin VP. Specific brain antigens as the indicators of the blood-brain barrier permeability in Alzheimer's disease. Zh Nevropatol Psikhiatr Im S S Korsakova. 1991;91(9):50-52.

274. Homocysteine and risk of ischemic heart disease and stroke: a metaanalysis. JAMA. 2002;288(16):2015-2022.

275. Bautista LE, Arenas IA, Penuela A, Martinez LX. Total plasma homocysteine level and risk of cardiovascular disease: a metaanalysis of prospective cohort studies. J Clin Epidemiol. 2002;55(9): $882-887$.

276. Liu XQ, Jiang P, Huang H, Yan Y. Plasma levels of endogenous hydrogen sulfide and homocysteine in patients with Alzheimer's disease and vascular dementia and the significance thereof. Zhonghua Yi Xue Za Zhi. 2008;88(32):2246-2249.

277. Moller J, Nielsen GM, Tvedegaard KC, Andersen NT, Jorgensen PE. A meta-analysis of cerebrovascular disease and hyperhomocysteinaemia. Scand J Clin Lab Invest. 2000;60(6):491-499.

278. Wald DS, Law M, Morris JK. Homocysteine and cardiovascular disease: evidence on causality from a meta-analysis. BMJ. 2002; 325(7374):1202.
279. Boushey CJ, Beresford SA, Omenn GS, Motulsky AG. A quantitative assessment of plasma homocysteine as a risk factor for vascular disease. Probable benefits of increasing folic acid intakes. JAMA. 1995;274(13):1049-1057.

280. Troen AM, Shea-Budgell M, Shukitt-Hale B, Smith DE, Selhub J, Rosenberg IH. B-vitamin deficiency causes hyperhomocysteinemia and vascular cognitive impairment in mice. Proc Natl Acad Sci USA. 2008;105(34):12474-12479.

281. Yao H, Sadoshima S, Kuwabara Y, Ichiya Y, Fujishima M. Cerebral blood flow and oxygen metabolism in patients with vascular dementia of the Binswanger type. Stroke. 1990;21(12):1694-1699.

282. Picardi A, Navajas F, Spoto S, Palma Modoni A, De Galasso L, Costantino S. A 74-year-old woman with macrocytic anemia. Clin Ter. 2002;153(1):65-67.

283. Chin AV, Robinson DJ, O'Connell H, et al. Vascular biomarkers of cognitive performance in a community-based elderly population: the Dublin Healthy Ageing study. Age Ageing. 2008;37(5): 559-564.

284. Sala I, Belen Sanchez-Saudinos M, Molina-Porcel L, et al. Homocysteine and cognitive impairment. Relation with diagnosis and neuropsychological performance. Dement Geriatr Cogn Disord. 2008;26(6):506-512

285. Selhub J, Morris MS, Jacques PF, Rosenberg IH. Folate-vitamin B-12 interaction in relation to cognitive impairment, anemia, and biochemical indicators of vitamin B-12 deficiency. Am J Clin Nutr. 2009;89(2):702S-706S.

286. Stewart R, Asonganyi B, Sherwood R. Plasma homocysteine and cognitive impairment in an older British African-Caribbean population. J Am Geriatr Soc. 2002;50(7):1227-1232.

287. Ravaglia G, Forti P, Maioli F, et al. Homocysteine and cognitive function in healthy elderly community dwellers in Italy. Am J Clin Nutr. 2003;77(3):668-673

288. Prins ND, Den Heijer T, Hofman A, et al. Homocysteine and cognitive function in the elderly: the Rotterdam Scan Study. Neurology. 2002;59(9):1375-1380.

289. Cole MG, Prchal JF. Low serum vitamin B12 in Alzheimer-type dementia. Age Ageing. 1984;13(2):101-105.

290. Malaguarnera M, Ferri R, Bella R, Alagona G, Carnemolla A Pennisi G. Homocysteine, vitamin B12 and folate in vascular dementia and in Alzheimer disease. Clin Chem Lab Med. 2004;42(9):1032-1035.

291. McCaddon A, Davies G, Hudson P, Tandy S, Cattell H. Total serum homocysteine in senile dementia of Alzheimer type. Int $J$ Geriatr Psychiatry. 1998;13(4):235-239.

292. Hagnelius NO, Wahlund LO, Nilsson TK. CSF/serum folate gradient: physiology and determinants with special reference to dementia. Dement Geriatr Cogn Disord. 2008;25(6):516-523.

293. Zoccolella S, Lamberti P, Iliceto G, et al. Plasma homocysteine levels in L-dopa-treated Parkinson's disease patients with cognitive dysfunctions. Clin Chem Lab Med. 2005;43(10):1107-1110.

294. Ozer F, Meral H, Hanoglu L, et al. Plasma homocysteine levels in patients treated with levodopa: motor and cognitive associations. Neurol Res. 2006;28(8):853-858.

295. Budge MM, de Jager C, Hogervorst E, Smith AD. Total plasma homocysteine, age, systolic blood pressure, and cognitive performance in older people. J Am Geriatr Soc. 2002;50(12):2014-2018.

296. Duthie SJ, Whalley LJ, Collins AR, Leaper S, Berger K, Deary IJ. Homocysteine, B vitamin status, and cognitive function in the elderly. Am J Clin Nutr. 2002;75(5):908-913.

297. Elias MF, Robbins MA, Budge MM, et al. Homocysteine and cognitive performance: modification by the ApoE genotype. Neurosci Lett. 2008;430(1):64-69.

298. Eussen SJ, Ueland PM, Clarke R, et al. The association of betaine, homocysteine and related metabolites with cognitive function in Dutch elderly people. Br J Nutr. 2007;98(5):960-968.

299. Garcia AA, Haron Y, Evans LR, Smith MG, Freedman M, Roman GC. Metabolic markers of cobalamin deficiency and cognitive function in normal older adults. J Am Geriatr Soc. 2004;52(1):66-71. 
300. Hin H, Clarke R, Sherliker P, et al. Clinical relevance of low serum vitamin B12 concentrations in older people: the Banbury B12 study. Age Ageing. 2006;35(4):416-422.

301. Kado DM, Karlamangla AS, Huang MH, et al. Homocysteine versus the vitamins folate, B6, and B12 as predictors of cognitive function and decline in older high-functioning adults: MacArthur Studies of Successful Aging. Am J Med. 2005;118(2):161-167.

302. Miller JW, Green R, Ramos MI, et al. Homocysteine and cognitive function in the Sacramento Area Latino Study on Aging. Am J Clin Nutr. 2003;78(3):441-447.

303. Morris MS, Jacques PF, Rosenberg IH, Selhub J. Folate and vitamin B-12 status in relation to anemia, macrocytosis, and cognitive impairment in older Americans in the age of folic acid fortification. Am J Clin Nutr. 2007;85(1):193-200.

304. Riggs KM, Spiro A, 3rd, Tucker K, Rush D. Relations of vitamin B-12, vitamin B-6, folate, and homocysteine to cognitive performance in the Normative Aging Study. Am J Clin Nutr. 1996;63(3):306-314.

305. Styczynska M, Strosznajder JB, Religa D, et al. Association between genetic and environmental factors and the risk of Alzheimer's disease. Folia Neuropathol. 2008;46(4):249-254.

306. Wolters M, Hickstein M, Flintermann A, Tewes U, Hahn A. Cognitive performance in relation to vitamin status in healthy elderly German women-the effect of 6-month multivitamin supplementation. Prev Med. 2005;41(1):253-259.

307. Annerbo S, Wahlund LO, Lokk J. The relation between homocysteine levels and development of Alzheimer's disease in mild cognitive impairment patients. Dement Geriatr Cogn Disord. 2005;20(4):209-214.

308. Clarke R, Birks J, Nexo E, et al. Low vitamin B-12 status and risk of cognitive decline in older adults. Am J Clin Nutr. 2007;86(5):1384-1391.

309. Elias MF, Sullivan LM, D'Agostino RB, et al. Homocysteine and cognitive performance in the Framingham offspring study: age is important. Am J Epidemiol. 2005;162(7):644-653.

310. Gabryelewicz T, Styczynska M, Luczywek E, et al. The rate of conversion of mild cognitive impairment to dementia: predictive role of depression. Int J Geriatr Psychiatry. 2007;22(6):563-567.

311. Garcia A, Haron Y, Pulman K, Hua L, Freedman M. Increases in homocysteine are related to worsening of stroop scores in healthy elderly persons: a prospective follow-up study. J Gerontol A Biol Sci Med Sci. 2004;59(12):1323-1327.

312. Haan MN, Miller JW, Aiello AE, et al. Homocysteine, B vitamins, and the incidence of dementia and cognitive impairment: results from the Sacramento Area Latino Study on Aging. Am J Clin Nutr. 2007;85(2):511-517.

313. Kim JM, Stewart R, Kim SW, et al. Changes in folate, vitamin B12, and homocysteine associated with incident dementia. J Neurol Neurosurg Psychiatry. 2008;79(8):864-868

314. Ravaglia G, Forti P, Maioli F, et al. Blood inflammatory markers and risk of dementia: The Conselice Study of Brain Aging. Neurobiol Aging. 2007;28(12):1810-1820.

315. Wright CB, Lee HS, Paik MC, Stabler SP, Allen RH, Sacco RL. Total homocysteine and cognition in a tri-ethnic cohort: the Northern Manhattan Study. Neurology. 2004;63(2):254-260.

316. Nurk E, Refsum H, Tell GS, et al. Plasma total homocysteine and memory in the elderly: the Hordaland Homocysteine Study. Ann Neurol. 2005;58(6):847-857.

317. Nurk E, Drevon CA, Refsum H, et al. Cognitive performance among the elderly and dietary fish intake: the Hordaland Health Study. Am J Clin Nutr. 2007;86(5):1470-1478.

318. McCaddon A, Hudson P, Davies G, Hughes A, Williams JH, Wilkinson C. Homocysteine and cognitive decline in healthy elderly. Dement Geriatr Cogn Disord. 2001;12(5):309-313.

319. Teunissen CE, Blom AH, Van Boxtel MP, et al. Homocysteine: a marker for cognitive performance? A longitudinal follow-up study. J Nutr Health Aging. 2003; 7(3):153-159.

320. Oulhaj A, Refsum H, Beaumont H, et al. Homocysteine as a predictor of cognitive decline in Alzheimer's disease. Int J Geriatr Psychiatry. 2009 May 29. [Epub ahead of print].
321. Campbell AK, Jagust WJ, Mungas DM, et al. Low erythrocyte folate, but not plasma vitamin B-12 or homocysteine, is associated with dementia in elderly Latinos. $J$ Nutr Health Aging. 2005;9(1):39-43.

322. Luchsinger JA, Tang MX, Shea S, Miller J, Green R, Mayeux R. Plasma homocysteine levels and risk of Alzheimer disease. Neurology. 2004;62(11):1972-1976.

323. Reitz C, Tang MX, Miller J, Green R, Luchsinger JA. Plasma homocysteine and risk of mild cognitive impairment. Dement Geriatr Cogn Disord. 2008;27(1):11-17.

324. Kalmijn S, Launer LJ, Lindemans J, Bots ML, Hofman A, Breteler MM. Total homocysteine and cognitive decline in a community-based sample of elderly subjects: the Rotterdam Study. Am J Epidemiol. 1999;150(3):283-289.

325. Mooijaart SP, Gussekloo J, Frolich M, et al. Homocysteine, vitamin B-12, and folic acid and the risk of cognitive decline in old age: the Leiden 85-Plus study. Am J Clin Nutr. 2005;82(4):866-871.

326. Clarke R, Harrison G, Richards S. Effect of vitamins and aspirin on markers of platelet activation, oxidative stress and homocysteine in people at high risk of dementia. J Intern Med. 2003;254(1):67-75.

327. Nilsson K, Gustafson L, Hultberg B. Plasma homocysteine concentration relates to the severity but not to the duration of Alzheimer's disease. Int J Geriatr Psychiatry. 2004;19(7):666-672.

328. Postiglione A, Milan G, Ruocco A, Gallotta G, Guiotto G, Di Minno G. Plasma folate, vitamin B(12), and total homocysteine and homozygosity for the C677T mutation of the 5,10-methylene tetrahydrofolate reductase gene in patients with Alzheimer's dementia. A case-control study. Gerontology. 2001;47(6):324-329.

329. Locascio JJ, Fukumoto H, Yap L, et al. Plasma amyloid beta-protein and C-reactive protein in relation to the rate of progression of Alzheimer disease. Arch Neurol. 2008;65(6):776-785.

330. Corder EH, Beaumont H. Susceptibility groups for Alzheimer's disease (OPTIMA cohort): integration of gene variants and biochemical factors. Mech Ageing Dev. 2007;128(1):76-82.

331. Engelborghs S, Vloeberghs E, Maertens K, et al. Correlations between cognitive, behavioural and psychological findings and levels of vitamin B12 and folate in patients with dementia. Int J Geriatr Psychiatry. 2004;19(4):365-370.

332. Roos D, Willanger R. Various degrees of dementia in a selected group of gastrectomized patients with low serum B12. Acta Neurol Scand. 1977;55(5):363-376.

333. Wang HX, Wahlin A, Basun H, Fastbom J, Winblad B, Fratiglioni L. Vitamin B(12) and folate in relation to the development of Alzheimer's disease. Neurology. 2001;56(9):1188-1194.

334. Eussen SJ, Ferry M, Hininger I, Haller J, Matthys C, Dirren H. Five year changes in mental health and associations with vitamin B12/ folate status of elderly Europeans. $J$ Nutr Health Aging. 2002;6(1): 43-50.

335. Garrod MG, Green R, Allen LH, et al. Fraction of total plasma vitamin B12 bound to transcobalamin correlates with cognitive function in elderly Latinos with depressive symptoms. Clin Chem. 2008;54(7):1210-1217.

336. Lopez OL, Becker JT, Klunk W, et al. Research evaluation and diagnosis of possible Alzheimer's disease over the last two decades: II. Neurology. 2000;55(12):1863-1869.

337. Luchsinger JA, Tang MX, Miller J, Green R, Mayeux R. Relation of higher folate intake to lower risk of Alzheimer disease in the elderly. Arch Neurol. 2007;64(1):86-92.

338. Small BJ, Viitanen M, Winblad B, Backman L. Cognitive changes in very old persons with dementia: the influence of demographic, psychometric, and biological variables. J Clin Exp Neuropsychol. 1997;19(2):245-260.

339. Small BJ, Backman L. Predictors of longitudinal changes in memory, visuospatial, and verbal functioning in very old demented adults. Dement Geriatr Cogn Disord. 1998;9(5):258-266.

340. Prodan CI, Cowan LD, Stoner JA, Ross ED. Cumulative incidence of vitamin B12 deficiency in patients with Alzheimer disease. $J$ Neurol Sci. 2009;284(1-2):144-148. 
341. American Academy of Neurology. Practice Parameter: Diagnosis of Dementia. American Academy of Neurology Guideline Summary for Clinicians. Detection, Diagnosis, and Management of Dementia: American Academy of Neurology. Current guideline - reaffirmed February 13, 2004. Available from: http://www.aan.com/ professionals/practice/pdfs/dementia_guideline.pdf. Accessed on September 7, 2009.

342. Valkovic P, Benetin J, Blazicek P, Valkovicova L, Gmitterova K, Kukumberg P. Reduced plasma homocysteine levels in levodopa/ entacapone treated Parkinson patients. Parkinsonism Relat Disord. 2005;11(4):253-256.

343. Postuma RB, Espay AJ, Zadikoff C, et al. Vitamins and entacapone in levodopa-induced hyperhomocysteinemia: a randomized controlled study. Neurology. 2006;66(12):1941-1943.

344. Lamberti P, Zoccolella S, Iliceto G, et al. Effects of levodopa and COMT inhibitors on plasma homocysteine in Parkinson's disease patients. Mov Disord. 2005;20(1):69-72.

345. Lamberti P, Zoccolella S, Armenise E, et al. Hyperhomocysteinemia in L-dopa treated Parkinson's disease patients: effect of cobalamin and folate administration. Eur J Neurol. 2005;12(5):365-368.

346. Abyad A. Prevalence of vitamin B12 deficiency among demented patients and cognitive recovery with cobalamin replacement. $J$ Nutr Health Aging. 2002;6(4):254-260.

347. Aisen PS, Schneider LS, Sano M, et al. High-dose B vitamin supplementation and cognitive decline in Alzheimer disease: a randomized controlled trial. JAMA. 2008;300(15):1774-1783.

348. Balk EM, Raman G, Tatsioni A, Chung M, Lau J, Rosenberg IH. Vitamin B6, B12, and folic acid supplementation and cognitive function: a systematic review of randomized trials. Arch Intern Med. 2007;167(1):21-30.

349. Cunha UG. An investigation of dementia among elderly outpatients. Acta Psychiatr Scand. 1990;82(3):261-263.

350. Eastley R, Wilcock GK, Bucks RS. Vitamin B12 deficiency in dementia and cognitive impairment: the effects of treatment on neuropsychological function. Int J Geriatr Psychiatry. 2000;15(3):226-233.

351. Eussen SJ, de Groot LC, Joosten LW, et al. Effect of oral vitamin B12 with or without folic acid on cognitive function in older people with mild vitamin B12 deficiency: a randomized, placebo-controlled trial. Am J Clin Nutr. 2006;84(2):361-370.

352. Hvas AM, Juul S, Lauritzen L, Nexo E, Ellegaard J. No effect of vitamin B-12 treatment on cognitive function and depression: a randomized placebo controlled study. J Affect Disord. 2004;81(3):269-273.

353. Kwok T, Tang C, Woo J, Lai WK, Law LK, Pang CP. Randomized trial of the effect of supplementation on the cognitive function of older people with subnormal cobalamin levels. Int J Geriatr Psychiatry. 1998;13(9):611-616.

354. Lin YT, Lin MH, Lai HY, Chen LK, Hwang SJ, Lan CF. Regular vitamin $\mathrm{B}(12)$ supplementation among older Chinese men in a veterans care home in Taiwan. Arch Gerontol Geriatr. 2009;49(1): 186-189.

355. Malouf M, Grimley EJ, Areosa SA. Folic acid with or without vitamin B12 for cognition and dementia. Cochrane Database Syst Rev. 2003(4):CD004514.

356. Martin DC, Francis J, Protetch J, Huff FJ. Time dependency of cognitive recovery with cobalamin replacement: report of a pilot study. $J \mathrm{Am}$ Geriatr Soc. 1992;40(2):168-172.

357. McMahon JA, Green TJ, Skeaff CM, Knight RG, Mann JI, Williams SM. A controlled trial of homocysteine lowering and cognitive performance. $N$ Engl J Med. 2006;354(26):2764-2772.

358. Nilsson K, Gustafson L, Hultberg B. Improvement of cognitive functions after cobalamin/folate supplementation in elderly patients with dementia and elevated plasma homocysteine. Int J Geriatr Psychiatry. 2001;16(6):609-614.

359. Osimani A, Berger A, Friedman J, Porat-Katz BS, Abarbanel JM. Neuropsychology of vitamin B12 deficiency in elderly dementia patients and control subjects. J Geriatr Psychiatry Neurol. 2005; 18(1):33-38.
360. Stott DJ, MacIntosh G, Lowe GD, et al. Randomized controlled trial of homocysteine-lowering vitamin treatment in elderly patients with vascular disease. Am J Clin Nutr. 2005;82(6):1320-1326.

361. Sun Y, Lu CJ, Chien KL, Chen ST, Chen RC. Efficacy of multivitamin supplementation containing vitamins B6 and B12 and folic acid as adjunctive treatment with a cholinesterase inhibitor in Alzheimer's disease: a 26-week, randomized, double-blind, placebo-controlled study in Taiwanese patients. Clin Ther. 2007;29(10):2204-2214.

362. van Dyck CH, Lyness JM, Rohrbaugh RM, Siegal AP. Cognitive and psychiatric effects of vitamin B12 replacement in dementia with low serum B12 levels: a nursing home study. Int Psychogeriatr. 2008:1-10

363. van Uffelen JG, Chin APMJ, Hopman-Rock M, van Mechelen W. The effect of walking and vitamin B supplementation on quality of life in community-dwelling adults with mild cognitive impairment: a randomized, controlled trial. Qual Life Res. 2007;16(7):1137-1146.

364. van Uffelen JG, Chinapaw MJ, van Mechelen W, Hopman-Rock M. Walking or vitamin B for cognition in older adults with mild cognitive impairment? A randomised controlled trial. Br J Sports Med. 2008;42(5):344-351.

365. Ruscin JM, Page RL 2nd, Valuck RJ. Vitamin B(12) deficiency associated with histamine(2)-receptor antagonists and a proton-pump inhibitor. Ann Pharmacother. 2002;36(5):812-816.

366. Valuck RJ, Ruscin JM. A case-control study on adverse effects: H2 blocker or proton pump inhibitor use and risk of vitamin B12 deficiency in older adults. J Clin Epidemiol. 2004;57(4):422-428.

367. Mitchell SL, Rockwood K. The association between antiulcer medication and initiation of cobalamin replacement in older persons. J Clin Epidemiol. 2001;54(5):531-534.

368. Oh R, Brown DL. Vitamin B12 deficiency. Am Fam Physician. 2003;67(5):979-986.

369. Metz J. The deoxyuridine suppression test. Crit Rev Clin Lab Sci. 1984;20(3):205-241.

370. Allen RH, Stabler SP, Savage DG, Lindenbaum J. Diagnosis of cobalamin deficiency I: usefulness of serum methylmalonic acid and total homocysteine concentrations. Am J Hematol. 1990;34(2):90-98.

371. Clarke R, Sherliker P, Hin H, et al. Detection of vitamin B12 deficiency in older people by measuring vitamin $\mathrm{B} 12$ or the active fraction of vitamin B12, holotranscobalamin. Clin Chem. 2007;53(5): 963-970.

372. Herrmann W, Obeid R, Schorr H, Geisel J. Functional vitamin B12 deficiency and determination of holotranscobalamin in populations at risk. Clin Chem Lab Med. 2003;41(11):1478-1488.

373. Lindenbaum J, Savage DG, Stabler SP, Allen RH. Diagnosis of cobalamin deficiency: II. Relative sensitivities of serum cobalamin, methylmalonic acid, and total homocysteine concentrations. Am J Hematol. 1990;34(2):99-107.

374. Miller JW, Garrod MG, Rockwood AL, et al. Measurement of total vitamin B12 and holotranscobalamin, singly and in combination, in screening for metabolic vitamin B12 deficiency. Clin Chem. 2006;52(2):278-285.

375. Pennypacker LC, Allen RH, Kelly JP, et al. High prevalence of cobalamin deficiency in elderly outpatients. J Am Geriatr Soc. 1992;40(12): 1197-1204.

376. Smith DL. Anemia in the elderly. Am Fam Physician. 2000;62(7): 1565-1572.

377. Obeid R, Morkbak AL, Munz W, Nexo E, Herrmann W. The cobalaminbinding proteins transcobalamin and haptocorrin in maternal and cord blood sera at birth. Clin Chem. 2006;52(2):263-269.

378. Krasinski SD, Russell RM, Samloff IM, et al. Fundic atrophic gastritis in an elderly population. Effect on hemoglobin and several serum nutritional indicators. J Am Geriatr Soc. 1986;34(11):800-806.

379. Carmel R. Mild transcobalamin I (haptocorrin) deficiency and low serum cobalamin concentrations. Clin Chem. 2003;49(8):1367-1374

380. Metz J, Bell AH, Flicker L, et al. The significance of subnormal serum vitamin B12 concentration in older people: a case control study. $J \mathrm{Am}$ Geriatr Soc. 1996;44(11):1355-1361. 
381. Bor MV, Cetin M, Aytac S, Altay C, Nexo E. Nonradioactive vitamin B12 absorption test evaluated in controls and in patients with inherited malabsorption of vitamin B12. Clin Chem. 2005;51(11): 2151-2155.

382. McCaddon A, Hudson P, Abrahamsson L, Olofsson H, Regland B. Analogues, ageing and aberrant assimilation of vitamin B12 in Alzheimer's disease. Dement Geriatr Cogn Disord. 2001;12(2):133-137.

383. Refsum H, Smith AD. Low vitamin B12 status in confirmed Alzheimer's disease as revealed by serum holotranscobalamin. J Neurol Neurosurg Psychiatry. 2003;74(7):959-961.

384. McCracken C, Hudson P, Ellis R, McCaddon A. Methylmalonic acid and cognitive function in the Medical Research Council Cognitive Function and Ageing Study. Am J Clin Nutr. 2006;84(6): 1406-1411.

385. Stabler SP, Allen RH, Savage DG, Lindenbaum J. Clinical spectrum and diagnosis of cobalamin deficiency. Blood. 1990;76(5): 871-881.

386. Zeitlin A, Frishman WH, Chang CJ. The association of vitamin b 12 and folate blood levels with mortality and cardiovascular morbidity incidence in the old old: the Bronx aging study. Am J Ther. 1997;4(7-8):275-281.

387. Dharmarajan TS, Norkus EP. Approaches to vitamin B12 deficiency. Early treatment may prevent devastating complications. Postgrad Med. 2001;110(1):99-105; quiz 106.

388. Hultberg B, Isaksson A, Nilsson K, Gustafson L. Homocysteine and methylmalonic acid as markers of cobalamin/folate status. The association to neuropsychiatric symptoms in the elderly is explored. Lakartidningen. 2000;97(38):4131-4134, 4136.

389. Nilsson K, Gustafson L, Hultberg B. Optimal use of markers for cobalamin and folate status in a psychogeriatric population. Int $J$ Geriatr Psychiatry. 2002;17(10):919-925.

390. Savage DG, Lindenbaum J, Stabler SP, Allen RH. Sensitivity of serum methylmalonic acid and total homocysteine determinations for diagnosing cobalamin and folate deficiencies. Am J Med. 1994;96(3):239-246.

391. Galimberti G, Conti E, Zini M, et al. Post-methionine load test: A more sensitive tool to reveal hyperhomocysteinemia in Alzheimer patients? Clin Biochem. 2008;41(10-11):914-916.

392. Kuzminski AM, Del Giacco EJ, Allen RH, Stabler SP, Lindenbaum J. Effective treatment of cobalamin deficiency with oral cobalamin. Blood. 1998;92(4):1191-1198.

393. Little DR. Ambulatory management of common forms of anemia. Am Fam Physician. 1999;59(6):1598-1604.

394. Hill DM, Johnson LJ, Burns PJ, Neale AM, Harmening DM, Kenney AC. Effects of temperature on stability of blood homocysteine in collection tubes containing 3-deazaadenosine. Clin Chem. 2002; 48(11):2017-2022.

395. Hansrani M, Stansby G. Extended storage of whole blood with 3-deazaadenosine for homocysteine assay. Ann Clin Biochem. 2007;44(Pt 4):388-390.

396. Joosten E, Pelemans W, Devos P, et al. Cobalamin absorption and serum homocysteine and methylmalonic acid in elderly subjects with low serum cobalamin. Eur J Haematol. 1993;51(1):25-30.

397. van Asselt DZ, Pasman JW, van Lier HJ, et al. Cobalamin supplementation improves cognitive and cerebral function in older, cobalamin-deficient persons. J Gerontol A Biol Sci Med Sci. 2001;56(12):M775-M779.

398. Annanmaki T, Pessala-Driver A, Hokkanen L, Murros K. Uric acid associates with cognition in Parkinson's disease. Parkinsonism Relat Disord. 2008;14(7):576-578.

399. Moretti R, Torre P, Antonello RM, Cazzato G, Cattaruzza T, Scapicchio PL. Vitamin B12 and folate depletion: clinical evidence in a neurological population. Neurologist. 2004;10(6):338-343.

400. Selhub J, Morris MS, Jacques PF. In vitamin B12 deficiency, higher serum folate is associated with increased total homocysteine and methylmalonic acid concentrations. Proc Natl Acad Sci USA. 2007;104(50): 19995-20000.
401. Clarke R, Sherliker P, Hin H, et al. Folate and vitamin B12 status in relation to cognitive impairment and anaemia in the setting of voluntary fortification in the UK. Br J Nutr. 2008;100(5):1054-1059.

402. Santiesteban-Freixas R, Serrano-Verdura C, Gutierrez-Gil J, et al. The neuropathy epidemic in Cuba: eight years of investigation and follow-up. Rev Neurol. 2000;31(6):549-566.

403. Epidemic optic neuropathy in Cuba - clinical characterization and risk factors. The Cuba Neuropathy Field Investigation Team. $N$ Engl J Med. 1995;333(18):1176-1182.

404. Dominguez YL, Hernandez M, Matos CM, Zhou D. Is B vitamins deficiency associated with prevalence of Alzheimer's disease in Cuban elderly? Nutr Health. 2006;18(2):103-118.

405. Hedges TR 3rd, Hirano M, Tucker K, Caballero B. Epidemic optic and peripheral neuropathy in Cuba: a unique geopolitical public health problem. Surv Ophthalmol. 1997;41(4):341-353.

406. Roman GC. An epidemic in Cuba of optic neuropathy, sensorineural deafness, peripheral sensory neuropathy and dorsolateral myeloneuropathy. J Neurol Sci. 1994;127(1):11-28.

407. Roman GC. On politics and health: an epidemic of neurologic disease in Cuba. Ann Intern Med. 1995;122(7):530-533.

408. Roman GC. Epidemic neuropathy in Cuba: a public health problem related to the Cuban Democracy Act of the United States. Neuroepidemiology. 1998;17(3):111-115.

409. Tucker K, Hedges TR. Food shortages and an epidemic of optic and peripheral neuropathy in Cuba. Nutr Rev. 1993;51(12):349-357.

410. The Flour Fortification Initiative. Countries with Mandatory Fortification of Flour with Iron and/or Folic Acid (Total = 57). Available from: http://www.sph.emory.edu/wheatflour/COUNTRYDATA/ Mandatory_countries.pdf. Accessed on August 11, 2009.

411. Smithells RW, Sheppard S, Schorah CJ. Vitamin dificiencies and neural tube defects. Arch Dis Child. 1976;51(12):944-950.

412. Mills JL, McPartlin JM, Kirke PN, et al. Homocysteine metabolism in pregnancies complicated by neural-tube defects. Lancet. 1995;345(8943):149-151.

413. Bjorke-Monsen AL, Ueland PM, Schneede J, Vollset SE, Refsum H. Elevated plasma total homocysteine and C677T mutation of the methylenetetrahydrofolate reductase gene in patients with spina bifida. QJM. 1997;90(9):593-596.

414. Vollset SE, Refsum H, Irgens LM, et al. Plasma total homocysteine, pregnancy complications, and adverse pregnancy outcomes: the Hordaland Homocysteine study. Am J Clin Nutr. 2000;71(4): 962-968.

415. Czeizel AE, Dudas I. Prevention of the first occurrence of neural-tube defects by periconceptional vitamin supplementation. $N$ Engl J Med. 1992;327(26):1832-1835.

416. Prevention of neural tube defects: results of the Medical Research Council Vitamin Study. MRC Vitamin Study Research Group. Lancet. 1991;338(8760):131-137.

417. Smithells RW, Sheppard S, Schorah CJ, et al. Possible prevention of neural-tube defects by periconceptional vitamin supplementation. Lancet. 1980;1(8164):339-340.

418. Laurence KM, James N, Miller MH, Tennant GB, Campbell H. Double-blind randomised controlled trial of folate treatment before conception to prevent recurrence of neural-tube defects. $\mathrm{Br} \mathrm{Med} J$ (Clin Res Ed). 1981;282(6275):1509-1511.

419. Czeizel AE. Prevention of congenital abnormalities by periconceptional multivitamin supplementation. BMJ. 1993;306(6893): 1645-1648.

420. Trends in wheat-flour fortification with folic acid and iron - worldwide, 2004 and 2007. MMWR Morb Mortal Wkly Rep. 2008;57(1):8-10.

421. Jacobsen DW. Homocysteine and vitamins in cardiovascular disease. Clin Chem. 1998;44(8 Pt 2):1833-1843.

422. Pitkin RM. Folate and neural tube defects. Am J Clin Nutr. 2007; 85(1):285S-288S.

423. Liu S, West R, Randell E, et al. A comprehensive evaluation of food fortification with folic acid for the primary prevention of neural tube defects. BMC Pregnancy Childbirth. 2004;4(1):20. 
424. Lewis DP, Van Dyke DC, Stumbo PJ, Berg MJ. Drug and environmental factors associated with adverse pregnancy outcomes. Part III: Folic acid: pharmacology, therapeutic recommendations, and economics. Ann Pharmacother. 1998;32(10):1087-1095.

425. Leyva M. Folic acid intake and its effects on the prevention of neural tube defects, the masking of vitamin B12 deficiency and the reduction of homocysteine. J Okla State Med Assoc. 2002;95(5): 339-342.

426. Malinow MR, Duell PB, Hess DL, et al. Reduction of plasma homocyst(e)ine levels by breakfast cereal fortified with folic acid in patients with coronary heart disease. $N$ Engl J Med. 1998;338(15): 1009-1015.

427. Kristensen MO, Gulmann NC, Christensen JE, Ostergaard K, Rasmussen K. Serum cobalamin and methylmalonic acid in Alzheimer dementia. Acta Neurol Scand. 1993;87(6):475-481.

428. Carmel R. Prevalence of undiagnosed pernicious anemia in the elderly. Arch Intern Med. 1996;156(10):1097-1100.

429. Kuroda S, Morita S. A case of pernicious anemia with type A gastritis in an extremely elderly patient with dementia and heart failure. Nippon Ronen Igakkai Zasshi. 2008;45(3):335-337.

430. Argyriadou S, Vlachonikolis I, Melisopoulou H, Katachanakis K, Lionis C. In what extent anemia coexists with cognitive impairment in elderly: a cross-sectional study in Greece. BMC Fam Pract. 2001;2:5

431. McCaddon A, Kelly CL. Familial Alzheimer's disease and vitamin B12 deficiency. Age Ageing. 1994;23(4):334-337.

432. Nilsson K, Gustafson L, Faldt R, Andersson A, Hultberg B. Plasma homocysteine in relation to serum cobalamin and blood folate in a psychogeriatric population. Eur J Clin Invest. 1994;24(9):600-606.

433. McCaddon A, Tandy S, Hudson P, et al. Absence of macrocytic anaemia in Alzheimer's disease. Clin Lab Haematol. 2004;26(4): 259-263.

434. Gross JS, Weintraub NT, Neufeld RR, Libow LS. Pernicious anemia in the demented patient without anemia or macrocytosis. A case for early recognition. J Am Geriatr Soc. 1986;34(8):612-614.

435. Fox JH, Topel JL, Huckman MS. Dementia in the elderly - a search for treatable illnesses. J Gerontol. 1975;30(5):557-564.

436. Ikeda T, Furukawa Y, Mashimoto S, Takahashi K, Yamada M. Vitamin B12 levels in serum and cerebrospinal fluid of people with Alzheimer's disease. Acta Psychiatr Scand. 1990;82(4):327-329.

437. Kountouras J, Tsolaki M, Boziki M, et al. Association between Helicobacter pylori infection and mild cognitive impairment. Eur $J$ Neurol. 2007;14(9):976-982.

438. Kountouras J, Boziki M, Gavalas E, et al. Eradication of Helicobacter pylori may be beneficial in the management of Alzheimer's disease. J Neurol. 2009;256(5):758-767.

439. Malaguarnera M, Bella R, Alagona G, Ferri R, Carnemolla A, Pennisi G. Helicobacter pylori and Alzheimer's disease: a possible link. Eur J Intern Med. 2004;15(6):381-386.

440. Kountouras J, Tsolaki M, Gavalas E, et al. Relationship between Helicobacter pylori infection and Alzheimer disease. Neurology. 2006;66(6):938-940.

441. Vasconcellos LF, Correa RB, Chimelli L, et al. Myelopathy due to vitamin B12 deficiency presenting as transverse myelitis. Arq Neuropsiquiatr. 2002;60(1):150-154.

442. Gottfries J, Blennow K, Lehmann MW, Regland B, Gottfries CG One-carbon metabolism and other biochemical correlates of cognitive impairment as visualized by principal component analysis. J Geriatr Psychiatry Neurol. 2001;14(3):109-114.

443. Faxen-Irving G, Basun H, Cederholm T. Nutritional and cognitive relationships and long-term mortality in patients with various dementia disorders. Age Ageing. 2005;34(2):136-141.

444. Jones S, Small BJ, Fratiglioni L, Backman L. Predictors of cognitive change from preclinical to clinical Alzheimer's disease. Brain Cogn. 2002;49(2):210-213.

445. McCaddon A, Kelly CL. Alzheimer's disease: a 'cobalaminergic' hypothesis. Med Hypotheses. 1992;37(3):161-165.
446. Opala G, Jasinska-Myga B, Ochudlo S, Janiec K. Diagnostic problems in the case of dementia with coexisting hematological disorders. Wiad Lek. 2001;54(7-8):456-461.

447. Carmel R, Ellenbogen L, Herbert VD. Dietary Supplement Fact Sheet Vitamin B12. Bethesda, MD: Office of Dietary Supplements, National Institutes of Health; 2006. Available from: From http://ods.od.nih.gov/ factsheets/VitaminB12_pf.asp. Accessed on January 18, 2009.

448. American Regent I. Cyanocobalamin Injection, USP. Package Insert. Shirley, NY: American Regent; 2003.

449. Braun-Falco O, Lincke $H$. The problem of vitamin B6/B12 acne. A contribution on acne medicamentosa (author's transl). MMW Munch Med Wochenschr. 1976;118(6):155-160.

450. Toole JF, Malinow MR, Chambless LE, et al. Lowering homocysteine in patients with ischemic stroke to prevent recurrent stroke, myocardial infarction, and death: the Vitamin Intervention for Stroke Prevention (VISP) randomized controlled trial. JAMA. 2004;291(5): 565-575.

451. Schnyder G, Roffi M, Pin R, et al. Decreased rate of coronary restenosis after lowering of plasma homocysteine levels. $N$ Engl J Med. 2001;345(22):1593-1600.

452. Schnyder G, Roffi M, Flammer Y, Pin R, Hess OM. Effect of homocysteine-lowering therapy with folic acid, vitamin B12, and vitamin B6 on clinical outcome after percutaneous coronary intervention: the Swiss Heart study: a randomized controlled trial. JAMA. 2002;288(8):973-979.

453. Albert CM, Cook NR, Gaziano JM, et al. Effect of folic acid and $\mathrm{B}$ vitamins on risk of cardiovascular events and total mortality among women at high risk for cardiovascular disease: a randomized trial. JAMA. 2008;299(17):2027-2036.

454. Bonaa KH, Njolstad I, Ueland PM, et al. Homocysteine lowering and cardiovascular events after acute myocardial infarction. $N$ Engl J Med. 2006;354(15):1578-1588.

455. Ebbing M, Bleie O, Ueland PM, et al. Mortality and cardiovascular events in patients treated with homocysteine-lowering B vitamins after coronary angiography: a randomized controlled trial. JAMA. 2008;300(7):795-804.

456. Lange H, Suryapranata H, De Luca G, et al. Folate therapy and in-stent restenosis after coronary stenting. $N$ Engl J Med. 2004;350(26): 2673-2681.

457. Lonn E, Yusuf S, Arnold MJ, et al. Homocysteine lowering with folic acid and B vitamins in vascular disease. N Engl J Med. 2006;354(15): 1567-1577.

458. Mann JF, Sheridan P, McQueen MJ, et al. Homocysteine lowering with folic acid and B vitamins in people with chronic kidney disease - results of the renal Hope-2 study. Nephrol Dial Transplant. 2008;23(2):645-653.

459. Bazzano LA, Reynolds K, Holder KN, He J. Effect of folic acid supplementation on risk of cardiovascular diseases: a metaanalysis of randomized controlled trials. JAMA. 2006;296(22): 2720-2726.

460. Wang X, Qin X, Demirtas H, et al. Efficacy of folic acid supplementation in stroke prevention: a meta-analysis. Lancet. 2007;369(9576): 1876-1882.

461. Brattstrom L, Wilcken DE, Ohrvik J, Brudin L. Common methylenetetrahydrofolate reductase gene mutation leads to hyperhomocysteinemia but not to vascular disease: the result of a meta-analysis. Circulation . 1998;98(23):2520-2526.

462. Dangour AD, Breeze E, Clarke R, Shetty PS, Uauy R, Fletcher AE. Plasma homocysteine, but not folate or vitamin B-12, predicts mortality in older people in the United Kingdom. J Nutr. 2008;138(6): 1121-1128.

463. den Heijer M, Rosendaal FR, Blom HJ, Gerrits WB, Bos GM. Hyperhomocysteinemia and venous thrombosis: a meta-analysis. Thromb Haemost. 1998;80(6):874-877.

464. Den Heijer M, Lewington S, Clarke R. Homocysteine, MTHFR and risk of venous thrombosis: a meta-analysis of published epidemiological studies. J Thromb Haemost. 2005;3(2):292-299. 
465. Dhonukshe-Rutten RA, Pluijm SM, de Groot LC, Lips P, Smit JH, van Staveren WA. Homocysteine and vitamin B12 status relate to bone turnover markers, broadband ultrasound attenuation, and fractures in healthy elderly people. J Bone Miner Res. 2005;20(6): 921-929.

466. Kuo HK, Sorond FA, Chen JH, Hashmi A, Milberg WP, Lipsitz LA. The role of homocysteine in multisystem age-related problems: a systematic review. J Gerontol A Biol Sci Med Sci. 2005;60(9): $1190-1201$.

467. Sato Y, Honda Y, Iwamoto J, Kanoko T, Satoh K. Homocysteine as a predictive factor for hip fracture in stroke patients. Bone. 2005;36(4):721-726.

468. Sato Y, Iwamoto J, Kanoko T, Satoh K. Homocysteine as a predictive factor for hip fracture in elderly women with Parkinson's disease. Am J Med. 2005;118(11):1250-1255.

469. Lehmann M, Regland B, Blennow K, Gottfries CG. Vitamin B12-B6folate treatment improves blood-brain barrier function in patients with hyperhomocysteinaemia and mild cognitive impairment. Dement Geriatr Cogn Disord. 2003;16(3):145-150.

470. Flicker L, Martins RN, Thomas J, et al. B-vitamins reduce plasma levels of beta amyloid. Neurobiol Aging. 2008;29(2): 303-305.

471. Stuerenburg HJ, Mueller-Thomsen T, Methner A. Vitamin B12 plasma concentrations in Alzheimer disease. Neuro Endocrinol Lett. 2004;25(3):176-177.

472. La Rue A, Koehler KM, Wayne SJ, Chiulli SJ, Haaland KY, Garry PJ. Nutritional status and cognitive functioning in a normally aging sample: a 6-y reassessment. Am J Clin Nutr. 1997;65(1):20-29.

473. Bryan J, Calvaresi E, Hughes D. Short-term folate, vitamin B-12 or vitamin B-6 supplementation slightly affects memory performance but not mood in women of various ages. $J$ Nutr. 2002;132(6): $1345-1356$.

474. Remington R, Chan A, Paskavitz J, Shea TB. Efficacy of a vitamin/ nutriceutical formulation for moderate-stage to later-stage Alzheimer's disease: a placebo-controlled pilot study. Am J Alzheimers Dis Other Demen. 2009;24(1):27-33.

475. Ikeda T, Yamamoto K, Takahashi K, et al. Treatment of Alzheimer-type dementia with intravenous mecobalamin. Clin Ther. 1992;14(3): 426-437.

476. Alfthan G, Tapani K, Nissinen K, Saarela J, Aro A. The effect of low doses of betaine on plasma homocysteine in healthy volunteers. $\mathrm{Br} J$ Nutr. 2004;92(4):665-669.

477. Bell KM, Plon L, Bunney WE Jr, Potkin SG. S-adenosylmethionine treatment of depression: a controlled clinical trial. Am J Psychiatry. 1988;145(9):1110-1114.

478. Bottiglieri T. Ademetionine (S-adenosylmethionine) neuropharmacology: implications for drug therapies in psychiatric and neurological disorders. Expert Opin Investig Drugs. 1997;6(4):417-426.

479. Bressa GM. S-adenosyl-1-methionine (SAMe) as antidepressant: meta-analysis of clinical studies. Acta Neurol Scand Suppl. 1994; 154:7-14.

480. D'Angelo A, Selhub J. Homocysteine and thrombotic disease. Blood. 1997;90(1):1-11.

481. Di Rocco A, Rogers JD, Brown R, Werner P, Bottiglieri T. S-AdenosylMethionine improves depression in patients with Parkinson's disease in an open-label clinical trial. Mov Disord. 2000;15(6): 1225-1229.

482. Dudman NP, Guo XW, Gordon RB, Dawson PA, Wilcken DE. Human homocysteine catabolism: three major pathways and their relevance to development of arterial occlusive disease. J Nutr. 1996;126(4 Suppl):1295S-1300S.

483. Ho PI, Ashline D, Dhitavat S, et al. Folate deprivation induces neurodegeneration: roles of oxidative stress and increased homocysteine. Neurobiol Dis. 2003;14(1):32-42.

484. Jacob RA, Jenden DJ, Allman-Farinelli MA, Swendseid ME. Folate nutriture alters choline status of women and men fed low choline diets. J Nutr. 1999;129(3):712-717.
485. Kagan BL, Sultzer DL, Rosenlicht N, Gerner RH. Oral S-adenosylmethionine in depression: a randomized, double-blind, placebo-controlled trial. Am J Psychiatry. 1990;147(5):591-595.

486. Knopman D, Patterson M. An open-label, 24-week pilot study of the methyl donor betaine in Alzheimer disease patients. Alzheimer Dis Assoc Disord. 2001;15(3):162-165.

487. Lipinski JF, Cohen BM, Frankenburg F, et al. Open trial of S-adenosylmethionine for treatment of depression. Am J Psychiatry. 1984;141(3):448-450.

488. McCaddon A. Homocysteine and cognitive impairment; a case series in a General Practice setting. Nutr J. 2006;5:6.

489. Melse-Boonstra A, Holm PI, Ueland PM, Olthof M, Clarke R, Verhoef P. Betaine concentration as a determinant of fasting total homocysteine concentrations and the effect of folic acid supplementation on betaine concentrations. Am J Clin Nutr. 2005;81(6):1378-1382.

490. Mitsuyama Y, Kogoh H. Serum and cerebrospinal fluid vitamin B12 levels in demented patients with CH3-B12 treatment - preliminary study. Jpn J Psychiatry Neurol. 1988;42(1):65-71.

491. Montero Brens C, Dalmau Serra J, Cabello Tomas ML, Garcia Gomez AM, Rodes Monegal M, Vilaseca Busca A. Homocystinuria: effectiveness of the treatment with pyridoxine, folic acid, and betaine. An Esp Pediatr. 1993;39(1):37-41.

492. Schwab U, Torronen A, Toppinen L, et al. Betaine supplementation decreases plasma homocysteine concentrations but does not affect body weight, body composition, or resting energy expenditure in human subjects. Am J Clin Nutr. 2002;76(5):961-967.

493. Selhub J, Bagley LC, Miller J, Rosenberg IH. B vitamins, homocysteine, and neurocognitive function in the elderly. Am J Clin Nutr. 2000;71(2):614S-620S.

494. Shippy RA, Mendez D, Jones K, Cergnul I, Karpiak SE. S-adenosylmethionine (SAM-e) for the treatment of depression in people living with HIV/AIDS. BMC Psychiatry. 2004;4:38.

495. Tavoni A, Jeracitano G, Cirigliano G. Evaluation of S-adenosylmethionine in secondary fibromyalgia: a double-blind study. Clin Exp Rheumatol. 1998;16(1):106-107.

496. Connelly PJ, Prentice NP, Cousland G, Bonham J. A randomised double-blind placebo-controlled trial of folic acid supplementation of cholinesterase inhibitors in Alzheimer's disease. Int J Geriatr Psychiatry. 2008;23(2):155-160.

497. Ito T, Yamadera H, Ito R, Suzuki H, Asayama K, Endo S. Effects of vitamin B12 on bright light on cognitive and sleep-wake rhythm in Alzheimertype dementia. Psychiatry Clin Neurosci. 2001;55(3):281-282.

498. Haidemenos A, Kontis D, Gazi A, Kallai E, Allin M, Lucia B. Plasma homocysteine, folate and B12 in chronic schizophrenia. Prog Neuropsychopharmacol Biol Psychiatry. 2007;31(6):1289-1296.

499. King JC. Dietary Guidelines for Americans 2005. US Department of Health and Human Services and US Department of Agriculture. 2005. Available from: http://www.cnpp.usda.gov/Publications/ DietaryGuidelines/2005/2005DGPolicyDocument.pdf. Accessed on January 18, 2009.

500. Dierkes J, Domrose U, Ambrosch A, et al. Supplementation with vitamin B12 decreases homocysteine and methylmalonic acid but also serum folate in patients with end-stage renal disease. Metabolism. 1999;48(5):631-635.

501. Hoffer LJ, Saboohi F, Golden M, Barre PE. Cobalamin dose regimen for maximum homocysteine reduction in end-stage renal disease. Metabolism. 2005;54(6):835-840.

502. Eussen SJ, de Groot LC, Clarke R, et al. Oral cyanocobalamin supplementation in older people with vitamin B12 deficiency: a dose-finding trial. Arch Intern Med. 2005;165(10):1167-1172.

503. Nyholm E, Turpin P, Swain D, et al. Oral vitamin B12 can change our practice. Postgrad Med J. 2003;79(930):218-220.

504. Lederle FA. Oral cobalamin for pernicious anemia: back from the verge of extinction. J Am Geriatr Soc. 1998;46(9):1125-1127.

505. Kwong JC, Carr D, Dhalla IA, Tom-Kun D, Upshur RE. Oral vitamin B12 therapy in the primary care setting: a qualitative and quantitative study of patient perspectives. BMC Fam Pract. 2005;6(1):8. 
506. Hengstermann S, Hanemann A, Nieczaj R, et al. Does an association between increased homocystein levels and cognitive dysfunction also exist in multimorbid geriatric patients? Z Gerontol Geriatr. 2009; 42(2):131-136.

507. Hengstermann S, Laemmler G, Hanemann A, et al. Total serum homocysteine levels do not identify cognitive dysfunction in multimorbid elderly patients. J Nutr Health Aging. 2008;12(6):411-416.

508. Huang YC, Kuo YW, Lee TH, et al. Hypoalbuminemia and not hyperhomocysteinemia as a risk factor for dementia in hemodialysis patients. J Ren Nutr. 2008;18(4):347-354.
509. Stipanuk MH, Dominy JE Jr, Lee JI, Coloso RM. Mammalian cysteine metabolism: new insights into regulation of cysteine metabolism. J Nutr. 2006;136(6 Suppl):1652S-1659S.

510. Fernandez HH, Wu CK, Ott BR. Pharmacotherapy of dementia with Lewy bodies. Expert Opin Pharmacother. 2003;4(11):2027-2037.

511. McKeith I, Del Ser T, Spano P, et al. Efficacy of rivastigmine in dementia with Lewy bodies: a randomised, double-blind, placebocontrolled international study. Lancet. 2000;356(9247):2031-2036.

\section{Publish your work in this journal}

Neuropsychiatric Disease and Treatment is an international, peerreviewed journal of clinical therapeutics and pharmacology focusing on concise rapid reporting of clinical or pre-clinical studies on a range of neuropsychiatric and neurological disorders. This journal is indexed on PubMed Central, the 'PsycINFO' database and CAS, and is the official

Submit your manuscript here: http://www.dovepress.com/neuropsychiatric-disease-and-treatment-journal journal of The International Neuropsychiatric Association (INA). The manuscript management system is completely online and includes a very quick and fair peer-review system, which is all easy to use. Visit http://www.dovepress.com/testimonials.php to read real quotes from published authors. 